\title{
Risk in pension plans
}

Citation for published version (APA):

Tyagi, M. (2016). Risk in pension plans. [Doctoral Thesis, Maastricht University]. Datawyse / Universitaire Pers Maastricht. https://doi.org/10.26481/dis.20160426mt

Document status and date:

Published: 01/01/2016

DOI:

10.26481/dis.20160426mt

Document Version:

Publisher's PDF, also known as Version of record

\section{Please check the document version of this publication:}

- A submitted manuscript is the version of the article upon submission and before peer-review. There can be important differences between the submitted version and the official published version of record.

People interested in the research are advised to contact the author for the final version of the publication, or visit the DOI to the publisher's website.

- The final author version and the galley proof are versions of the publication after peer review.

- The final published version features the final layout of the paper including the volume, issue and page numbers.

Link to publication

\footnotetext{
General rights rights.

- You may freely distribute the URL identifying the publication in the public portal. please follow below link for the End User Agreement:

www.umlib.nl/taverne-license

Take down policy

If you believe that this document breaches copyright please contact us at:

repository@maastrichtuniversity.nl

providing details and we will investigate your claim.
}

Copyright and moral rights for the publications made accessible in the public portal are retained by the authors and/or other copyright owners and it is a condition of accessing publications that users recognise and abide by the legal requirements associated with these

- Users may download and print one copy of any publication from the public portal for the purpose of private study or research.

- You may not further distribute the material or use it for any profit-making activity or commercial gain

If the publication is distributed under the terms of Article $25 \mathrm{fa}$ of the Dutch Copyright Act, indicated by the "Taverne" license above, 


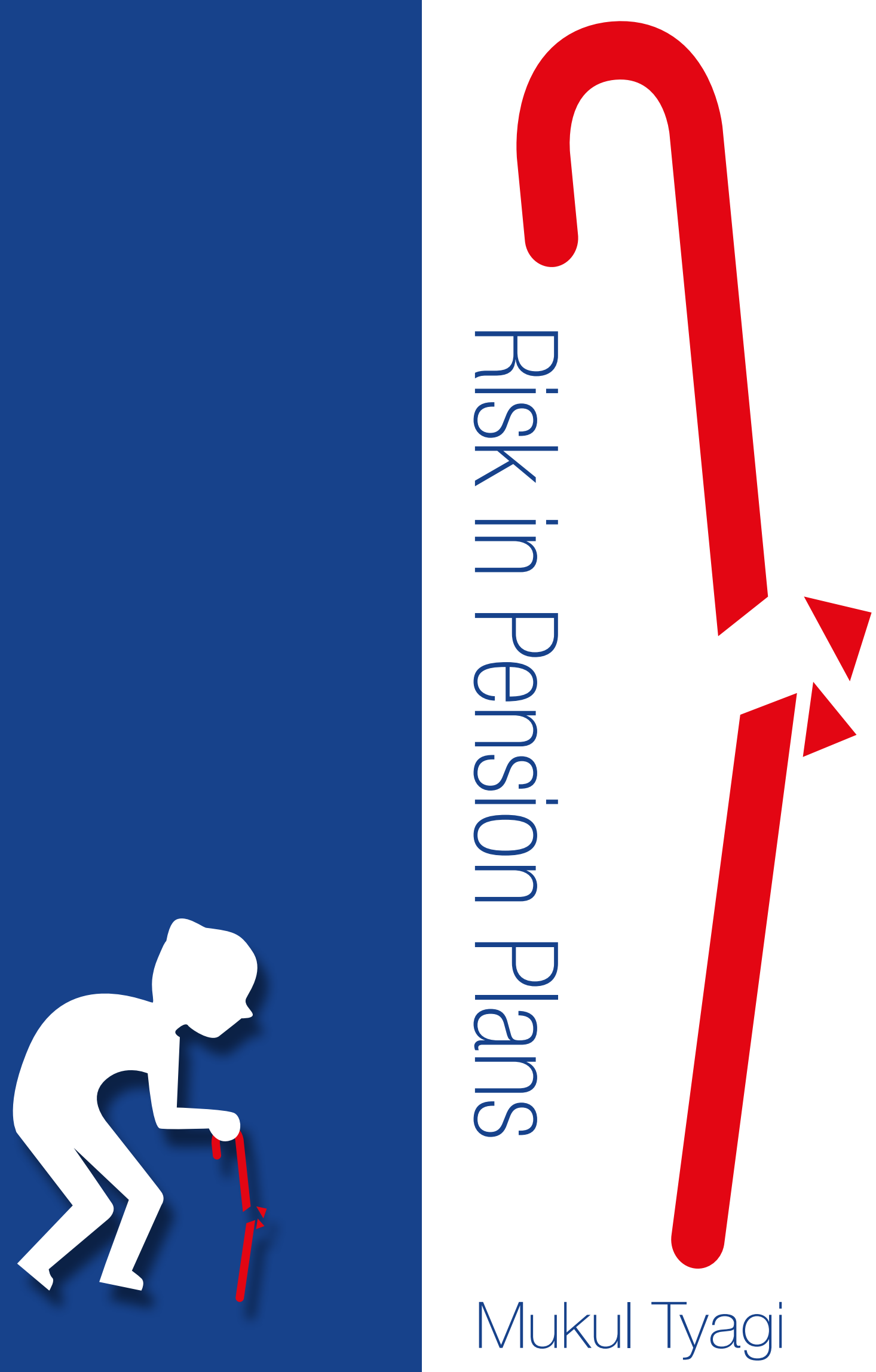





\title{
Risk in Pension Plans
}

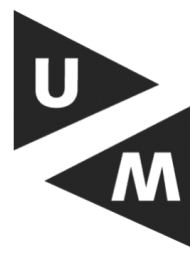

\author{
Mukul Tyagi \\ Maastricht University School of Business and Economics \\ Maastricht
}

A thesis submitted for the degree of

Doctor of Philosophy at Maastricht University 
(C) 2016 by Mukul Tyagi

All rights reserved. No part of this publication may be reproduced, stored in a retrieval system, or transmitted, in any form, or by any means, electronic, mechanical, photocopying, recording or otherwise, without the prior permission in writing from the author.

ISBN 9789461595515

Printed by Datawyse / Universitaire Pers Maastricht

This book was typeset using $\mathrm{H}_{\mathrm{E}} \mathrm{X}$.

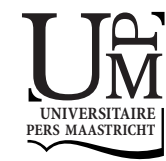




\section{Risk in Pension Plans}

\section{DISSERTATION}

to obtain the degree of Doctor at Maastricht University, by the authority of Prof. dr. L.L.G. Soete, Rector Magnificus, in accordance with the decision of the Board of Deans, to be defended in public on Tuesday, April 26th 2016, at 16:00 hours

by

Mukul Tyagi 


\section{Promotores:}

Prof. dr. W.F.M. (Dennis) Bams

Prof. dr. Peter C. Schotman

\section{Assessment Committee:}

Prof. dr. Rob Bauer, Chairman

Prof. dr. Dirk Broeders

Prof. dr. E.H.M. (Eduard) Ponds, Tilburg University

Prof. dr. Alfred Slager, Tilburg University 
To my parents Renu and Pramod 



\section{Acknowledgements}

The last few years have been incredible for me, both in terms of learning as well as fun. This has been possible because of some amazing people. I would like to thank them in the next few paragraphs.

Two very special people deserve the first word of thanks, my PhD advisors. Peter has extensive knowledge of academic literature and his talent for new ideas is exceptional. I will genuinely miss our email conversations just before a conference presentation. He is a great source of inspiration to me. In additional to his econometric expertise, Dennis is very meticulous, has a great eye for detail as well as an emphasis for the bigger picture. His very personal coaching style is truly effective. All the three papers in the dissertation are a result of many simulating discussions with them and I cannot stress enough how privileged I have been to have them as my supervisors.

I would like to thank Rob Bauer, Dirk Broeders, Eduard Ponds, and Alfred Slager for providing me with a very helpful and constructive feedback. I am truly honored that they agreed to be on my evaluation committee.

This dissertation was made possible by generous financial help from Rabobank, Utrecht. I would specially like to thank Erik Winands and Mâcé Mesters for their support from Rabobank. In addition, I was a co-recipient of a research grant by Global Risk Institute in Financial Services (GRI), Toronto. I also gratefully acknowledge research allowance received from Rotman International Center for Pension Management, Toronto.

I spent some time at the Rotman School of Management at University of Toronto during my PhD. I owe special debt to Susan Christofferson for hosting me and making this visit possible. I am very grateful to Ann Henhoeffer and Karen Clarke from Rotman International Centre for Pension Management (ICPM) who helped me immensely from start to finish of my visit. I would also like to specially thank Peter Christofferson, Alexander Dyck, Lisa Kramer, and Moshe Milevsky for invaluable discussions about my research during this visit.

I have been very lucky to tutor finance courses at Maastricht University. I would like to thank Dennis, Kristof, Jeroen, Iman, Carl, Sjoke, Francien, and Stefan for their teaching advice. I also received invaluable help and guidance from fellow tutors. More- 
over, I am indebted to my students, whose hard work and intellect have surprised me many times. They have taught me a lot with their questions and feedback. Although teaching has not been directly related to my research, I am certain that it has affected my research in an unquantifiable way.

The leadership of Piet Eichholtz and Jaap Bos has made Maastricht's Finance department at great place to be in. I have very much enjoyed insightful seminars from some of the brightest people in academia, thanks largely to Thomas Post. I would like to thank Arvid, Stefanie, Georges, Roger and Rachel for great conversations.

Many thanks to Els, Cécile, Francien, and Carina for their help throughout the four years and even afterwards. They made it a breeze to tackle all the administrative issues.

I am very grateful to Paul and Iman for agreeing to be my paranymphs. I have learnt many things from Paul, including but not limited to making not so politically correct jokes and Blackjack strategies. I will always remember our visit to Pinkpop and the Netspar conferences. Iman has been perhaps too kind to me. Once he drove me all the way to the Brussels airport early in the morning. It was so early that he forgot where he parked his car at the airport. And I can only hope that one day I can play as good poker as them, in which I have always lost to them.

Thanks to a lovely bunch of people who call themselves the Musketeers- Gildas, Gaby, Iman, and Omar - with whom I had countless fun evenings in the Tribunal. I am still smiling remembering all the banter. I will always remember the surprise birthday party organized by them at my own place. Gabys enthusiasm is infectious. Thank you for being host to great parties and I am very sorry for poking a hole in the lampshade. Gildas had all the answers to my problems, thank you for all the fun we had while you were my not-so-official officemate. I will truly miss the lunches and fun conversations with Omar.

Amongst many other things, Johannes has taught me how to eat and drink properly. We had a lot of fun evenings playing Carrom when I could completely forget any PhD stress. Dinner evenings with Anant and Abhimanyu were very special. Thanks to Pierre for great crêpes and a lot of fun playing cricket at his place. A big thanks to Atul for hosting me whenever I was in Amsterdam. I always had fun and insightful conversations about research with Leonard. It is wonderful to have Oana in Amsterdam, so that we can meet and we always end up discussing Maastricht memories.

I must really thank Judy for correcting my Indian accent, and I think it is a good time to confess that her accent is much better than mine. Rogier's ability to find great Indian videos is as good as, if not better than, his econometrics knowledge. I really enjoyed Patrick's company at various conferences, especially the AFA in San Diego and Netspar in Frankfurt. Many thanks to Alessandro, Erkan, Aleksandar, Arian, Anna, Wiekbe, Inka, Hang, Sally, Lei, Sajid, Michael, Jameel, Clarissa, Rogier H, Ehsan, Tobias, Vincent, Juan, Paulo, Simone, Matteo, and Andrea for their friendship and great conversations. 
I had amazing time running with 'Finance and Friends' running group. This fantastic group includes Nico, Wiekbe, Inka, Gaby, Iman, Gildas, Pepijn, Clémentine, Lulia, Jelle, and Ehsan. We finished three amazing runs together: Maastricht Mooist, City Run Maastrict, and Zweit Veur Leid. Thank you for giving me a life-long hobby.

Lastly, I owe immense thanks to my parents for their constant encouragement and guidance. They are my two pillars of strength and everything I am, I owe it to them. Whenever I needed advice, my brother Rahul and sister-in-law Madhuri were always there for me. Many thanks to my sister Aarti and brother-in-law Vipin; talking to them always brings a smile to my face. Last but not the least, big thanks to Aaradhya, Medhansh, Purnika, and Ria. They are the loveliest people in my life! 



\section{Contents}

Acknowledgements

List of Figures $\quad$ ix

List of Tables $\quad$ xi

1 Introduction 1

1.1 What's new in pensions? . . . . . . . . . . . . . . . . . 1

1.2 Why retirement risks should be shared . . . . . . . . . . . . . 2

1.3 How (not) to invest for the long-term . . . . . . . . . . . . . . 5

1.4 What challenges do low interest rates pose for pension funds? . . . . . . 6

2 Optimal risk sharing in a collective defined contribution pension system 9

2.1 Introduction . . . . . . . . . . . . . . . . . . . . . . 9

2.2 Risk sharing by return smoothing . . . . . . . . . . . . . . . . . . 12

2.2.1 Model ......................... 12

2.2.2 Preferences and the fund policy . . . . . . . . . . . . . 15

2.3 Results . . . . . . . . . . . . . . . . . . . . . 17

2.3.1 Stochastic steady state . . . . . . . . . . . . . . 17

2.3.2 Optimal risk sharing . . . . . . . . . . . . . . . 20

2.3 .3 Implicit exposure to risky asset . . . . . . . . . . . . . . . 24

2.4 Concluding remarks . . . . . . . . . . . . . . . . . . . 26

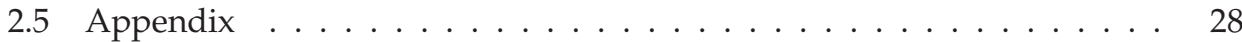

2.5 .1 Initial conditions . . . . . . . . . . . . . . . . 28

3 Asset Allocation Dynamics of Pension Funds 29

3.1 Introduction . . . . . . . . . . . . . . . . . . . . . . 29

3.2 Data description . . . . . . . . . . . . . . . . 32

3.3 Rebalancing of fund portfolio . . . . . . . . . . . . . . 37

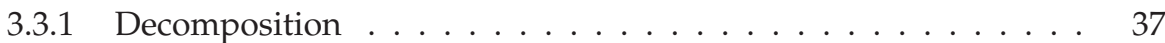

3.3.2 Rebalancing regressions ................... 38 
3.3.3 Robustness check . . . . . . . . . . . . . . . . . . . . . 44

3.3.4 Asymmetric rebalancing . . . . . . . . . . . . . . . . . . 44

3.3 .5 Rebalancing costs . . . . . . . . . . . . . . . . . . . 48

3.4 Extensions . . . . . . . . . . . . . . . . . . . . . . 49

3.4.1 Cross-sectional variation in rebalancing . . . . . . . . . . . 49

3.4.2 Contribution of differently managed funds to rebalancing . . . . 51

3.4.3 Rebalancing in other asset classes . . . . . . . . . . 52

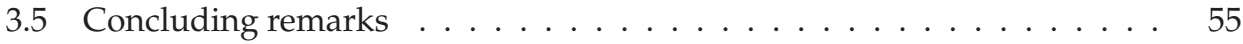

4 Pension Fund Asset Allocation In Low Interest Rate Environment 57

4.1 Introduction . . . . . . . . . . . . . . . . . . . 57

4.2 Portfolio implications from the strategic asset allocation literature . . . 60

4.2.1 Optimal portfolio choice with liabilities . . . . . . . . . . 67

4.3 How do low interest rates affect asset allocation? . . . . . . . . . . . . 69

4.3 .1 Robustness check . . . . . . . . . . . . . . . . . 76

4.4 Pension fund asset allocation and predictive variables . . . . . . . 77

4.4.1 Active changes and asset allocation . . . . . . . . . . 79

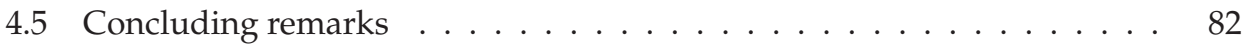

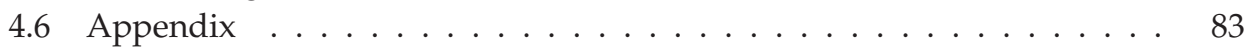

4.6 .1 Data sources . . . . . . . . . . . . . . . . . . 83

4.6 .2 Optimal asset allocation with liabilities $\ldots \ldots \ldots \ldots$. . . . 84

4.6 .3 Figures . . . . . . . . . . . . . . . . . . . 85

5 Conclusion 89

5.1 Summary of findings . . . . . . . . . . . . . . . . . . . . . . . 89

5.2 Future research . . . . . . . . . . . . . . . . . . . . 91

6 Valorisation $\quad 93$

$\begin{array}{lr}\text { References } & 97\end{array}$

$\begin{array}{ll}\text { Curriculum Vitae } & 103\end{array}$ 


\section{List of Figures}

2.1 Smoothing effect of the parameter $\alpha \ldots \ldots$. . . . . . . . . . . 19

2.2 Distribution of pension return in steady state . . . . . . . . . . 20

2.3 Distribution of funding ratio in steady state . . . . . . . . . . . . 21

2.4 Average funding ratio of the pension fund following different initial fund-

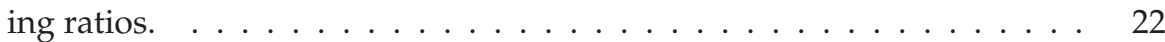

2.5 Certainty equivalent per annum $\ldots \ldots \ldots \ldots \ldots \ldots$

2.6 Equivalent funding ratio . . . . . . . . . . . . . . . . . . . 25

2.7 Sensitivity of the pension wealth to past returns $\ldots \ldots \ldots \ldots$

3.1 Portfolio dynamics $\ldots \ldots \ldots \ldots \ldots \ldots \ldots$

4.1 The level of interest rates . . . . . . . . . . . . . . . . . . . . . . . 64

4.2 The average strategic allocation of the pension funds . . . . . . . . 65

4.3 The model implied optimal strategic asset allocation and actual allocation of pension funds before and since the low-interest rate environment 86

4.4 Asset allocation in a regime switching model . . . . . . . . . . 87 



\section{List of Tables}

2.1 Pension fund indicators in steady state . . . . . . . . . . . . . 18

2.2 Optimal risk sharing parameter $\alpha \ldots \ldots \ldots \ldots \ldots \ldots \ldots \ldots$

2.3 Sustainability of the pension fund $\ldots \ldots \ldots \ldots \ldots \ldots$

3.1 Summary statistics I $\ldots \ldots \ldots \ldots$

3.2 Summary statistics II . . . . . . . . . . . . . . . . 36

3.3 Regression of total change on passive change . . . . . . . . . . . . 39

3.4 Longer horizon rebalancing $\ldots \ldots \ldots \ldots$

3.5 Rebalancing costs . . . . . . . . . . . . . . . . . . 46

3.6 Actual change on passive change: asymmetric re-balancing . . . . . . . 47

3.7 Cross-sectional differences in rebalancing . . . . . . . . . . . . 50

3.8 Contributions of asset classes to equity rebalancing $\ldots \ldots \ldots \ldots$

3.9 Rebalancing regressions within asset classes $\ldots \ldots \ldots \ldots \ldots \ldots$

4.1 Summary statistics I . . . . . . . . . . . . . . . . . . 60

4.2 VAR parameter estimation results (1952.Q2-2014.Q4) . . . . . . . . 61

4.3 Sensitivity of the optimal portfolio allocation to changes in the state vari-

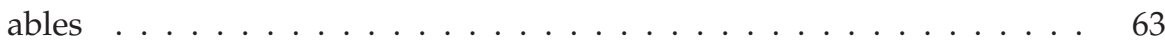

4.4 Sensitivity of portfolio choice to state variables, with liabilities and longer

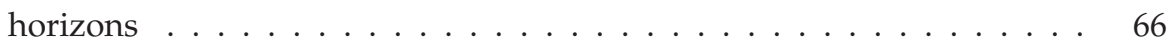

4.5 Summary statistics II . . . . . . . . . . . . . . . . . . . 70

4.6 Average change in strategic asset allocation before and during low-interest rate environment . . . . . . . . . . . . . . . . . 71

4.7 Robustness check . . . . . . . . . . . . . . . . . . . . . . . 74

4.8 Robustness regressions . . . . . . . . . . . . . . . . . . . . . 75

4.9 Levels of predictive variables and pension fund strategic asset allocation 80

4.10 Active changes in asset allocation and changes in predictive variables . 81 



\section{Chapter 1}

\section{Introduction}

\subsection{What's new in pensions?}

Pension funds are arguably the most important institutional investors in the world today. The pension assets in 16 major pension markets at the end of 2014 totaled USD 36 trillion, which is approximately $84 \%$ of the combined gross domestic product (GDP) of their respective economies. This alone speaks volumes about their importance and influence. ${ }^{1}$ Moreover, pension assets in Australia, the Netherlands, Switzerland, the UK, and the US exceed their respective GDPs. However, pension funds are arguably not robust, even though retirees depend crucially on them for their retirement security. Many examples can be given to illustrate their current problems, on which I elaborate in this chapter. These have been a constant source of concern for corporations as well as governments for many years, and can be due to inherent drawbacks in the way pension funds have been set up but also to current trends in financial markets and demographics. It is now well understood by industry experts as well as academics that pension funds require innovative ideas to overcome their current problems. These range from designing appropriate pension contracts to investing in a smarter way that adds value for the participants.

Pension problems are not an entirely new phenomenon. Drucker (1976) was among the first to identify the impending problems with the US pension system. Even Chatham Chest, possibly the oldest funded occupational pension fund in the world, had funding problems. It was set up to pay benefits for Royal Navy seamen in the UK who became disabled on active duty. The contribution into the fund at its inception was about $5 \%$ of the wages of the seamen; it did not however keep increasing with salaries. This meant that it was not properly funded and would inevitably run out of funds to keep paying the beneficiaries. Other problems included mismanagement of funds by senior Navy

\footnotetext{
${ }^{1}$ Global pension assets study, Towers Watson, 2015.
} 
officials. $^{2}$ Eventually, it could only operate with shortfalls covered by the government on a pay-as-you-go basis, until its ultimate closure in 1814. More recently, Lowenstein (2008) provides case studies of the pension funds of General Motors, the New York City subway system, and the city of San Diego, each of which has been in serious trouble. Chicago, the biggest city in the Midwest, has more than $\$ 20$ billion in unfunded pension liabilities. Chicago's credit rating has been downgraded to junk status partly due to its pension problems. The state of Illinois, where Chicago is located, has $\$ 111$ billion in unfunded pension liabilities. ${ }^{3}$ All these pension problems are increasing at exactly the same time as the number of people entering retirement is going up. These are only a few examples of many pension funds with problems, the consequences of which can be terrible for the retirees.

I focus on three main issues that pension funds face today. First, due to funding problems in defined benefit (DB) pension funds, these are being replaced by socalled collective defined contribution (CDC) pension schemes. In these types of pension schemes, the assets are pooled and invested. However, there are no sponsor guarantees and the fund is allowed to reduce benefits in case of poor returns in financial markets. One major benefit of a switch to CDC instead of a pure defined contribution (DC) scheme is that the benefits of intergenerational risk sharing can be exploited. In chapter 2, I specifically address these new types of contracts and demonstrate the benefits of a CDC pension fund scheme in the context of intergenerational risk sharing. Secondly, I focus on the long-term nature of pension funds and evaluate whether they invest in a way that is value adding for a long-term investor. One essential requirement of long-term investing is not to be pro-cyclical. In chapter 3, I assess whether pension funds are behaving counter-cyclically by investigating their portfolio rebalancing. Thirdly, in chapter 4 , I focus on how pension funds take macro-economic variables into account when investing. In particular, I investigate their response to the current low interest-rate environment. I also compare their actual behavior with the behavior predicted by the literature on strategic asset allocation. In the remainder of this chapter, I discuss these three themes around which this dissertation revolves and provide a brief overview of the motivations behind the underlying questions.

\subsection{Why retirement risks should be shared}

Sharing retirement risks is not a new concept. For example, tontine is a type of group annuity that was prevalent in France, the Netherlands, England, and the United States in the late 17th/18th century. This was an early variant of longevity risk sharing for retirement payments. It works by dividing the total periodic payment to a group of

\footnotetext{
2"Funding the Chatham Chest", The Actuary, 2003

${ }^{3}$ Illinois's public pensions, The bottomless pit, The Economist, May 16th 2015.
} 
annuity purchasers amongst the surviving members. The working of a tontine is best illustrated by an example. A tontine share could be purchased at say $€ 100$, which would provide a dividend payment at say 10\% every year. Now, assuming 100 people subscribed to the scheme, the total dividend paid out will be $€ 1000$. If all 100 annuitants are alive, then the payment will equal $€ 10$ each. However, if only 50 are alive then the payment to each member will be $€ 20$. Therefore the members that die earlier contribute to the annuity payments of the members that live longer. The retirement benefits increase over time, as if being indexed for inflation. One of the earliest known tontines was issued by King William in 1693, when one share could be purchased for $£ 100$. The last tontine nominee received $£ 1081$ before she died in $1783 .{ }^{4}$ By the midtwentieth century, the tontines were extinct.

The concept of intergenerational risk sharing refers to the ability to transfer risks between cohorts of people who are not born at the same time. These risks can be demographic (for example, longevity) and/or economic, for example risk originating from the financial markets where the pension savings are invested. Various academic studies have shown that intergenerational risk sharing is welfare improving. ${ }^{5}$ Pension funds can have a special role in facilitating intergenerational risk sharing, as they can help transfer the risks from old people to young people. ${ }^{6}$ Effectively, young people insure the retirement of old people. It has been shown theoretically that ex-ante Pareto improvement is possible in this type of arrangement. Since the financial instruments for trading these risks do not exist, pension funds are a feasible vehicle for intergenerational risk sharing. Moreover, institutionally managed pensions also minimize suboptimal behavior by individuals in saving and investing for their retirement. ${ }^{7}$ Thus, a collective pension system makes sense in theory, even though an optimal way to set it up in practice remains elusive.

Risk sharing in regard to pensions has been facilitated by defined benefit (DB) pension plans, in which the pension paid in retirement is a function of the salary earned during the working years. However, they have run into trouble around the world. In particular, US pension funds are severely underfunded, that is, the assets under management of the pension funds are significantly less than the pensions promised to the members. ${ }^{8}$ The example of cuts in previously guaranteed public pensions in the city of

\footnotetext{
${ }^{4}$ I refer to Milevsky (2014) for a detailed discussion of the tontines issued by King William, and to Forman and Sabin (2014) for a discussion of tontines for resolving the current funding crises for pension funds.

${ }^{5}$ For a recent treatment of intergenerational risk sharing see Beetsma and Bovenberg (2009); Beetsma, Romp, and Vos (2013); Cui, Jong, and Ponds (2011); Gollier (2008)

${ }^{6}$ Shiller (1999) has suggested that old people are more risk averse than young people, therefore transfer of risk from more risk averse to less risk averse is logical.

${ }^{7}$ See Benartzi and Thaler (2001) and Brown, Liang, and Weisbenner (2007) for a discussion on suboptimal behavior by individuals in saving and investing for retirement.

${ }^{8}$ For a brief overview of the financial situation of the public pension plans in the US see http:
} 
Detroit shows that in times of serious downturn, pensions will have to be reduced, no matter what was agreed upon in the contract. ${ }^{9}$ It therefore emerges that the participants do indeed bear the ultimate risk of the pension fund going under. Thus the employees are the ultimate risk bearers of their pension, and the pension fund contracts should explicitly state this. Moreover, sponsors of corporate pension funds want to withdraw any guarantees as they do not want any spillover on the company's balance sheet. This has led to the freezing of DB pension plans (Rauh, Stefanescu, and Zeldes, 2013) and introduction of DC pension plans. However, a new type of collective pension contract is emerging, which is the "middle ground" between Defined Benefit (DB) and Defined Contribution (DC). These new pension contracts have been becoming popular under various names, being called Target Benefit Plans in Canada, Defined Ambition pension schemes in the UK, ${ }^{10}$ and Collective Defined Contributions (CDC) plans in the Netherlands. Another similar type of contract is called the Performance Linked Annuity Adjustments (PLAA), ${ }^{11}$ which is used in the Wisconsin Retirement System in the US. Simply put, this is a DB type contract with pension benefits that adjust over time in response to investment returns earned by the pension fund.

An example of a CDC pension contract already in place is the Rabobank Pension Fund. A shift was made from a Defined Benefit (DB) plan to a Collective Defined Contribution (CDC) plan from January 1, 2014. ${ }^{12}$ The obligation of the employer to make additional deposits was abolished. The pension fund cannot therefore ask for additional contributions from the employer in times of underfunding. Instead, the new contract gives the pension fund the authority to reduce the pension rights "in case of a funding ratio deficit". Additionally, the pension accrual rate for those still working can be reduced "pro rata to the shortfall". The contribution policy is explicitly described as not being a risk management tool. The pension scheme is now identified as "Group defined contribution" but designed as an average-pay scheme, hence emphasizing its DB character. In summary, contributions are fixed, there is no sponsor guarantee and benefits are flexible depending on the financial situation of the fund. Is this a better way to arrange the pension system? The contribution of the second chapter is to analyze this type of pension contract, which aims at intergenerational risk sharing among different age cohorts using the so-called return smoothing mechanism. This mechanism transfers the positive or negative returns on the pension assets to participants over a period of time. In this type of risk sharing arrangement, participants are the ultimate bearers of the risk. I demonstrate that risk sharing implemented in this way is welfare-improving

\footnotetext{
//publicplansdata.org/quick-facts/national/

${ }^{9}$ see for example, A phoenix emerges, Detroit's bankruptcy plan, Nov 7th 2014, The Economist

${ }^{10}$ Defined Ambition Pension Schemes, Djuna Thurley, House of Commons Standard note no. SN 6902, 2014

${ }^{11}$ For more details see Novy-Marx and Rauh (2014)

${ }^{12}$ For more details see https : //www. rabobankpensioenfonds .nl/
} 
compared to a plan with no risk sharing, and more sustainable compared to defined benefit pension fund plans.

\subsection{How (not) to invest for the long-term}

Once the pension fund has decided on its strategic asset allocation, investing for the long term is straightforward. When the realized returns on various parts of the portfolio move the actual portfolio away from the strategic benchmark, the pension fund should rebalance it back. ${ }^{13}$ Next, I provide two examples, one where this rebalancing was not executed as expected and one where it was properly executed, which was ultimately beneficial to the performance of the fund. The first example is that of California Public Employees' Retirement System (CalPERS). Before the 2008 financial crisis, the equity weighting of CalPERS was $60 \%$. Due to the stock market decline, this went down to $52 \%$. CalPERS then sold equity to bring down the weighting further to $44 \%$. It sold equity to raise cash for short-term liquidity problems. This is theoretically unexpected, because pension funds are long-term investors with relatively fixed short-term liquidity needs. The liquidity problems stemmed from obligations relating to private equity and real estate deals. In 2009, CalPERS missed out on the rebound in equity markets. (Ang and Kjaer, 2012). Realizing its mistake, CalPERS introduced a formal rebalancing process to avoid such problems in the future. By contrast, Norges Bank Investment Management (NBIM), the investment manager of Norway's global pension fund, made a strategic decision in 2007 to increase the allocation to equity in the fund's portfolio from $40 \%$ to $60 \%$. This unfortunate timing meant that immediately following the decision, the portfolio experienced significant losses on the equity part of the portfolio. Continuing on with its new strategic allocation meant that the fund would be buying in a falling market when everyone else was selling: the pension fund therefore had to invest counter-cyclically. In 2008, NBIM actually made the decision to behave counter-cyclically and to continue to buy equity with the inflows to the fund. The fund made an equity return of $34 \%$ in the following year when the markets rebounded. If it had decided to give in to external pressure instead and had not bought equity, fund would have suffered significant losses.

In chapter three, I evaluate how pension funds rebalance their portfolio over time. Since funds have long investment horizons, they should rebalance to preserve the riskreturns characteristics of their portfolio. This requires pension funds to behave countercyclically. They should sell assets that have increased in value and buy assets that have lost value. Merton $(1969,1971)$ shows that an individual investor has a uniquely

\footnotetext{
${ }^{13}$ There has been some initiative from industry to encourage long horizon focus for institutional and corporations, see: focusing on the long term initiative: http://www.fclt.org/en/home.html and Focusing Capital on the Long Term, Dominic Barton and Mark Wiseman, January-February 2014, Harvard Business Review.
} 
optimal portfolio assuming that returns are independent and identically distributed and therefore should rebalance it back to that optimal portfolio if the realized returns move the portfolio away from it. Ang, Brandt, and Denison (2014) calculate the gains from a rebalancing strategy historically. Comparing rebalancing to a fixed $60 \%-40 \%$ stock-bond portfolio with a passive strategy that holds market capitalizations in stocks and bonds, they show that rebalancing a portfolio results in both higher cumulative returns and a higher risk-to-reward ratio. Long-term investors like pension funds have an additional incentive to rebalance - mean-reversion in equity prices. ${ }^{14}$ Long-term investors can buy even more when equity prices indicate higher expected returns and sell when expected returns are depressed (Ang, Brandt, and Denison, 2014). Moreover, if the pension funds do not rebalance, they are then moving with the market and thus behaving pro-cyclically. This is harmful not only for their own performance but also for the stability of the financial system, given the size of their portfolios.

\subsection{What challenges do low interest rates pose for pension funds?}

Both short-term and long-term interest rates have been at historic lows since the 2008 financial crisis. Since these interest rates play an important role in the valuation of financial securities, they can have a substantial effect on financial institutions. Rajan (2006) claims that periods of low interest rates provide investors with incentives to engage in search-for-yield and invest more in risky assets. Furthermore, an accommodative monetary policy can provide incentives that introduce pro-cyclicality into financial markets in the form of herding and risk-shifting. Low nominal short-term interest rates are also associated with higher risk-taking by banks. Maddaloni and Peydró (2011) find that low short-term interest rates induce more risk-taking by banks via softening of lending standards for households and corporate loans. This risk-taking is amplified by extended periods of low short-term interest rates, among other things (Altunbas, Gambacorta, and Marques-Ibanez, 2012).

Pension funds are particularly concerned by low interest rates. In a 2011 survey of senior executives of US corporate DB plan sponsors, the low interest rate environment was the second most important decision-making factor, after volatility in financial markets. It was deemed to have a substantial effect on the company's policy for DBplan funding, risk management, and investment in the preceding five as well as in the following two years. ${ }^{15}$ Consider the following example to understand the importance of short-term interest rates for pension fund portfolios. Most pension funds have an expected rate of return assumption, as do, for example, defined benefit funds in the

\footnotetext{
${ }^{14}$ Fama and French (1988b) and Poterba and Summers (1988) were the first to provide evidence of meanreversion in equity prices and more recently Balvers, $\mathrm{Wu}$, and Gilliland (2000) have found the same in a cross-country analysis.

${ }^{15}$ Redefining Pension Risk Management in a Volatile Economy, CFO Publishing LLC, 2011.
} 
United States. Many pension funds have nominal return targets, generally around 8\%. If the short-term risk-free interest rate is at $4 \%$ and pension funds expect $8 \%$ returns nominally they have to take on additional risk of $4 \%$ worth of risk premium. However, short term interest rates are currently close to zero and have been so for some time. This implies that pension funds have to take on additional risk if they plan to achieve the $8 \%$ nominal return target. This implies a significant change in their portfolio. Similarly, low long-term interest rates have substantial consequences for pension fund liabilities. Since some pension funds discount their liabilities with long-term interest rates, a decline in long-term interest rates lowers the funding ratio because of the increase in the market value of liabilities. What should pension funds do to mitigate the impact of this special macro-economic situation? Are there any insights from strategic asset allocation models? What have the pension funds actually done so far in the low-interest rate environment?

Many DB pension funds have shown a clear interest in a Liability Driven Investments (LDI) strategy for investing. In this approach, pension funds aim to invest in such a way that the duration of assets matches that of the liabilities. This generally involves an increase in the fixed income allocation in the portfolio at the expense of equity. It appears to be a good idea, but there are at least the following two caveats that could negate the benefits of this approach. First, this type of approach involves an enhanced focus on the funding ratio of the pension fund. Unless the pension fund is fully duration matched, which is unlikely to be the case, any variation in interest rates will introduce variation in the funding ratio. With market-consistent valuation of pension liabilities and a heightened focus on the funding ratio, the pension fund would have to make frequent adjustments to its portfolio in response to small movements in interest rates. Secondly, the current funding status of the pension fund needs to be taken into account when considering any portfolio shift towards fixed income. Since a shift to fixed income allocation in a low interest rate environment implies that it will lock-in low yields, it will be difficult to achieve a sufficient return on the portfolio. It has to be recognized that an underfunded pension fund would then find it difficult to recover to a fully funded status. I specifically highlight the second drawback in chapter 4 .

The vast literature on stock return predictability and strategic asset allocation provides the theoretical background for the optimal behavior of pension funds. There is a general consensus in the academic literature that stock returns are predictable, and substantial empirical evidence exists for this predictability (Ang and Bekaert, 2007; Campbell and Yogo, 2006; Cochrane, 2008). There are several popular predictor variables such as dividend-price ratio, earnings-price ratio and measures of interest rates. In particular, nominal short term interest rates, which are especially important currently, robustly predict future excess returns (Ang and Bekaert, 2007; Campbell and Viceira, 2002; Campbell and Yogo, 2006). Campbell and Yogo (2006) find that short-term inter- 
est rate and long-short yield spread are strongly significant in predicting stock returns. Low short-term interest rates predict high stock returns and this predictability is generally stronger at short horizons than relatively longer horizons. Investigating the behavior of pension funds in chapter 4, I find that the pension funds have done exactly the opposite to what the strategic asset allocation models predict. More generally, pension funds are unable to "time-the-market" according to macroeconomic information. These findings are consistent with a recent survey of UK DB pension schemes, which found that the discipline of liability hedging is increasing in pension funds despite the low interest rates. Liability hedging implies allocating more of the portfolio to fixed income securities, thus locking into a historically low interest rate environment. Not only are the pension funds with existing mandates for liability hedging increasing their efforts in this regard, other pension funds have also started to invest in a manner consistent with liability hedging. This shows that pension funds are concerned about the further decline in already low long term interest rates. ${ }^{16}$

I summarize the finding of the dissertation in the concluding chapter five. Additionally, I point out some limitations of the thesis and put forward some ideas for future research. Finally, in chapter five, I discuss the impact of my research by outlining some recommendations for individuals, pension funds and regulators that are implied by my research.

\footnotetext{
${ }^{16}$ Navigating the UK LDI Market, KPMG LDI Survey, 2015
} 


\section{Chapter 2}

\section{Optimal risk sharing in a collective defined contribution pension system $^{*}$}

\subsection{Introduction}

Despite the crucial dependence of current working generations and retirees on the pension system for their retirement security, pension systems around the world have not lived up to their expectations. There are well-known problems associated with traditional plans, in particular with Defined Benefit (DB) plans. Novy-Marx and Rauh (2011) have documented large unfunded liabilities in US public pension plans. For corporate pension funds, sponsors are increasingly withdrawing their guarantees as they do not want spillover effects of underfunding on the company's balance sheet and therefore they prefer the workers to be the risk bearers for their own pensions. This usually involves freezing DB pension plans (Rauh, Stefanescu, and Zeldes (2013)) and replacing them with Defined Contribution (DC) plans for new and old employees. ${ }^{2}$ However, in this case the responsibility for making complex financial decisions falls on individual households, who can make sub-optimal decisions. This has been documented by, for example, Choi, Laibson, and Madrian (2011), who demonstrate that individual households make poor choices in investing for their retirement, and by Lusardi and Mitchelli (2007), who show that households lack financial skills for retirement planning.

\footnotetext{
*This chapter is co-authored with Dennis Bams (Maastricht University, Netspar) and Peter Schotman (Maastricht University, Netspar).

${ }^{2}$ Freezes can either be mandatory or voluntary, see Brown and Weisbenner (2014). Another common solution implemented is reducing the generosity of pensions, for example by withholding inflation protection or cost of living adjustments (COLA) for pension payments. Again this solution is far from ideal and erodes trust in the pension system as it amounts to an ex-post reduction in benefits.
} 
We analyze a Collective Defined Contribution (CDC) pension system, which is one promising solution to the DB problem discussed in the literature. In this type of pension contract, the assets of the fund are pooled and institutionally managed, and the benefits depend on the financial situation of the fund. This keeps the pension system collective, as needed because individuals make poor financial decisions when it comes to retirement saving and investing. ${ }^{3}$ Another important benefit of collective pension funds is risk-sharing. Gollier (2008) finds potentially large benefits of intergenerational risk-sharing; a 25\% increase in the certainty equivalent of the pension benefits paid to all current and future generations. In this chapter, we provide an estimate of the benefits of intergenerational risk sharing in the absence of any form of sponsor guarantee and with no option of increasing contributions. We find that a collective pension fund is able to reap the benefits of intergenerational risk sharing purely by managing pension rights.

Intergenerational risk sharing is generally welfare-increasing. ${ }^{4}$ However, efficiency of risk-sharing can depend on the risk-sharing mechanism in place. For example, Cui, Jong, and Ponds (2011) find a decrease in welfare compared to optimal individual welfare in the cases of for defined-benefit plans with benefit adjustments only and of defined-benefit plans with contributions adjustments only. ${ }^{5}$ In this chapter, we analyze a collective defined contribution pension system that allows for intergenerational risk sharing through return smoothing. ${ }^{6}$ We model intergenerational risk sharing with an explicit age independent return smoothing rule to provide full transparency in risksharing. Only a fraction of any financial shock is transferred to the individual cohorts' pension wealth, while the rest is smoothed through a buffer. Our first contribution is that we find that intergenerational risk-sharing implemented in this way increases the certainty equivalent of pension benefits paid by approximately $6 \%(\gamma=3)$ for all current and future generations, compared to a pension fund with no risk-sharing.

\footnotetext{
${ }^{3}$ It is also possible to share portfolio risk and take advantage of economies of scale in these pension systems.

${ }^{4}$ For a recent treatment of welfare benefits of intergenerational risk-sharing see Cui, Jong, and Ponds (2011); Beetsma and Bovenberg (2009); Beetsma, Romp, and Vos (2012); Beetsma, Romp, and Vos (2013); Chen, Beetsma, Ponds, and Romp (2014);van Bilsen and Bovenberg (2014) etc. Risk sharing can be amongst all generations currently in the scheme or amongst all current and future generations, the latter is welfare enhancing with market-traded risks. Moreover, limiting risk sharing to participants only in accumulation or decumulation phase will limit the benefits.

${ }^{5}$ See also Beetsma and Bucciol (2015)

${ }^{6}$ Some pension funds in the Netherlands have implemented reforms to switch from DB to CDC plans. One specific plan where this change happened in January, 2014 is Rabobank Pension Fund (www.rabobankpensioenfonds.nl). There is no sponsor guarantee, and benefits are flexible and depend on the financial situation of the fund. The UK government is considering similar 'Defined Ambition' pension schemes for the Pension Schemes Bill 2014-15 see for example Thurley (2014). In the US, cash balance plans and the Wisconsin Retirement System (WRS) are in a similar spirit of risk sharing, see Novy-Marx and Rauh (2014) who find substantial benefits in reducing unfunded liabilities by making pensions a function of returns
} 


\subsection{Introduction}

Our second contribution is that we demonstrate that there is a tradeoff between low risk-sharing which is beneficial for current working generations and high risk-sharing which is beneficial for current retirees and generations close to retirement. If there is high smoothing (more risk-sharing) then this is beneficial to current retirees and generations closer to retirement as they will not fully experience a shock. However, this is not preferable for the current working population and future generations entering the pension system, as they may enter into an underfunded fund. Due to this tradeoff, it is possible to calculate the optimal level of risk-sharing or smoothing in our model. The board of a pension fund needs to decide on optimal risk allocation, as it needs to balance the interests of current and future participants. Depending on the social discount factor considered, optimal risk-sharing implies that only about one-fourth to one-third of underfunding should be passed on to all the future generations in the year underfunding occurs.

The pension funds portfolio allocation to risky assets remains constant in our model. Our third contribution is that we demonstrate that the individuals exposure to risky returns decreases as the individual approaches retirement. This is consistent with lifecycle portfolio choice theory. It also extends the findings of Guillén, Jørgensen, and Nielsen (2006) to collective pension systems. Furthermore, we look at the long-term steady state of pension funds and find that CDC pension funds are more sustainable compared to our proxy of DB fund. Lastly, we calculate the minimum funding ratio that is required to ensure that the benefits of risk sharing are not outweighed by the detrimental effect of underfunding for the generation that is about to enter the fund. It may still be welfare-improving to enter into a underfunded pension fund when intergenerational risk sharing provides a welfare improvement compared to a system with no risk sharing. We find that at about $11 \%(\gamma=3)$ underfunding, it is still welfare improving for a new generation to join the fund. ${ }^{7}$

Our model is based on Gollier (2008). We first extend his model by departing from the assumption that the present value of future contributions and present value of future payouts are part of the pension funds balance sheet. Secondly, our risk-sharing rule resembles that of Goecke (2013). Like him, we specify the smoothing rule as a function of the asset liability ratio, but we extend his model by explicitly modeling overlapping generations and cash flows due to premiums and pension payments. ${ }^{8}$ Third, we develop a utility framework that can take into account intra-generational fairness. We model an open fund in which a new cohort enters each year and shares in the risk with the existing cohorts. This aids in understanding the behavior of the fund in the long

\footnotetext{
${ }^{7}$ Discontinuity risk for pension fund can also arise from a very high funding ratio (Van Bommel, 2007), something that we do not consider here. See also Siegmann (2011) for a discussion of minimum fundings ratios for defined-benefit pension funds.

8 See Grosen and Lochte Jorgensen (2000) for a treatment of return smoothing mechanisms in life insurance products.
} 
run, and enables the sustainability of the pension system to be checked. In our model, the accumulation of the assets through the investment returns deviates from the accumulation of the pension rights at a rate which is a smoothed function of investment returns. We refer to the latter as the pension return. The assets are a function of market returns, whereas the pension rights are dependent on the funding ratio of the fund. Since the pension rights are adjusted based on the funding level, a smoothing parameter is used for risk sharing across cohorts. This parameter determines the extent of intergenerational risk sharing.

In our model, the benefits are defined implicitly through a pension indexation rule. The ultimate objective of the fund is to design an optimal benefits policy. For the special case of power utility and lump-sum pension payments, Gollier (2008) shows that the optimal benefit policy is a linear function of current assets. Another example of a benefit rule is given by Cui, Jong, and Ponds (2011), who suggest a cohort-specific benefit rule, where each generation receives a fixed benefit plus a fraction of the returns earned on their contributions. Our benefit rule is similar to Gollier (2008) and Cui, Jong, and Ponds (2011) but differs in the way that risk sharing is implemented.

\subsection{Risk sharing by return smoothing}

\subsubsection{Model}

We consider a pension fund with $N$ working and $K$ retired overlapping generations. Each year the oldest generation dies and a young generation enters the system. Each generation lives $N+K$ years. The pension scheme has mandatory enrollment. Participants accumulate pension rights when working and decumulate the rights during retirement. We assume that the entire cohort $\tau$ dies at time $\tau+K$. Generations are indexed by their retirement date $\tau$; therefore at time $t$ working generations are in $\mathcal{W}_{t}=\{\tau: t<\tau \leq t+N\}$ and retired generations are in $\mathcal{R}_{t}=\{\tau: t-K<\tau \leq t\}$.

The pension rights at time $t$ of participants retiring at time $\tau$ are denoted by $Z_{t}(\tau)$. Working generations pay annual contributions equal to $C_{t}(\tau)$. Their pension rights accumulate as

$$
Z_{t+1}(\tau)=\left(Z_{t}(\tau)+C_{t}(\tau)\right) I_{t}
$$

where $I_{t}=\mathrm{e}^{i_{t}}$ is a pension return factor set by the fund. The pension rights of all generations are adjusted by the same $I_{t}$. Total contributions to the fund are defined as $C_{t}=\sum_{\tau \in \mathcal{W}_{t}} C_{t}(\tau)$. Retired generations receive pension payments $X_{t}(\tau)$ and decumulate their pension rights according to

$$
Z_{t+1}(\tau)=\left(Z_{t}(\tau)-X_{t}(\tau)\right) I_{t}
$$


After benefit payments, the remaining rights accumulate with the same pension return in a similar manner as the rights of the working generations. Thus, risk is not only shared during the working life but also during the retirement years, with benefit payments determined in part by the investment returns. While risk taking during retirement is not essential to the return smoothing mechanism described below, this assumption is in line with Koijen, Nijman, and Werker (2011), who find that individuals should optimally convert a sizable proportion of their retirement wealth to variable annuities.

Benefit payments are assumed to come in the form of a variable annuity with $i_{t}$ as the "assumed interest rate" (cf. Brown and Poterba (2006)),

$$
X_{t}(\tau)=a_{t}(\tau) Z_{t}(\tau), \quad \tau \in \mathcal{R}_{t},
$$

with annuity factor $a_{t}(\tau)=\left(1-I_{t}^{-1}\right)\left(1-I_{t}^{t-K-\tau}\right)^{-1}$. The payout would be a level annuity if the pension index $I_{t}$ is constant. With a time-varying $I_{t}$ the payout is a variable annuity. The total fund payout is $X_{t}=\sum_{\tau \in \mathcal{R}_{t}} X_{t}(\tau)$. The sum of all rights of both working and retired generations is

$$
Z_{t}=\sum_{\tau \in \mathcal{W}_{t} \cup \mathcal{R}_{t}} Z_{t}(\tau)
$$

The accrued pension rights can be considered as the liability of the pension fund. However, since $Z_{t}$ is not a guaranteed claim on the fund, it is not a formal liability. It does not include the present value of the future expected increase in the pension rights of both working and retired generations. In that sense $Z_{t}$ is similar to the actuarial concept of Accumulated Benefit Obligations (ABO).

The fund has assets $A_{t}$. After paying out the benefits to the retired generations and collecting the contributions from the working generations, assets are invested in the financial market where they earn a risky return $R_{t}=\mathrm{e}^{r_{t}}$. Therefore the assets of the fund develop according to

$$
A_{t+1}=\left(A_{t}-X_{t}+C_{t}\right) R_{t+1}
$$

The assets of the fund should be balanced against the accrued pension rights $Z_{t}$. In principle the fund has two policy variables: the pension indexation $I_{t}$, and the investment portfolio which determines the risk/return trade-off of the returns $R_{t}$. We consider $I_{t}$ as the policy instrument of the fund, and assume that it sets $I_{t}$ to maintain a long-term balance.

The pension rights are adjusted annually based on the returns earned by the fund portfolio by using a return smoothing mechanism. The pension rights are indexed 
depending on the funding position of the fund through

$$
i_{t}=\mu_{p}+\alpha \ln \left(\frac{A_{t}}{Z_{t}}\right)
$$

where $\mu_{p}$ is the expected return of the pension fund portfolio. The pension return $i_{t}$ in year $t$ is the expected portfolio return with an adjustment. This adjustment depends on the funding mismatch between assets and liabilities, where the parameter $\alpha$ is used for smoothing this mismatch. It determines the extent to which the accumulation of asset returns is passed on to accumulation of pension rights. This has a dampening effect on liabilities, resulting in a smooth development of the liabilities. Since only part of the mismatch is passed on to the current generations, the parameter $\alpha$ determines the extent to which intergenerational risk sharing is allowed.

The adjustment is symmetrical: pension rights increase faster than average if the funds assets yield above average returns. Pension rights can also decrease after bad returns. Since the fund does not offer a minimum return guarantee, all investment risk is borne by current and future generations. Linearity of the adjustment mechanisms also means that there is no limit to pension wealth. ${ }^{9}$ The return smoothing makes risk sharing possible both over all cohorts in a given year and over time. It provides a relatively stable accumulation of pension rights compared to the more volatile asset return. The pension return rule provides a means of automatic adjustment of pension rights to enable the pension fund to maintain a healthy solvency level. However, since a shock is not immediately passed on to participants, new entrants may be faced with large unrealized bad returns. The pension return rule generates mean reversion in the funding ratio of the fund. ${ }^{10}$

To complete the model, we need to specify the contributions and portfolio choice. In the stylized model, we keep both fairly simple. Many assumptions of the stylized model can be relaxed in an empirical application. All the generations are assumed to have an equal number of workers. We assume that for each period $t$

$$
C_{t}(\tau)=1, \quad \tau \in \mathcal{W}_{t}
$$

Contributions are constant in real terms. With the fixed population size, they can be normalized to one. In a more elaborate realistic setting, it is possible to add income risk and demographics. If $y_{t}$ is real per capita income and $n(\tau)$ the size of the entering cohort, contributions could be $C_{t}(\tau)=\kappa n(\tau) y_{t}$.

\footnotetext{
${ }^{9}$ Other possible alternatives for the pension return rule could be a S-shape function which would avoid extreme values in assets, but also slow down the recovery after a bad shock. However, since we want to illustrate the simple return smoothing for pension funds, we refrain from such extended rules.

${ }^{10}$ Since the fund does not have liabilities in a strict sense, the term funding ratio is not entirely accurate. However, it is used here and elsewhere in the chapter for lack of a better term.
} 
The pension fund invests in a portfolio of risk-free and risky assets. The return on the risky assets at time $t$ is denoted by $R_{t}^{S}$. The risk-free interest rate is assumed constant and denoted by $R^{f}$. The share in the risky asset is denoted by $\omega$, which is assumed to be constant. Hence the portfolio return at time $t$ equals $R_{t}=\omega R_{t}^{S}+(1-\omega) R^{f}$. For the risky asset we assume that the $\log$ return $r_{t}^{S}=\ln R_{t}^{S}$ is independently normally distributed with mean $\mu$ and variance $\sigma^{2}$. Both the existence of a real risk-free rate and the normality of the returns are clearly simplifications to explain the main ideas of the model. Under the assumption of constant investment opportunities and a constant population size, the optimal portfolio weight $\omega$ will also be constant.

\subsubsection{Preferences and the fund policy}

This section considers the optimal return smoothing parameter $\alpha$ in (2.6). We assume that the pension fund designs the adjustment rule with the aim of maximizing the welfare of all the participants of the fund. Since the pension fund board represents both current working and retired cohorts as well as future generations, it faces an intertemporal trade-off in the benefits paid to current and future retirees. Since there are also $K$ overlapping generations receiving benefits at each time $t$, the fund should also consider the intratemporal distribution of benefits over different age groups. Several utility functions express both the intratemporal and intertemporal effects of the benefits policies. We use the following simple parametric specification

$$
Q_{t}=\mathrm{E}_{t}\left[\sum_{s=0}^{\infty} \delta^{s} U_{t+s}\right] \text {, }
$$

and where

$$
\begin{aligned}
U_{t} & =\frac{V_{t}^{1-\gamma}}{1-\gamma} \\
V_{t} & =\left(\sum_{\tau \in \mathcal{R}_{t}} X_{t}(\tau)^{\rho}\right)^{1 / \rho}
\end{aligned}
$$

The intertemporal choice is determined by the pension fund's social discount factor $\delta$ and the constant relative risk aversion parameter $\gamma$. The intratemporal choice is specified by using a CES specification as an aggregator of the benefits to the different overlapping generations. The parameter $\rho$ defines the preference for equality over cohorts. If $\rho=1$, the fund is only concerned with the total payout and $V_{t}=X_{t}$. For smaller $\rho$ the pension fund views a large dispersion in payments made in the same year to different cohorts as an undesirable feature. Such preferences induce a degree of fairness in the distribution of payments. In the limit as $\rho \rightarrow-\infty$ the intratemporal utility reduces 
to $V_{t}=\min _{\tau \in \mathcal{R}_{t}} X_{t}(\tau)$, which is the 'Rawlsian social welfare functional' and appears standard in the literature (c.f. Kreps (1990), p 160). Since the CES function is first degree homogeneous, an overall proportional increase in payments $X_{t}(\tau)$ to all cohorts raises the utility $V_{t}$ by the same proportion. The CES specification is related to a multiplicative habit model, in which individuals view their utility as a function of their benefits relative to the average payments to all retirees.

The pension fund's utility function is still time-separable in $V_{s}$. The utility function is not necessarily separable in the benefit payments of the individual cohorts. With an objective function as in (2.8), the pension board makes decisions for the fund such that higher payouts are better, smoothing over time is encouraged $(\gamma)$ and intratemporal equality has value $(\rho)$.

The optimal risk-sharing parameter $\alpha$ is chosen such that it maximizes the discounted sum of expected utility generated by pension wealth. The fund faces a budget constraint in its optimization, since contributions are fixed by design as we are considering a collective defined contribution pension system. Changing $\alpha$ generally has two effects. First, a smaller $\alpha$ provides more smoothing and will reduce risk for older generations. Secondly, a smaller $\alpha$ increases the volatility of the funding ratio, which increases the risk for young generations of entering the fund when its funding ratio is very low.

To obtain a transparent adjustment rule with a fixed smoothing parameter we solve for the optimal $\alpha$ that maximizes the average of $Q_{0}$ when we start the system in a steady state. From there, we simulate a series of paths of length $T$ and compute the realized fund utilities

$$
Q_{0}=\sum_{t=0}^{T} \delta^{t} \frac{1}{1-\gamma}\left(\sum_{\tau \in \mathcal{R}_{t}} X_{t}(\tau)^{\rho}\right)^{(1-\gamma) / \rho},
$$

and find the value of $\alpha$ that maximizes the average $\bar{Q}_{0}$.

For the optimal smoothing parameter, we look at the utility from the perspective of the pension fund, not from an individual's perspective. For an individual cohort retiring at time $\tau$, the life-time utility is $V_{\tau-N}(\tau)=\mathrm{E}_{\tau-N} \sum_{s=0}^{K-1} \delta_{\tau}^{s} U\left(X_{\tau+s}(\tau)\right)$, where $U$ is a utility function and $\delta$ is pension fund's social discount factor. The pension fund's objective is not simply the sum of the individual utilities, but rather at each time $t$ it calculates the utility by including all cohorts that are alive, both working and retired, at that time. The fund needs to aggregate individual cohorts' utilities, without being able to assess whether individual utilities are preference independent. In defining preferences for a pension scheme, inter-cohort comparisons may be an important consideration, since generations may view their benefits from the system relative to what other cohorts receive at the same time. A reduction in pension seems less painful when everyone is facing a reduction. Additionally, an extensive literature on habit formation (cf. Abel (1990) ) questions the assumption of preference independence. Luttmer (2005) 
provides empirical evidence for the effect of the neighbor's consumption on the individual's own well-being. For this reason, we have chosen the objective function (2.8).

\subsection{Results}

We analyse the pension system using simulation. As in Cui, Jong, and Ponds (2011) we take $N=40$ and $K=15$ and thus have 55 overlapping generations. We set the return parameters for the risky asset at $\mu=5 \%$ and $\sigma=15 \%$, and its portfolio share at $\omega=0.6$. The risk-free rate is $R^{f}=2 \%$. We start the simulations at $t=0$, assuming that returns before $t=0$ have always been equal to the expected return $\mathrm{E}\left[R_{t}\right]$. Section 2.5.1 provides the details for the initial pension rights $Z_{0}(\tau)$. The initial conditions for the pension rights are set independently of the adjustment parameter $\alpha$.

\subsubsection{Stochastic steady state}

Using 100,000 simulated paths, we evaluate the cross-sectional distribution of the outcomes at time $t=200$, assuming that after such a long period we have reached the stationary distribution. Table 2.1 presents the value of various pension fund indicators for different values of the policy parameter $\alpha$. First of all, with $\alpha<1$, the distribution of the pension index $I_{t}$ is much more concentrated than that of the actual portfolio returns $R_{t}$, showing that the smoothing of risk across generations implies less uncertainty in pension returns. The standard deviation (and 95\% interval) shrinks with $\alpha$. Another aspect of the smoothing is that the pension return is highly autocorrelated, even though returns themselves are not autocorrelated. The autocorrelation increases as we decrease $\alpha$. To characterize the pension returns further, we consider the regression of the pension return on current and lagged asset returns

$$
i_{t}=c+\sum_{j=0}^{60} b_{j} r_{t-j}+e_{t}
$$

Figure 2.1 plots the regression coefficients for different values of $\alpha$. For $\alpha<1$ the coefficients show a slowly (geometrically) declining pattern. The coefficient $b_{0}$ for the current return is approximately the weight in the risky asset $(\omega)$ times the risk-sharing parameter $(\alpha)$. The coefficients decline faster for the larger $\alpha$; for small $\alpha$, the pension return is simply a long weighted moving average of market returns. The log-linear relationship between the pension return and the market returns is almost perfect, with $R^{2}$ of the regression above 0.993 . 
Table 2.1: Pension fund indicators in steady state

\begin{tabular}{lccccc}
\hline & Mean & 95 percentile & 5 percentile & Std. error & Autocorrelation \\
\hline Panel A. $\alpha=0.25$ & & & & \\
Pension return & 1.042 & 1.109 & 0.981 & 0.0001 & 0.7063 \\
Payouts & 157.0 & 326.0 & 63.0 & 0.2913 & 0.8804 \\
Assets & 2660 & 5190 & 1210 & 4.2920 & 0.8754 \\
Liabilities & 2630 & 4730 & 1370 & 3.5483 & 0.9454 \\
Funding ratio & 0.995 & 1.264 & 0.774 & 0.0005 & 0.7027 \\
\hline Panel A. $\alpha=0.5$ & & & & & \\
Pension return & 1.044 & 1.143 & 0.956 & 0.0002 & 0.4808 \\
Payouts & 157.0 & 315.0 & 64.0 & 0.2684 & 0.7424 \\
Assets & 2656 & 4810 & 1332 & 3.6136 & 0.8626 \\
Liabilities & 2640 & 4610 & 1410 & 3.3012 & 0.9332 \\
Funding ratio & 0.999 & 1.193 & 0.835 & 0.0003 & 0.4781 \\
\hline Panel A. $\alpha=0.75$ & & & & & \\
Pension return & 1.046 & 1.177 & 0.930 & 0.0002 & 0.2524 \\
Payouts & 157.0 & 317.0 & 63.0 & 0.2704 & 0.5612 \\
Assets & 2660 & 4700 & 1370 & 3.4216 & 0.8554 \\
Liabilities & 2650 & 4570 & 1420 & 3.2331 & 0.9140 \\
Funding ratio & 1.001 & 1.170 & 0.856 & 0.0003 & 0.2510 \\
\hline Panel A. $\alpha=1$ & & & & & \\
Pension return & 1.048 & 1.217 & 0.902 & 0.0003 & 0.0236 \\
Payouts & 157.0 & 324.0 & 60.0 & 0.2814 & 0.3506 \\
Assets & 2660 & 4660 & 1400 & 3.3391 & 0.8506 \\
Liabilities & 2660 & 4560 & 1430 & 3.2134 & 0.8859 \\
Funding ratio & 1.002 & 1.164 & 0.863 & 0.0003 & 0.0241 \\
\hline Fte & & & & \\
\hline
\end{tabular}

Note: This table shows the average, standard deviation, 95 and 5 percentiles, and first order autocorrelation for various outcomes of the pension fund in steady state (here at time point 200 after start) for different values of the smoothing parameter $\alpha$. The number of simulated paths is 100,000 . The mean return for each of the simulations is 1.046 , with 95 th percentile $=1.216$ and 5 th percentile $=0.901$. The parameters of the log-normal distribution are $\mu=5 \%$ and $\sigma=15 \%$; the share in the risky asset is fixed at $\omega=0.6$. The risk-free rate is $R^{f}=2 \%$ 


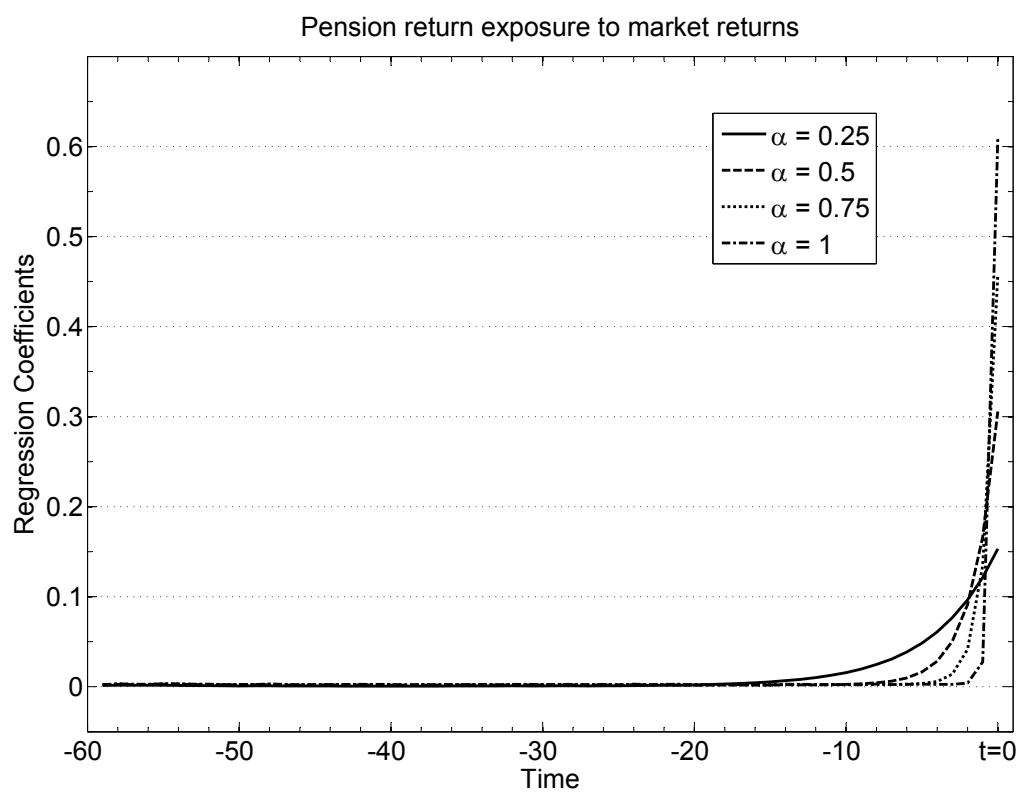

Figure 2.1: Smoothing effect of the parameter $\alpha$. This figure plots the coefficients of regression (2.12) for different values of the return smoothing parameter $\alpha$.

Table 2.1 also shows the downside of return smoothing: a lower $\alpha$ implies a more volatile funding ratio. This is because the fund does not adjust quickly to the mismatch in funding ratio with a lower value of $\alpha$, but delays the shock over a long horizon. This has implications for generations entering the fund during times of underfunding. For them, the return smoothing may be sub-optimal. When entering at a low funding ratio, the expected return will be below the market average. New entrants will thus face a low expected return, although they will later benefit from the lower risk at retirement. This shows the tradeoff between uncertainty in pension returns and uncertainty in funding ratio. The distributions of pension return and funding ratio are shown in figures 2.2 and 2.3 respectively. It is clear from the figures that the model with highest risk sharing $(\alpha=$ 0.25 ) has the highest standard deviation of funding ratio but lowest standard deviation of pension return. Table 2.1 also shows that the average benefit level and the average pension return are independent of $\alpha$. Given the specification of the return smoothing rule (2.6), the average funding ratio is equal to one, and assets are on average equal to the total liabilities. The average level of the assets is also independent of the adjustment 


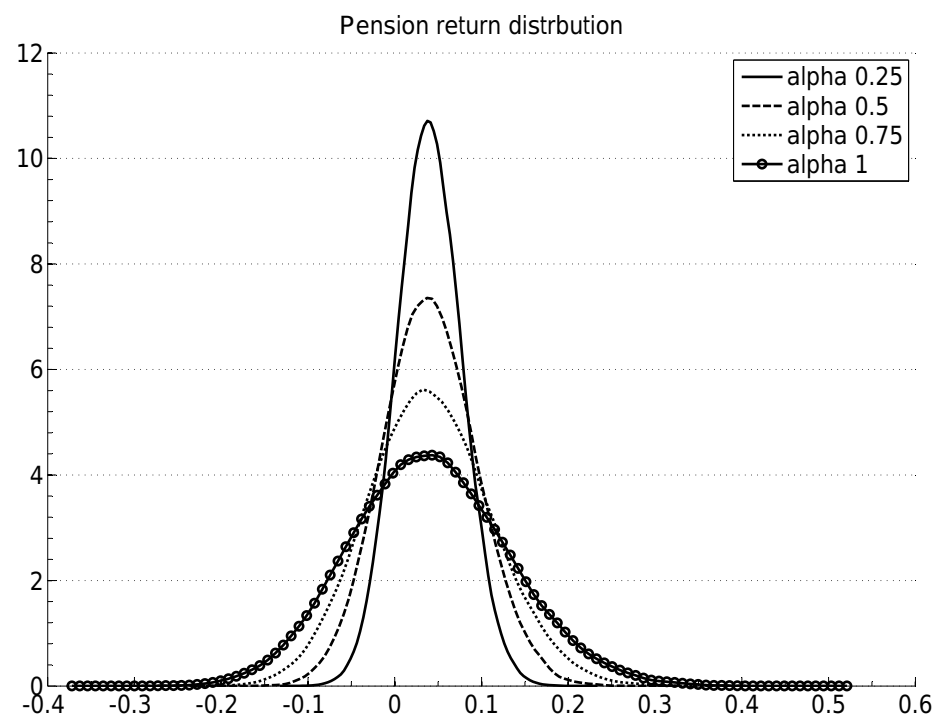

Figure 2.2: Distribution of pension return in steady state for different values of the return smoothing parameter $\alpha$.

parameter $\alpha$. In the stylized model, the effect of $\alpha$ is concentrated on the volatility of the funding ratio and the stability of the pension return and benefits. To learn more about the stability and adjustment speed of the system, we rerun the simulations with different initial conditions for the assets at time $t=0$. We experiment with different values for the funding ratio $f_{0}=A_{0} / Z_{0}$ ranging between $80 \%$ and $120 \%$, Given the funding ratio, the initial assets are taken as the funding ratio times the pension rights, $A_{0}=f_{0} Z_{0}$. Figure 2.4 presents the result of the shock to the assets on the evolution of the system. The fund reaches the steady-state ratio of approximately one after some years. Convergence to the steady state is faster in case of a higher value for $\alpha$.

\subsubsection{Optimal risk sharing}

To compute the optimal adjustment parameter, we need to choose the pension fund preference parameters. To compare the welfare of different generations over time, we require a discount factor $(\delta)$ that reflects the rate of social time preference. This social discount factor is used to discount future utility from the point of view of the social planner. There is considerable debate on the choice of this long-term discount rate. 


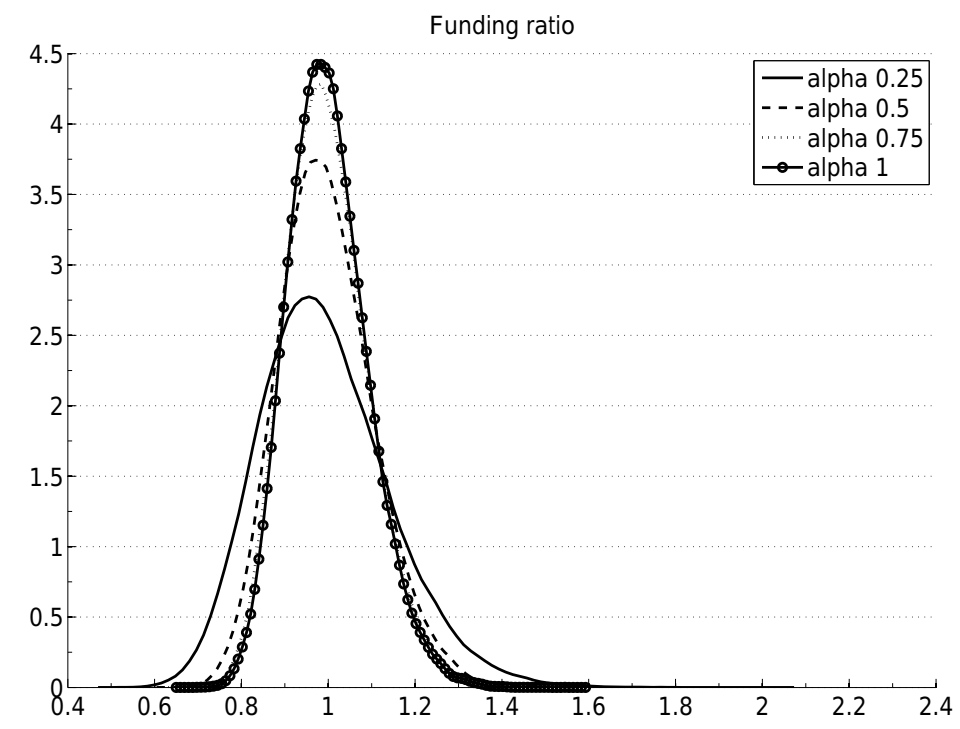

Figure 2.3: Distribution of funding ratio in steady state for different values of the return smoothing parameter $\alpha$.

Studies that look at intergenerational risk-sharing in the pension context like Gollier (2008) use a discount factor of 0.9728, whereas Cui, Jong, and Ponds (2011) use 0.9615 and in climate change literature, Nordhaus (2007) uses 0.9852. We compare results for different values of $\delta$ between 0.96 and 0.98 as the values for the discount factor. We also use alternative values for the preference parameters $\gamma$ and $\rho$. For each set of preference parameters, we determine numerically the value of $\alpha$ that maximises the pension fund objective (2.11). Table 2.2 reports the results. The optimal value of the risk-sharing parameter generally falls between $1 / 4$ and $1 / 3$. Thus it is optimal to have the risk sharing such that about one third or one fourth of the funding mismatch is passed on to all participants and retirees in the next year. The optimal value for $\alpha$ decreases as the discount factor decreases. A lower discount factor implies that the pension fund cares less about future generations. Thus lower $\alpha$ is preferred, which means more risk sharing, less uncertainty in pension returns and high auto-correlation but also high uncertainty on the funding ratio (see table 2.1). High uncertainty on the funding ratio is not preferable for cohorts just entering the fund, as they may be joining an underfunded pension system. The parameter $\rho$ is used to emphasize equality across generations at a particular point in time. If $\rho=1$, the fund is only concerned with the total payout. 


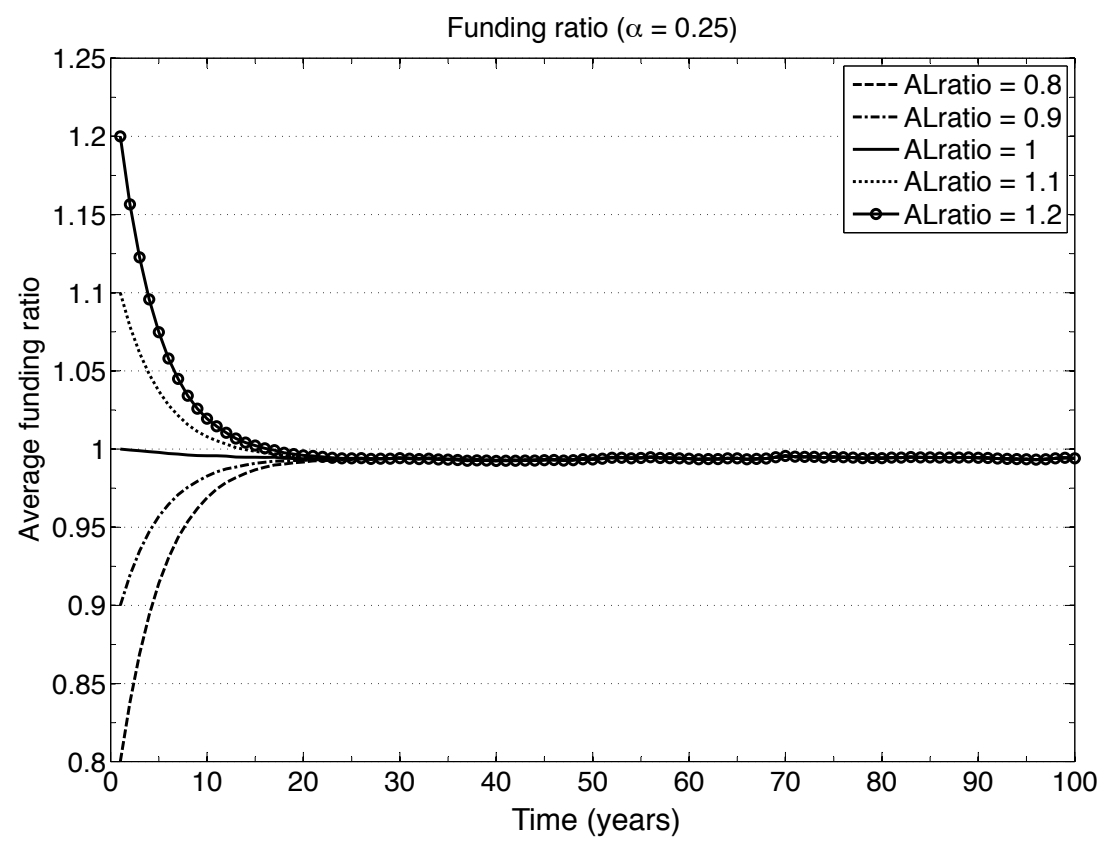

Figure 2.4: Average funding ratio of the pension fund following different initial funding ratios.

For smaller $\rho$, the pension fund views a large dispersion in payments made in the same year to different cohorts as an undesirable feature. Thus it is optimal to have more risk sharing if intra-generational equality is valued.

As an economically interpretable measure of the cost of a suboptimal $\alpha$, we calculate a certainty equivalent. For an arbitrary value of $\alpha$, we compute the objective $\bar{Q}_{0}(\alpha)$. By construction this will be less than the maximized value $\bar{Q}_{0}$ at the optimal $\alpha$. We then find a constant $c$ such that if we multiply all the payouts $X_{t}(\tau)$ of the suboptimal policy with that constant, these benefits would yield the same expected utility as the optimal policy. This is equivalent to $c=\left(\bar{Q}_{0} / \bar{Q}_{0}(\alpha)\right)^{\frac{1}{1-\gamma}}$. Figure 2.5 presents the value of $c$ against the value of given $\alpha$ for the preference parameters $\gamma=3, \delta=0.97$ and $\rho=1$, which corresponds to an optimal $\alpha$ of 0.31 (see table 2.2). At $\alpha=1$ the pension payments should be increased by as much as $7 \%$ per annum as compared to the benefits at the optimal $\alpha{ }^{11}$ The certainty equivalents are U-shaped, showing the clear optimum for

\footnotetext{
${ }^{11}$ See Bonenkamp, Meijdam, Ponds, and Westerhout (2014) for a comparison of welfare gains of inter-
} 
Table 2.2: Optimal risk sharing parameter $\alpha$

\begin{tabular}{lccc}
\hline$\rho$ & 0.96 & $\begin{array}{c}\text { Discount factor }(\delta) \\
0.97\end{array}$ & 0.98 \\
\hline Panel $A . \gamma=2$ & & & \\
0.50 & 0.22 & 0.29 & 0.35 \\
0.75 & 0.23 & 0.30 & 0.35 \\
1.00 & 0.24 & 0.31 & 0.36 \\
\hline Panel B. $\gamma=3$ & & & 0.35 \\
0.50 & 0.23 & 0.30 & 0.36 \\
0.75 & 0.24 & 0.30 & 0.36 \\
1.00 & 0.25 & 0.31 & 0.36 \\
\hline
\end{tabular}

Note: This table shows the optimal value of $\alpha$ obtained by numerically maximizing the pension fund objective (2.11). Return parameters are as in table 2.1.

$\alpha$. Too much risk sharing is not optimal. The limiting case of $\alpha=0$, a defined benefit system where the pension payments are fixed, is not sustainable in this model without sponsor guarantees.

Another way to measure the value of optimal risk sharing is by computing the equivalent initial funding ratio at different values of $\alpha$. The equivalent funding ratio is such that the utility generated by a underfunded pension system with risk sharing $\alpha$ is the same as the utility generated by a pension system that is fully funded $\left(f_{0}=1\right)$ and has no risk smoothing $(\alpha=1)$. Without risk smoothing, all return shocks in the system are immediately passed on to the current generations. How much lower can the initial funding ratio $f_{0}$ be at different values of $\alpha$ without a loss in expected utility? We find $f_{0}$ by numerically solving

$$
\bar{Q}_{0}\left(f_{0}, \alpha\right)=\bar{Q}_{0}\left(f_{0}=1, \alpha=1\right)
$$

The funding ratio of $f_{0}$ can be interpreted as the minimum funding ratio that needs to be maintained so that it is still welfare improving for future generations to enter this pension fund. The collective defined contribution pension system in our model goes through cycles of over and under-funding depending on the returns of the fund portfolio. Some generations therefore enter the system when it is in a state of underfunding. The generations that enter the fund at a funding ratio below the minimum level may refuse to enter into the mandatory pension contract and choose to renegotiate, thus rendering the pension system unsustainable. If the funding ratio drops below this level, newly entering cohorts would be better off in welfare terms to save and invest individually. Even for them, however, it could still be worthwhile to enter the pension fund for generation risk sharing in the literature which range from 1 to $25 \%$. 


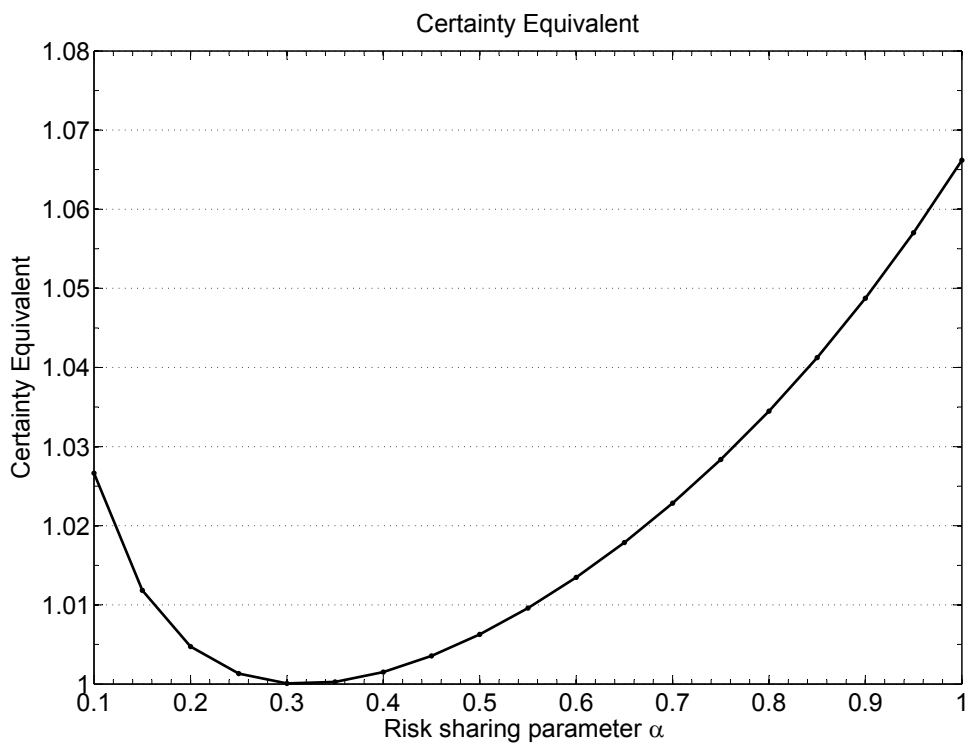

Figure 2.5: This figure shows certainty equivalent per annum. Preference parameters are $\gamma=3, \delta=0.97$ and $\rho=1$. Return parameters are as in table 2.1.

reasons outside the model, for example to avoid welfare loss resulting from financial mistakes by households and to benefit from scale economies of pension funds. Figure 2.6 shows the minimum funding ratio for a given level of risk sharing. For the optimal level of risk sharing, the minimum required funding ratio is approximately $89 \%$ percent. Therefore about $11 \%$ underfunding is sustainable without creating incentives to abandon the risk smoothing rule. Table 2.3 shows probabilities of underfunding (funding ratio less than one) of the pension fund with various values for $\alpha$. Note that although for $\alpha=0.5$, the probability of underfunding is about $53 \%$ the probability of the funding ratio falling below the sustainability threshold is relatively low at approximately $19 \%$.

\subsubsection{Implicit exposure to risky asset}

Optimal life-cycle theory (Merton (1969), Merton (1971), Bodie, Merton, and Samuelson (1992) and Bovenberg, Koijen, Nijman, and Teulings (2007)) states that a young person should hold a larger component of financial wealth in risky assets than an older person. Some models advise borrowing to invest in risky investments at a young age when 


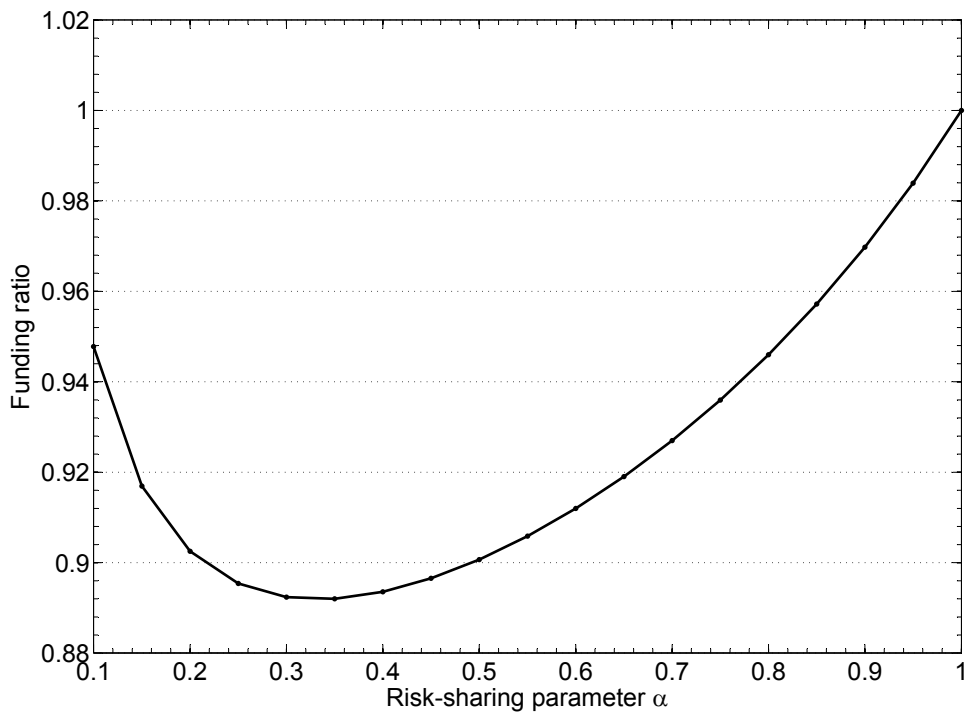

Figure 2.6: This figure shows the equivalent funding ratio (EFR) for different levels of risksharing. It is calculated using (2.13).

financial capital is small and human capital is large, in order to obtain optimal exposure to the risky assets. ${ }^{12}$ However, young people might be reluctant to do so, which may explain the emergence of institutionally managed life-cycle or target date funds which invest more conservatively over time. Individuals may also lack the capability to do so, due to limited financial literacy (Lusardi and Mitchelli, 2007). Pension wealth is a significant component of an individual's financial wealth and therefore there are arguments in favor of age-dependent exposure to risky assets by a pension fund on behalf of the members of the fund (Bikker, Broeders, Hollanders, and Ponds, 2012). We evaluate how the benefits provided by a collective defined contribution system with risk sharing implemented via return-smoothing are dependent on past returns on the risky asset. To keep the analysis simple, we assume here that $N=40$ and $K=1$, thus considering lump-sum pension wealth. We regress this lump-sum pension wealth at retirement date on the past returns on equity, using the regression

$$
\log \left(X_{t}\right)=c+\sum_{j=1}^{60} b_{j} r_{t-j}+e_{t}
$$

\footnotetext{
${ }^{12}$ This also depends on the riskiness of human capital including covariance with stock returns.
} 
Table 2.3: Sustainability of the pension fund

\begin{tabular}{lccccc}
\hline$\alpha$ & $\mathrm{P}(\mathrm{FR}<0.7)$ & $\mathrm{P}(\mathrm{FR}<1)$ & $\mathrm{P}(\mathrm{FR}>1.3)$ & $\mathrm{EFR}(\gamma=3)$ & $\mathrm{P}(\mathrm{FR}<\mathrm{EFR})$ \\
\hline 0.10 & 0.128 & 0.592 & 0.127 & 0.948 & 0.515 \\
0.25 & 0.010 & 0.555 & 0.034 & 0.895 & 0.268 \\
0.50 & 0.000 & 0.532 & 0.009 & 0.901 & 0.187 \\
0.75 & 0.000 & 0.523 & 0.005 & 0.936 & 0.260 \\
1.00 & 0.000 & 0.519 & 0.004 & 1.000 & 0.519 \\
\hline
\end{tabular}

Note: This table reports the probability of underfunding, significant shortfall and significant overfunding. The table also reports equivalent funding ratio (EFR) for different levels of risk-sharing and the probability that the funding ratio falls below this level. It is calculated using (2.13). Return parameters are as in table 2.1.

similar to (2.12). Figure 2.7 plots the coefficients for different values of $\alpha$. For $\alpha=1$ the payouts only depend on the returns during the working life and payouts are most sensitive to the most recent returns close to retirement. For smaller $\alpha$ the payout also depends on returns before a generation enters the fund. This illustrates the benefits of intergenerational risk sharing. When a young worker enters the pension system, he has a higher exposure to risky asset than in a system with no risk sharing. This is in line with the optimal life-cycle theory. Initially the exposure still increases with age due to annual contributions, but the most important element of the graph is the decreasing exposure closer to retirement. Because of the return smoothing, the exposure to the risky asset decreases automatically, again in line with life cycle theory.

\subsection{Concluding remarks}

We have analyzed a stylized model of a collective pension system that allows for intergenerational risk sharing based on return smoothing. The pension fund's board sets the optimal amount of return smoothing taking into account the payouts to current and future generations as well as intra-generational fairness. Since a tradeoff exists between uncertainty in pension returns and uncertainty in the funding ratio, there is an optimal level of return smoothing. Given our specification of the risk and return tradeoff in the financial market, and given the preference parameters of the pension fund, the optimal amount of return smoothing implies that only less than one third of a shock should be passed on immediately. As a result, the pension return for participants becomes a long weighted moving average of past returns. The implied age-related exposure to the risky asset return automatically attains a shape that is broadly in line with life-cycle portfolio choice. Certainty equivalent calculations show that the welfare improvements provided by the intergenerational risk sharing are economically significant in the order of a $6 \%$ increase in annual benefits compared to the case without return smoothing. 


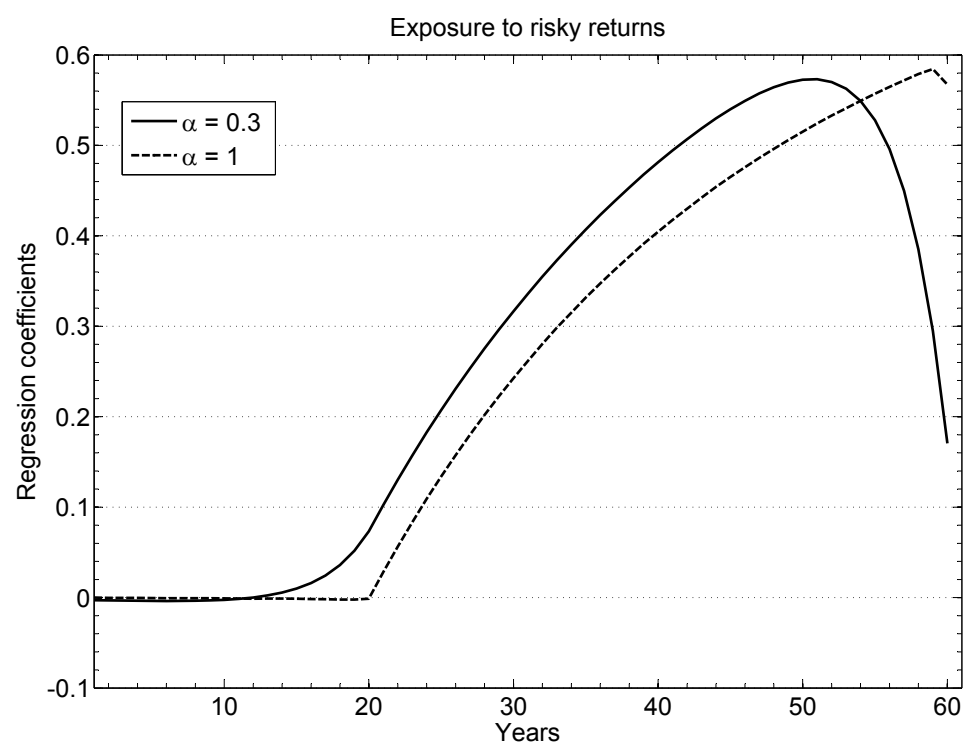

Figure 2.7: Sensitivity of the pension wealth to past returns. This figure plots the coefficients of regression (2.14) for two different values of the return smoothing parameter $\alpha$.

The current stylized model can be extended in several directions. First, instead of focusing solely on financial risks, an empirical model should also include income and demographic risks. In the collective defined contribution system these risks affect both the contributions and the retirement benefits. Secondly, a more realistic return model would deviate from a normal distribution with independent returns and constant mean and variance. Thirdly, we assumed the existence of a real risk-free rate. With only nominal financial instruments, inflation should also be included as an additional risk factor. Fourthly, given these additional risks, the portfolio allocation problem can be treated more seriously by including additional financial instruments and optimizing over the portfolio weights.

A separate aspect is the robustness of the pension system. In our stylized model, the log-linear adjustment rule contains the expected portfolio return as a constant that determines the average pension return. This parameter will be hard to estimate from the data. Misspecification of the expected return parameter may have consequences for the dynamic behavior of the system. For example, setting the expected return too low will give current generations a low indexation of their pension rights, leading to the creation of a persistent financial buffer in the fund that will benefit future genera- 
tions. To avoid an explosion or collapse of the system the simple log-linear rule needs amendment at the extremes when the assets are either exceptionally high or low.

\subsection{Appendix}

\subsubsection{Initial conditions}

We start our simulations from a deterministic steady state. At time $t=0$ the fund starts as if returns have always been equal to $R=\mathrm{E}\left[\mathrm{e}^{r}\right]=\exp \left(\mu_{p}+\frac{1}{2} \omega \sigma^{2}\right)$ and pension indexation equal to $I=R$. With contributions normalised to one, the initial conditions for pension rights become

$$
Z_{0}(\tau)= \begin{cases}R \frac{R^{N-\tau}-1}{R-1} & \tau \in \mathcal{W}_{0} \\ R \frac{R^{N-\tau}-1}{R-1} \times \frac{1-R^{-(K+\tau)}}{1-R^{-K}} & \tau \in \mathcal{R}_{0}\end{cases}
$$

and $Z_{0}(\tau)=0$ for all other $\tau$. The initial conditional can be interpreted as the value of individual accounts, where each cohort has been contributing one unit per year during the working life and where retired generations have been extracting annuity benefits. Implicitly the payouts to the retired cohorts are then equal to

$$
X_{0}(\tau)=\frac{R^{N}-1}{1-R^{-K}}
$$

To fix the inital funding ratio at one, the starting value for the assets is equal to the sum of the pension rights

$$
A_{0}=\sum_{\tau \in \mathcal{W}_{0} \cup R_{0}} Z_{0}(\tau)
$$

These initial conditions are independent of the smoothing parameter $\alpha$. 


\section{Chapter 3}

\section{Asset Allocation Dynamics of Pension Funds*}

\subsection{Introduction}

How do long-term investors like pension funds adjust their portfolios over time? Empirical investigations of pension fund portfolios have provided evidence that past investment returns are important drivers of their investment policy. Rauh (2009) finds that the one-year lagged investment return of corporate pension funds in the US is positively correlated with the next time period investment in equity. Pennacchi and Rastad (2011) find that US public pension funds choose greater portfolio risk following periods of poor investment performance, due to the agency behavior of public pension fund management. Additionally, using the same data, Mohan and Zhang (2014) find that past investment returns are negatively correlated to the percentage of equity allocation in the fund portfolio. Why do past returns influence the pension fund portfolio allocation and how does the portfolio change relative to stated policy or strategic portfolio allocation?

Realized returns on different asset classes will lead to changes in actual portfolio weights. If pension funds chose not to fully rebalance these mechanical variations, they would then be "moving with the market" or behaving pro-cyclically. ${ }^{2}$ Since this can become a buy-high sell-low strategy, it can be detrimental to their performance (Papaioannou, Park, Pihlman, and Van der Hoorn, 2013). Moreover, pension funds as institutional investors constitute a big part of the economy, with their holdings some-

\footnotetext{
*This chapter is co-authored with Dennis Bams (Maastricht University, Netspar) and Peter Schotman (Maastricht University, Netspar).

${ }^{2}$ Papaioannou, Park, Pihlman, and Van der Hoorn (2013) provide an example of the pro-cyclical behavior of US Pension Funds who were net sellers of equities in 2008 and 2009. They were selling equities when the equity prices were low and expected returns were high. This indicates that US Pension funds engaged in pro-cyclical investment action during the recent crisis.
} 
times almost as large as the gross domestic product (GDP) of the country or even larger. Pro-cyclical investment behavior by institutional investors can therefore have serious consequences for the stability of the financial system and could also be harmful for the real economy. Additionally, empirical evidence exists that pro-cyclical behavior can transmit financial shocks internationally. For example, Raddatz and Schmukler (2012) find that mutual funds transmit shocks internationally by their pro-cyclical behavior. Lastly, pension funds in particular can benefit from being contrarian as they have long investment horizons. This gives them an advantage over short-horizon investors and allows them to benefit from short-term mispricing in equities. ${ }^{3}$ In this chapter, we focus on portfolio rebalancing to analyze pension funds' response to realized returns, and hence evaluate their pro-cyclicality. ${ }^{4}$

We find that pension funds strongly rebalance their portfolios to counteract the impact of return on their portfolios. On average, pension funds rebalance about $80-90 \%$ of passive equity variation in the portfolio annually. However, a portion of the actual change in equity weights can be attributed to passive change due to realized returns. We find that on average about $10-20 \%$ of passive change is not rebalanced and contributes towards the actual change in the equity portfolio weight. Therefore, we find evidence that not rebalancing completely can be a reason for past returns being correlated with the investment policy. Although we observe this strong rebalancing following shocks like those of 2001 and 2008, funds can choose to rebalance to ensure that their actual asset allocation equals their strategic asset allocation or choose not to rebalance the portfolio to exploit any perceived change in the time-varying investment opportunity set. ${ }^{5}$ Pension funds could choose to rebalance their portfolio in line with their belief in mean-reversion in equity prices. This would imply that if stock markets rebound following a downturn, pension funds would recover their losses. However, since pension funds have liabilities, risk aversion can increase with declining wealth. If they become more risk averse, standard portfolio theory implies less investment in risky assets. Therefore, elevated risk-aversion can in the short term make pension funds pro-cyclical. Additionally, to preclude further underfunding and facing regulatory action, the pension fund can choose portfolio insurance behavior by not rebalancing or can even de-risk the portfolio.

\footnotetext{
${ }^{3}$ Ang and Kjaer (2012) define a long-term/ long-horizon investor as one who does not have short-term liabilities or liquidity demands or these are small compared to the total portfolio of the investor.

${ }^{4}$ See Ang, Brandt, and Denison (2014) and Ang and Kjaer (2012) for the institutionalized rebalancing strategy of California Public Employees' Retirement System (CalPERS) and Norwegian Government Pension Fund Global.

${ }^{5}$ Timmermann and Blake (2005) find that international portfolio weights of pension funds in the UK are highly correlated to the time-varying investment opportunities set i.e. time-varying expected returns, volatilities, and conditional covariances with global equity returns. However, they find negative average return of market timing, therefore providing further evidence on the importance of rebalancing towards the long-term strategic asset allocation.
} 


\subsection{Introduction}

The rebalancing coefficient that we estimate for professionally managed pension fund portfolios is much stronger than the coefficient estimated by Calvet, Campbell, and Sodini (2009) for risky and risk-free parts of the household portfolio. They find that approximately $50 \%$ of risky passive change is rebalanced. Our results are also stronger than Bikker, Broeders, and De Dreu (2010), who find that Dutch pension funds rebalance only $39 \%$ of passive change - albeit that this estimate is at quarterly frequency and is expected to increase as the horizon increases. Rebalancing of investment portfolios has also been studied in the context of international portfolio allocation. Curcuru, Thomas, Warnock, and Wongswan (2011) find evidence that US investors do not chase returns in international markets. They rebalance their international portfolio by selling past winners, which is a form of partial rebalancing.

Do pension funds rebalance the same amount each year or does this vary over time? Calvet, Campbell, and Sodini (2009) find that the rebalancing coefficient varies over time to a certain extent, when they estimate yearly regressions. Exploiting our long time-series of data, we find that pension funds follow asymmetric rebalancing. They rebalance more when the stock market is performing poorly but less when it is performing well. In the years following positive stock index return, the part of the equity return not rebalanced goes from $20 \%$ to $38 \%$, implying poor rebalancing. However, this coefficient comes down to $10 \%$ in case of negative stock index returns, showing strong rebalancing. Therefore they appear to be momentum-type investors when the stock market is doing well and contrarian when it is doing poorly.

We find that pension funds are slow in incorporating change in strategic asset allocation into their actual equity portfolio in line with expectations given that pension funds need time to implement the changes, e.g. due to liquidity constraints or to reduce potential market impact. Approximately $37 \%$ of the change in strategic asset allocation is incorporated by the pension funds in one year. Next, looking at longer-horizon extensions, it appears that pension funds rebalance fully over a 5-year horizon. However, over a 3-year horizon, a portion of return is still not fully rebalanced. Many pension funds use derivative strategies to achieve the desired shift in the risk exposure to keep it close to the long-term strategic allocation. Analyzing the costs of these strategies, we find that they show economies of scale. Moreover, the asset classes for which these strategies are used matters less, as we obtain similar coefficients for equities and alternatives as for bonds.

Next, we analyze cross-sectional variation in rebalancing behavior. Calvet, Campbell, and Sodini (2009) find that financially sophisticated households rebalance more. Do all pension funds rebalance similarly or are there any cross-sectional characteristics that influence their rebalancing behavior? Overall, we only find statistically qualified support for cross-sectional differences in rebalancing speeds. The results indicate that US and defined benefit funds are less likely to rebalance fully any change due to past 
returns. Unlike Bikker, Broeders, and De Dreu (2010), we do not find that the size of a pension fund is a determining factor. Ang and Kjaer (2012) and Papaioannou, Park, Pihlman, and Van der Hoorn (2013) have suggested that one of the causes of poor rebalancing behavior can be the principal-agent problem encountered by pension funds, in particular between internal and external managers. We test this hypothesis, and our results suggest that external managers can be identified as the major source of rebalancing coefficient observed in the baseline results. Moreover, as between passively and actively managed equity, the latter has the larger concentration of passive change that is not rebalanced. Lastly, analyzing rebalancing between equity, alternatives and bonds, we find that pension funds are more passive in alternatives. They are slower in rebalancing these than both the other asset classes and also in incorporating strategic changes and closing the existing gap between strategic and actual allocations.

\subsection{Data description}

Our data is obtained from CEM Benchmarking Inc., a pension fund cost benchmarking company located in Toronto, Canada that uses a survey to collect data annually from pension funds, primarily for cost benchmarking purposes. ${ }^{6}$ The original dataset contains 6129 observations from 1990 to 2011 of 978 unique funds. Most of the pension funds in our sample are defined-benefit (final average or career-average wage type) and are from the US, Canada or Europe. We also have some observations of funds from Australia and New Zealand. The database contains information about public as well as corporate pension plans, industry-wide pension funds and some sovereign wealth funds. The information available in the database for each pension fund can be grouped into three main categories: asset allocation, strategic asset allocation and plan characteristics.

The asset allocation section contains information about the assets held by the pension funds, costs associated in investing and return on the investments in as many as 186 asset-classes. The information is therefore highly disaggregated and helps us in calculating the passive return. The strategic asset allocation section contains information on the policy weights in the asset classes. Strategic asset allocation is the policy mix between asset classes reflecting the long-term target of the pension fund. ${ }^{7}$ The values

\footnotetext{
${ }^{6}$ Pension funds fill in the questionnaire approximately in May for their asset holdings for the year ended in December of last year, for the latest text of the survey see www.cembenchmarking.com/Files/ Documents/Surveys/2014_CEM_IBS_World_Survey.pdf

${ }^{7}$ CalPERS, for example, chooses a strategic asset mix after an Asset Liability Management (ALM) process. Given capital market assumptions, this process determines the appropriate mix of asset classes for a given expected return, minimizing the volatility of return. This ALM process takes into account actuarial factors like discount rate, funding ratio, contribution level, and contribution volatility. CalPERS currently revises its strategic asset allocation every three years. For CalPERS' investment committee report on strategic asset allocation implementation see https://www.calpers.ca.gov/docs/
} 
in our database reflect midpoints if the asset mix is chosen as ranges instead of points. Some pension funds utilize policy ranges around the target allocation to manage and monitor their portfolio. Unfortunately, we do not have any information on them or any widening or narrowing of them over the sample period. There is information on the benchmarks used by the fund and the benchmark returns. Plan characteristics include information on the type of plan e.g. public, private or corporate; defined benefit or defined contribution; location of the plan, i.e. US, Canada or Europe; number of plan members; number of plan members that are retired; type of inflation indexation that is provided; the liability associated with retired members; liability discount rate and expected rate of return assumptions. ${ }^{8}$

The mean pension plan observation in the full sample has asset under management of about $\$ 10.4$ billion and the median has an asset value of $\$ 2.3$ billion. Table 3.1 provides summary statistics of pension plan characteristics. The majority of pension plans are defined benefit (79\%) and United States based (58\%). The second biggest group is of Canadian pension funds (34\%). About $37 \%$ of the pension funds provide some contractual inflation protection of benefits. Table 3.1 also provides the details of plan member characteristics of the pension funds in the full sample. The mean percentage of retired members is $39 \%$. The mean pension plan observation has approximately 60 thousand active members and 33 thousand retired members. Furthermore, Table 3.1 provides the details of actuarial assumptions used by the pension funds. The mean pension plan observation has an expected rate of return of $7.5 \%$ whereas the actual realized return is higher at $8.7 \%$ which is also higher than the mean return of the benchmarks utilized by the pensions funds of approximately $8.2 \%$. The discount rate used by the pension funds for liabilities is only slightly smaller than the expected returns at approximately $7 \%$ where the 95th percentile is as high as $9 \%$.

Panel A of Table 3.2 shows the summary of actual and strategic asset allocation of the pension funds in our sample. Alternative assets include allocations to commodities, real estate, hedge funds, private equity etc. All the asset classes in the fixed income category are described as bonds or fixed income. Both equity and fixed income asset classes include allocations to international and domestic investments, active and passive mandates and internally and externally managed funds. On average, the ac-

board-agendas/201403/invest/item09a-00.pdf and for a brief description of strategic portfolio see https://www.calpers.ca.gov/docs/forms-publications/cerbt-strategy-1.pdf

${ }^{8}$ Since it is voluntary to participate in the survey, there could be potential self-reported bias arising from poorly performing pension plans choosing not to report or reporting only "good years". Recent papers using this database including Bauer, Cremers, and Frehen (2010) and Andonov, Bauer, and Cremers (2012) do not find any evidence of such behavior when checking for self-reporting bias in the dataset. Moreover, companies have an incentive to be honest in self-reporting to the data collector because they will know later about their own performance relative to their peers and intentionally wrong reporting will not do them any good. 


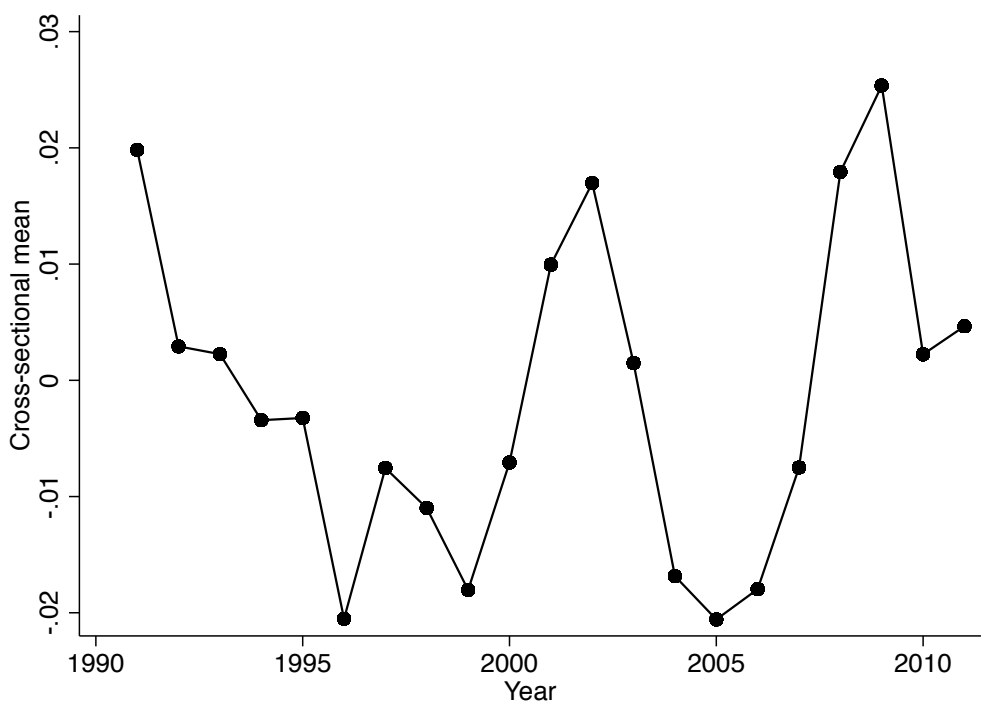

(a)

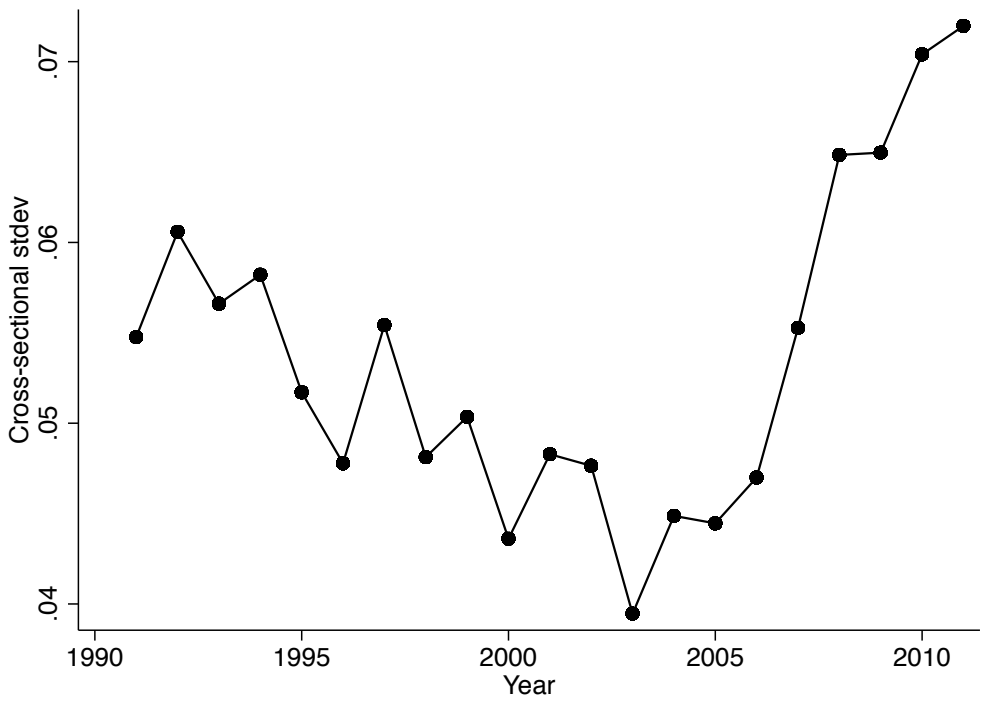

(b)

Figure 3.1: Portfolio dynamics: Panel (a) of the figure shows the time series of the crosssectional mean of actual minus strategic or policy allocation in Equity. The total portfolio adds to one. Panel (b) shows the cross-section standard deviation of the same variable. 


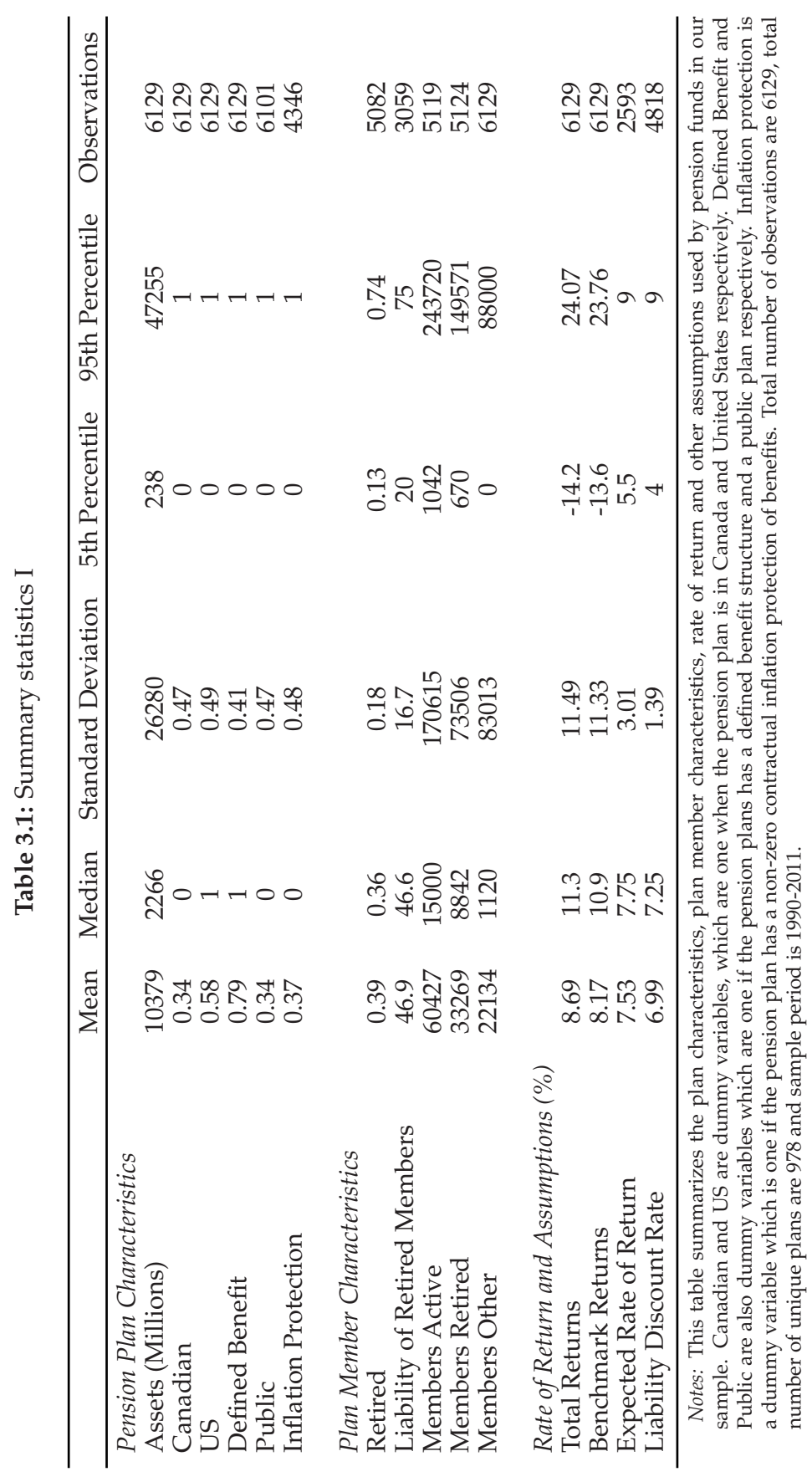




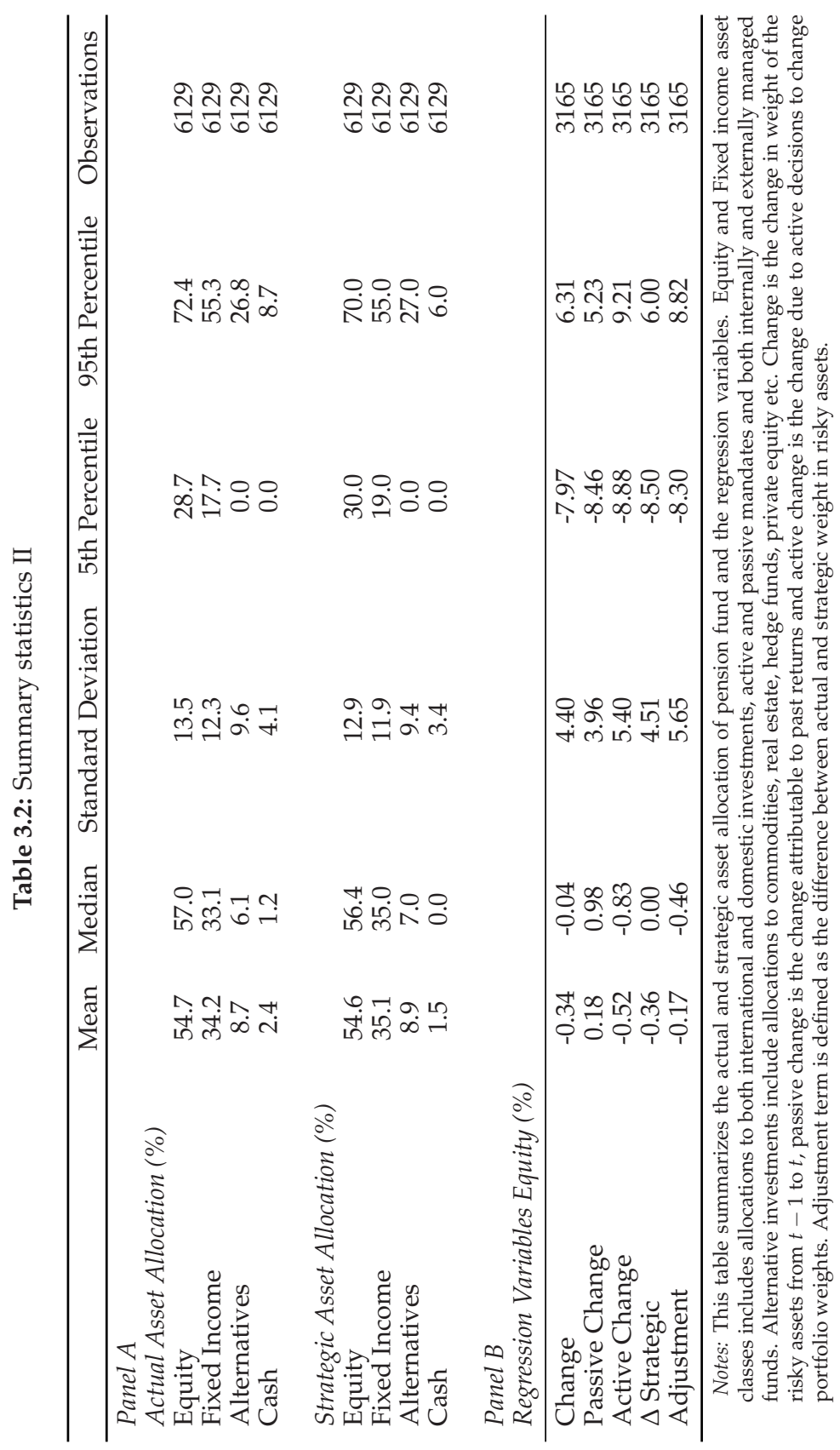


tual asset allocation is very close to the strategic asset allocation. The mean pension plan observation has approximately $54.7 \%$ of the assets invested in equity whereas the strategic asset allocation is $54.6 \%$. Figure 3.1 is a graphical presentation of the summary statistics of the difference between actual and strategic allocations to equity. Panel (a) of the figure shows the time series of the cross-sectional mean of actual minus strategic allocation to equity. The mean does not stay constant over time but exhibits considerable ups and downs. This variable is known as the adjustment term. Panel (b) shows the cross-section standard deviation of the same variable, which provides an indication of cross-sectional dispersion. The biggest difference in the asset allocation comes from cash. The mean pension plan observation has $2.4 \%$ of actual cash against the target of $1.5 \%$. Again, the median is zero, indicating that at least half of the pension funds do not target holding any cash at all. This may seem counter-intuitive since they have to pay pension benefits. However, the median of actual allocation indicates about $1.2 \%$ of cash holding in the portfolio. One possible explanation is provided by Novy-Marx and Rauh (2009), who point out that government accounting standards require pension funds to discount liabilities by expected rate of return. Therefore it is not optimal to have cash in the strategic portfolio as this will lower the liability discount rate, thereby increasing the liabilities of the fund.

\subsection{Rebalancing of fund portfolio}

\subsubsection{Decomposition}

To test the extent of portfolio rebalancing by the pension funds in our sample, we decompose the total change in the portfolio weights into active and passive changes following the methodology of Calvet, Campbell, and Sodini (2009). This decomposes the total change into passive change, which is the change that we would observe if there was no trading in the portfolio, and active change, which is the change attributable to rebalancing or trading in order to exploit the time-varying investment opportunities. Let $w_{i, t}$ at time $t$ for fund $i$ denote the fraction of the total fund portfolio invested in equities. Additionally, we define the passive equity return for fund $i$ in the period $(t, t+1]$ as $r_{i, t+1}$ which is the weighted average of returns in the equity asset classes $\left(r_{j, i, t+1}\right)$ where the weights $\left(w_{j, i, t}^{e}\right)$ are determined by the fraction of the asset in the equity part of the portfolio. Assuming there are $J$ equity asset classes

$$
1+r_{i, t+1}=\sum_{j=1}^{J} w_{j, i, t}^{e}\left(1+r_{j, i, t+1}\right)
$$

Return data for certain asset classes is missing for a few years. We adopt the fol- 
lowing strategy in order not to lose out on observations because passive returns cannot be calculated due to missing returns. First, we substitute the benchmark returns for the missing returns, and if there are still any missing returns, we replace them by the average return in that particular year in that asset class for that pension fund. For example, if the return for the fixed income Asia-Pacific asset class is missing for a certain year for a certain pension fund, we first try to replace the return by the benchmark return. If that is not possible, we replace the missing value with the average return for the fixed-income asset class of that particular pension fund in that year.

Now we define the passive equity weight at time $t+1$ as $w_{i, t+1}^{P A S}$ which is the zerorebalancing weight in equity. In other words, passive equity share is the weight in equity in year $t+1$ if the pension fund does not trade in equity in period $(t, t+1]$. Let $\tilde{r}_{i, t+1}$ be the return on the remaining (fixed-income, alternative and cash) part of the portfolio which is calculated in a similar way as passive equity return using equation (3.1) above. Then,

$$
w_{i, t+1}^{P A S}=\frac{w_{i, t}\left(1+r_{i, t+1}\right)}{w_{i, t}\left(1+r_{i, t+1}\right)+\left(1-w_{i, t}\right)\left(1+\tilde{r}_{i, t+1}\right)}
$$

Having defined the passive return and the passive weight, we can now define the passive change. The actual change denoted by $\Delta w_{i, t}$ is $w_{i, t}-w_{i, t-1}$ which is the total change in the weight of equity from year $t-1$ to year $t$. This total change is attributable to passive change due to realized returns, active change due to active investment decisions and to changes in strategic asset allocation. The passive change for fund $i$ is denoted by $\mathrm{PAS}_{i, t+1}$ and is the change in the weight of risky asset due to realized returns. It is calculated in the following way

$$
\mathrm{PAS}_{i, t+1}=w_{i, t+1}^{P A S}-w_{i, t}
$$

We summarize the variables used to study rebalancing in the panel B of Table 3.2. The mean of active and passive change add up to the mean of total change in equity. We can use a fund-year observation if we can calculate the passive risky share for which we require information on returns and portfolio weights in all sub-asset classes that make up the asset class. This results in 3165 fund-year observations, which we use for our regression analysis.

\subsubsection{Rebalancing regressions}

Superior performance in equity will automatically lead to an increase in the allocation of equity in the total portfolio unless the pension fund rebalance this increase completely. How do large institutional investors like pension funds adjust their risk exposure due to portfolio returns that they experience? Do they fully rebalance to maintain 
Table 3.3: Regression of total change on passive change

\begin{tabular}{lcccc}
\hline & \multicolumn{5}{c}{ Dependent: Change in Equity } \\
& $(1)$ & $(2)$ & $(3)$ & $(4)$ \\
\hline \multirow{2}{*}{ Passive change } & $0.10^{* *}$ & $0.20^{* * *}$ & $0.10^{* *}$ & $0.19^{* * *}$ \\
& $(2.40)$ & $(12.16)$ & $(2.52)$ & $(11.17)$ \\
Strategic change & $0.37^{* * *}$ & $0.44^{* * *}$ & $0.36^{* * *}$ & $0.44^{* * *}$ \\
& $(14.04)$ & $(16.48)$ & $(14.08)$ & $(17.31)$ \\
Adjustment & $0.40^{* * *}$ & $0.44^{* * *}$ & $0.30^{* * *}$ & $0.34^{* * *}$ \\
& $(11.83)$ & $(12.47)$ & $(10.06)$ & $(10.58)$ \\
Observations & & & & \\
Number of plans & 3,165 & 3,165 & 3,165 & 3,165 \\
Fund FE & 505 & 505 & 505 & 505 \\
Year FE & $\mathrm{Y}$ & $\mathrm{Y}$ & $\mathrm{N}$ & $\mathrm{N}$ \\
R-squared (within) & 0.464 & 0.352 & 0.455 & 0.344 \\
\hline
\end{tabular}

Notes: This table presents the results of panel regressions of change in actual portfolio weights of Equity on passive \& strategic or policy change in Equity and the adjustment variable. Adjustment is defined as the difference between actual and strategic weight in risky asset in the previous year. The regressions include all the funds that have information available in two consecutive years and we are able to calculate the passive risky share. Robust standard errors are clustered at fund level and associated t-statistics are in parentheses below the coefficient. Statistical significance is denoted by asterisks using $* * * \mathrm{p}<0.01, * * \mathrm{p}<0.05 \& * \mathrm{p}<0.1$ respectively.

the risk-return characteristics of their strategic asset allocation and focus on this for any variation in return over the long term? For example, a pension fund's response to the bad market conditions of 2001 and 2008 could go in three directions. First, they can choose to decrease risk, which can translate into reducing the equity allocation in the total portfolio. This could be motivated by (anticipated) regulatory pressure when the funding ratio becomes low. An increase in risk aversion could be another reason. If the pension fund becomes more risk averse, standard portfolio theory would indicate the reduction of risk in the portfolio. Secondly, pension funds can leave the risk unchanged, being long-term investors. Furthermore, as pointed out by Ang and Kjaer (2012), pension funds being long-term investors should be able to ride out this period of short-term mispricing. In fact, they should profit from it. Thirdly, they can choose to increase the risk. One possible motivation for this could be their belief in mean-reversion in prices. Poterba and Summers (1988) and Balvers, Wu, and Gilliland (2000) provide evidence 
of mean reversion in stock prices. By rebalancing, they can benefit from buy-low and sell-high strategy if the prices mean-revert. To estimate the rebalancing at the pension fund portfolio level, we estimate the following regression

$$
\Delta w_{i, t}=\beta_{0, t}+\beta_{1} \mathrm{PAS}_{i, t}+\beta_{2} \Delta w_{i, t}^{*}+\beta_{3}\left(w_{i, t-1}^{*}-w_{i, t-1}\right)+\phi_{i}+\epsilon_{i, t}
$$

where strategic asset allocation weights for fund $i$ in year $t$ are denoted by $w_{i, t}^{*}$. This equation explains how much of the change in equity allocation is explained by passive equity change. The regressor $\Delta w_{i, t}^{*}$ is included to capture the dependence of the change in strategic equity asset allocation on actual change. The regressor $w_{i, t-1}^{*}-w_{i, t-1}$ is included as an adjustment term. In addition to these variables, we also include fixed effects $\left(\phi_{i}\right)$ and year dummies $\left(\beta_{0, t}\right)$ in our regressions. They are mentioned specifically in the tables when switched on. For all the regressions we use robust standard errors for the coefficients which are clustered at fund level, and the associated standard errors are provided below the coefficient. $\beta_{1}$ estimates the part of portfolio change that is not rebalanced, $1-\beta_{1}$ therefore measures the part of portfolio change that is rebalanced. Note that $\beta_{1}$ measures the propensity to rebalance, distinguishing this from idiosyncratic shifts in policy weights and reversion to policy weight. If the pension fund managers periodically rebalance their portfolios to maintain a stable risk-return profile as their long-term objective, the coefficient $\beta_{1}$ will be measured as statistically indifferent from zero. This is because any change in the portfolio will be rebalanced and the total change in the portfolio will not be correlated with the passive change in it. This would imply that pension funds are fully active in rebalancing. On the other hand, if the pension funds follow a buy-and-hold strategy, then we should expect that the passive share coefficient is one.

The second coefficient $\beta_{2}$ measures the speed at which the changes in policy or strategic portfolio weights are incorporated in the actual portfolio. The coefficient $\beta_{2}$ being close to one implies that pension funds immediately incorporate any change in strategic asset allocation in the actual portfolio. Lastly, $\beta_{3}$ being close to one implies that any difference in portfolio weight and actual weight is immediately adjusted in the next time period. It thus measures the speed of adjustment towards the long-term strategic portfolio. The results of regression (3.4) are presented in Table 3.3. The regressions include all the funds that have data available in two consecutive years and where we are able to calculate passive change.

The coefficient estimate of $\beta_{1}$, the rebalancing coefficient, is 0.10 and statistically significant in the most comprehensive model with both year effects and fund-fixed effects. They rebalance $90 \%$ of the passive variation. This means that pension fund managers, on average, strongly rebalance towards their long-term strategic allocations instead of letting the weight of appreciating assets increase. Thus, we find evidence that pension 
fund managers strongly rebalance the portfolio to stabilize the risk-return profile of the pension fund, with active rebalancing reversing $90 \%$ of change due to returns on the equity. Next, we focus on how pension fund managers incorporate changes in strategic asset allocation. If the pension fund would fully incorporate the changes in strategic asset allocation in one year, than we would expect the coefficient of change in strategic asset allocation be close to one. Instead, the coefficient is positive but perhaps surprisingly considerably smaller than one. The coefficient estimate of $\beta_{2}$ is 0.37 , implying that pension funds are slow in incorporating policy change in equities. The coefficient implies that a one percent increase in the change in strategic equity asset allocation increases the actual change by approximately 37 basis points in one year.

Next, we discuss whether the initial difference between the actual and strategic weight has any influence on total change in the pension fund's equity allocation. Change in portfolio weights is indeed strongly affected by the difference between the actual and strategic weights of the pension fund in the previous year, in line with expectations. We find a positive coefficient and estimate of $\beta_{3}$ is 0.40 , implying that if the pension fund is far away from its stated objective, it then aggressively attempts to close this gap. However, pension fund managers are able to close only about $40 \%$ of this gap on average in one year. Lastly, our baseline model for the rebalancing discussion is the most comprehensive model so far, with both year dummies and fund-fixed effects. The year dummies capture the common rebalancing of all funds in each year. Interestingly, we find that the rebalancing coefficient doubles in magnitude to 0.20 when we switch off the year dummies. This indicates that pension funds rebalance $80 \%$ of passive equity change and the remaining $20 \%$ is not rebalanced.

The rebalancing coefficient that we estimate for professionally managed pension fund portfolios is much stronger than the coefficient estimated by Calvet, Campbell, and Sodini (2009) for risky and risk-free parts of the household portfolio. We find that pension funds rebalance $80-90 \%$ of the equity passive change, whereas Calvet, Campbell, and Sodini (2009) estimate that approximately 50\% of risky passive change is rebalanced. Their empirical evidence suggests that households only partially rebalance the passive variation in their portfolio. Our results are also stronger than Bikker, Broeders, and De Dreu (2010), who find that pension funds rebalance only 39\% of passive change. However, their sample is restricted to Dutch pension funds and they estimate rebalancing quarterly in contrast to our annual frequency. Furthermore, Bikker, Broeders, and De Dreu (2010) also analyze the effect of change of strategic asset allocation. They find that Dutch pension funds almost fully adjust their portfolios in response to any change in the policy weights. On the other hand, we find that pension funds are on average quite slow in implementing changes in their strategic asset allocation.

The empirical analysis of this section finds that although pension funds rebalance strongly, they do not do so completely. Pension funds have at least two theoretical rea- 
Table 3.4: Longer horizon rebalancing

Panel I

Actual change in Equity 3 years

(1)

(2)

(3)

(4)

\begin{tabular}{|c|c|c|c|c|}
\hline Passive change & $\begin{array}{l}0.12^{* *} \\
(2.39)\end{array}$ & $\begin{array}{c}0.16^{* * *} \\
(5.87)\end{array}$ & $\begin{array}{l}0.11^{* *} \\
(2.50)\end{array}$ & $\begin{array}{c}0.17^{* * *} \\
(6.40)\end{array}$ \\
\hline Strategic change & $\begin{array}{l}0.65^{* * *} \\
(15.88)\end{array}$ & $\begin{array}{l}0.74^{* * *} \\
(20.83)\end{array}$ & $\begin{array}{l}0.65^{* * *} \\
(16.83)\end{array}$ & $\begin{array}{l}0.75^{* * *} \\
(22.61)\end{array}$ \\
\hline Adjustment & $\begin{array}{l}0.81^{* * *} \\
(17.36)\end{array}$ & $\begin{array}{l}0.93^{* * *} \\
(20.36)\end{array}$ & $\begin{array}{l}0.73^{* * *} \\
(15.49)\end{array}$ & $\begin{array}{l}0.84^{* * *} \\
(17.71)\end{array}$ \\
\hline Observations & 1,994 & 1,994 & 1,994 & 1,994 \\
\hline Number of plans & 323 & 323 & 323 & 323 \\
\hline R-squared (within) & 0.714 & 0.650 & 0.712 & 0.647 \\
\hline Panel II & \multicolumn{4}{|c|}{ Actual change in Equity 5 years } \\
\hline Passive change & $\begin{array}{c}0.07 \\
(1.17)\end{array}$ & $\begin{array}{c}0.05 \\
(1.29)\end{array}$ & $\begin{array}{c}0.06 \\
(1.15)\end{array}$ & $\begin{array}{l}0.06^{*} \\
(1.65)\end{array}$ \\
\hline Strategic change & $\begin{array}{l}0.74^{* * *} \\
(15.58)\end{array}$ & $\begin{array}{l}0.87^{* * *} \\
(24.01)\end{array}$ & $\begin{array}{l}0.74^{* * *} \\
(17.06)\end{array}$ & $\begin{array}{l}0.86^{* * *} \\
(25.88)\end{array}$ \\
\hline Adjustment & $\begin{array}{l}0.91^{* * *} \\
(18.12)\end{array}$ & $\begin{array}{l}1.03^{* * *} \\
(22.05)\end{array}$ & $\begin{array}{l}0.87^{* * *} \\
(18.10)\end{array}$ & $\begin{array}{l}0.99 * * * \\
(22.15)\end{array}$ \\
\hline Observations & 1,322 & 1,322 & 1,322 & 1,322 \\
\hline Number of planid & 224 & 224 & 224 & 224 \\
\hline Fund FE & Y & $\mathrm{Y}$ & $\mathrm{N}$ & $\mathrm{N}$ \\
\hline Year FE & $\mathrm{Y}$ & $\mathrm{N}$ & $\mathrm{Y}$ & $\mathrm{N}$ \\
\hline R-squared (within) & 0.806 & 0.751 & 0.806 & 0.751 \\
\hline
\end{tabular}


sons to move away from their strategic asset allocation in the short-term. The first is due to costs associated with rebalancing the portfolio. The costs can be fixed, for example the opportunity cost of fund manager's time, or they can be proportional to the change in the value of asset holding, for example the transaction costs. Costs define optimal rebalancing rules which comprise a no-trade region around the strategic portfolio (Lynch and Balduzzi, 2000). For this reason, funds have bands around their strategic asset allocation which allows them some scope for not rebalancing very often (Bikker, Broeders, and De Dreu, 2010). The second reason can be a decision by pension fund to engage in active management of assets in order to outperform the market and exploit the perceived change in time-varying investment opportunity set. These active management decisions can be related to variation over time in allocation of funds across asset classes (market timing) and allocation of funds within certain asset class (security selection). ${ }^{9}$ Additionally, pension funds can choose to engage in momentum types of strategies and chase returns. ${ }^{10}$

In spite of these legitimate reasons why pension funds might not rebalance very often, it is very important that pension fund should rebalance at least a few times to stay close to their strategic asset allocation. If pension funds do not rebalance, they will be exposed to undesirable risks due to automatic variations in the portfolio. The actual portfolio will not represent the desired risk-return characteristics of the strategic asset allocation, determined optimally by the pension fund board. Additionally, the majority of the historical variations in returns on the fund portfolio historically are explained by the strategic asset allocation of the portfolio (Ibbotson and Kaplan (2000);Blake, Lehmann, and Timmermann (1999)), and engaging in market timing does not result in additional returns (Timmermann and Blake (2005)). ${ }^{11}$ Therefore, pension funds should try to stay as close as possible to the strategic asset allocation. Moreover, selling of equities that have performed well in the past is also consistent with the literature on mean reversion in equity prices. Rebalancing would therefore be especially important in the equity asset class.

Mohan and Zhang (2014); Pennacchi and Rastad (2011); Rauh (2009) have suggested that past investment returns can influence the investment behavior of pension funds. The results of this section supplement and extend these findings by showing that these empirical observations are possibly due to pension funds choosing not to fully rebalance their portfolio. Furthermore, these results have implications for theoretical models of life-cycle asset allocation which include professionally managed pensions. Thus, in-

\footnotetext{
${ }^{9}$ See Andonov, Bauer, and Cremers (2012) for an analysis of active management decisions of pension funds.

${ }^{10}$ See Curcuru, Thomas, Warnock, and Wongswan (2011) for an analysis of rebalancing behavior of US international investors.

${ }^{11}$ See Brown, Garlappi, and Tiu (2010) for university endowment funds that have multiple asset class portfolios like pension funds.
} 
dividuals exposed to risk due to mechanical variation like the above cannot adjust their privately held investments so that their total investment reflect their optimal allocation, as they will be unaware of any such risks.

\subsubsection{Robustness check}

In the previous section, we have used an annual time frame to judge the rebalancing behavior of the pension funds. This is also consistent with the frequency used by Calvet, Campbell, and Sodini (2009). Additionally, other short-term tactical investment strategies like momentum are effective over a shorter horizon, for example 6 months to one year (Jegadeesh and Titman, 1993). One might worry about the fact that pension funds do not rebalance annually, but rather as long-term investors rebalance over a two or three year horizon. In this section, we analyze the rebalancing behavior of pension funds over a 3-year (medium term) and a 5-year (long term) horizon. We estimate the rebalancing regression (3.4) with longer horizon passive change, longer horizon strategic change and the adjustment variable. The long horizon passive change can be calculated as in (3.2), using longer $K$ horizon returns: $\prod_{k=1 \text { opl }}^{K}\left(1+r_{i, t+k}\right)$. The results are presented in Table 3.4, with Panel I listing the results for medium three-year horizon and Panel II listing the longer five-year horizon results.

In the 3-year horizon regression, we find that pension funds still do not fully rebalance. However, a quantitatively larger coefficient is obtained for the strategic change variable, as well as for the adjustment variable. In the 5-year horizon regressions, we find no evidence of poor rebalancing. Therefore over the long horizon, pension funds seem to actively rebalance any passive variation in the portfolio. We also obtain larger coefficients for both the strategic change variable and the adjustment variable. This implies that pension funds almost fully incorporate policy weights in five years and any mismatch between strategic and actual allocation 5 years ago, as would be expected. It is also interesting to note that $\mathrm{R}^{2} \mathrm{~s}$ of the long horizon specification is very high (approximately $80 \%$ ) implying that we are able to explain most of the variation in long term changes in the pension funds portfolios using our empirical specification.

\subsubsection{Asymmetric rebalancing}

Do pension funds rebalance the same amount each year, and does the rebalancing behavior remain constant or does it vary over time? Calvet, Campbell, and Sodini (2009) find when they estimate yearly regressions that the rebalancing coefficient varies over time to a certain extent. For example, they estimate an overall rebalancing coefficient of around $50 \%$ which varies between $40 \%$ to $80 \%$ in yearly regressions. This can imply that quite different quantitative estimates can be obtained depending on the years in the sample if a short time series is used. Bikker, Broeders, and De Dreu (2010) find 
that pension funds behave differently in response to positive than to negative equity returns, rebalancing more when there are negative equity returns. Other studies such as Curcuru, Thomas, Warnock, and Wongswan (2011) also find asymmetric rebalancing by US investors in international portfolios. They find that US investors are contrarian when selling, i.e. they sell past winners. Similarly, other studies focus almost entirely on rebalancing in specific years. For example, Papaioannou, Park, Pihlman, and Van der Hoorn (2013) focus solely on the pro-cyclical behavior of institutional investors like pension funds in the recent financial crisis. In our baseline results from the previous section, the rebalancing coefficient varies substantially when we switch on the year dummies, which capture the common reallocations in each year.

The rebalancing behavior can be different in bull and bear markets because the liquidity needs during a time of crisis can be underestimated (Papaioannou, Park, Pihlman, and Van der Hoorn, 2013). ${ }^{12}$ To identify any asymmetric effects in rebalancing, we use a similar specification to that in our baseline regressions (3.4) but make the rebalancing coefficient $\beta_{1}$ a function of time-dependent dummy variables signifying different market conditions. We use the following two separate dummies a MSCI negative dummy and a high volatility dummy, and they are defined as follows. The MSCI negative dummy is 1 when the last year's return on the MSCI World Index is less than zero, otherwise zero. ${ }^{13}$ The high volatility dummy is one when the yearly standard deviation of daily returns on S\&P 500 index in the last year is greater than the sample mean, otherwise zero. Thus, the rebalancing coefficient is split into two values, one value when the dummy variable is one and another value when it is zero. The results are presented in Table 3.6.

The results reveal that rebalancing behavior changes a lot over time and is asymmetric. In the years when the previous MSCI World Index is positive and therefore the dummy is zero, the estimate of the rebalancing coefficient is 0.38 . This implies that pension funds do not rebalance, and exhibit a momentum-type behavior. On the other hand when the dummy is 1 , the total rebalancing coefficient is $0.38+(-0.24)=0.10$. This implies that when the stock market is doing well, pension funds rebalance significantly less. Similarly, we estimate that pension funds rebalance less when stock market volatility is low and more when it is high, with a rebalancing coefficient of 0.43 and 0.17 respectively. Curcuru, Thomas, Warnock, and Wongswan (2011) also observe asymmetric behavior; they find that US investors sell past winners in international portfolios. Bikker, Broeders, and De Dreu (2010) find that positive shocks are rebal-

\footnotetext{
${ }^{12}$ For example, California Public Employees' Retirement System (CalPERS) was forced to sell equity to raise cash instead of rebalancing by buying more equities during 2007-08, due to significant liquidity needs during the crisis period (Ang and Kjaer, 2012).

${ }^{13}$ When the MSCI index return is negative, it is highly likely that the equity return of the fund portfolio is also negative. This would imply a negative passive change. Therefore this analysis is in a similar spirit to Bikker, Broeders, and De Dreu (2010) and Curcuru, Thomas, Warnock, and Wongswan (2011), who also identify asymmetry based on the returns realized on the portfolio.
} 
Table 3.5: Rebalancing costs

\begin{tabular}{|c|c|c|c|c|c|}
\hline & \multicolumn{5}{|c|}{ Dependent variable: rebalancing overlays } \\
\hline Constant & $\begin{array}{l}0.43^{* * * *} \\
(10.82)\end{array}$ & $\begin{array}{l}0.34^{* * *} \\
(10.40)\end{array}$ & $\begin{array}{c}0.37^{* * * *} \\
(5.42)\end{array}$ & $\begin{array}{c}2.22^{* * * *} \\
(5.21)\end{array}$ & $\begin{array}{c}2.21^{* * *} \\
(5.43)\end{array}$ \\
\hline Adjustment Equity & & $\begin{array}{c}3.13^{* * *} \\
(2.69)\end{array}$ & $\begin{array}{c}3.08^{* * * *} \\
(2.68)\end{array}$ & $\begin{array}{l}3.81^{* *} \\
(2.02)\end{array}$ & $\begin{array}{l}3.74^{* *} \\
(2.00)\end{array}$ \\
\hline Adjustment Alternatives & & $\begin{array}{c}3.48^{* * *} \\
(2.75)\end{array}$ & $\begin{array}{c}3.43^{* * *} \\
(2.61)\end{array}$ & $\begin{array}{l}2.91^{*} \\
(1.80)\end{array}$ & $\begin{array}{l}2.85^{*} \\
(1.77)\end{array}$ \\
\hline Adjustment Bond & & $\begin{array}{c}3.43^{* * *} \\
(3.49)\end{array}$ & $\begin{array}{c}3.48^{* * * *} \\
(3.33)\end{array}$ & $\begin{array}{l}3.08^{* *} \\
(2.11)\end{array}$ & $\begin{array}{l}3.05^{* *} \\
(2.08)\end{array}$ \\
\hline Log fund size & & & & $\begin{array}{c}-0.15^{* * *} \\
(-3.94)\end{array}$ & $\begin{array}{c}-0.16^{* * * *} \\
(-4.05)\end{array}$ \\
\hline Retired & & & & $\begin{array}{l}-0.01 \\
(-0.04)\end{array}$ & $\begin{array}{c}0.02 \\
(0.13)\end{array}$ \\
\hline Public fund & & & & $\begin{array}{c}0.04 \\
(0.27)\end{array}$ & $\begin{array}{c}0.06 \\
(0.43)\end{array}$ \\
\hline Defined Benefit & & & & $\begin{array}{c}-0.34 \\
(-0.82)\end{array}$ & $\begin{array}{c}-0.33 \\
(-0.83)\end{array}$ \\
\hline US dummy & & & & $\begin{array}{l}-0.24^{* *} \\
(-2.56)\end{array}$ & $\begin{array}{l}-0.23^{* *} \\
(-2.17)\end{array}$ \\
\hline Observations & 162 & 162 & 162 & 137 & 137 \\
\hline R-squared & & 0.08 & 0.11 & 0.28 & 0.32 \\
\hline Time Dummies & & $\mathrm{N}$ & $\mathrm{Y}$ & $\mathrm{N}$ & $\mathrm{Y}$ \\
\hline
\end{tabular}

Notes: This table presents the results of pooled regressions of rebalancing overlays in basis points on differences between actual and strategic or policy weights in Equity, Alternatives and Bond. Rebalancing overlays are defined as the cost of strategies implemented using derivatives to implement asset class rebalancing. Columns $(4 \& 5)$ include crosssectional control varibales. Robust standard errors are clustered at fund level and associated t-statistics are in parentheses below the coefficient. Statistical significance is denoted by asterisks using $* * * \mathrm{p}<0.01, * * \mathrm{p}<0.05 \& * \mathrm{p}<0.1$ respectively. 


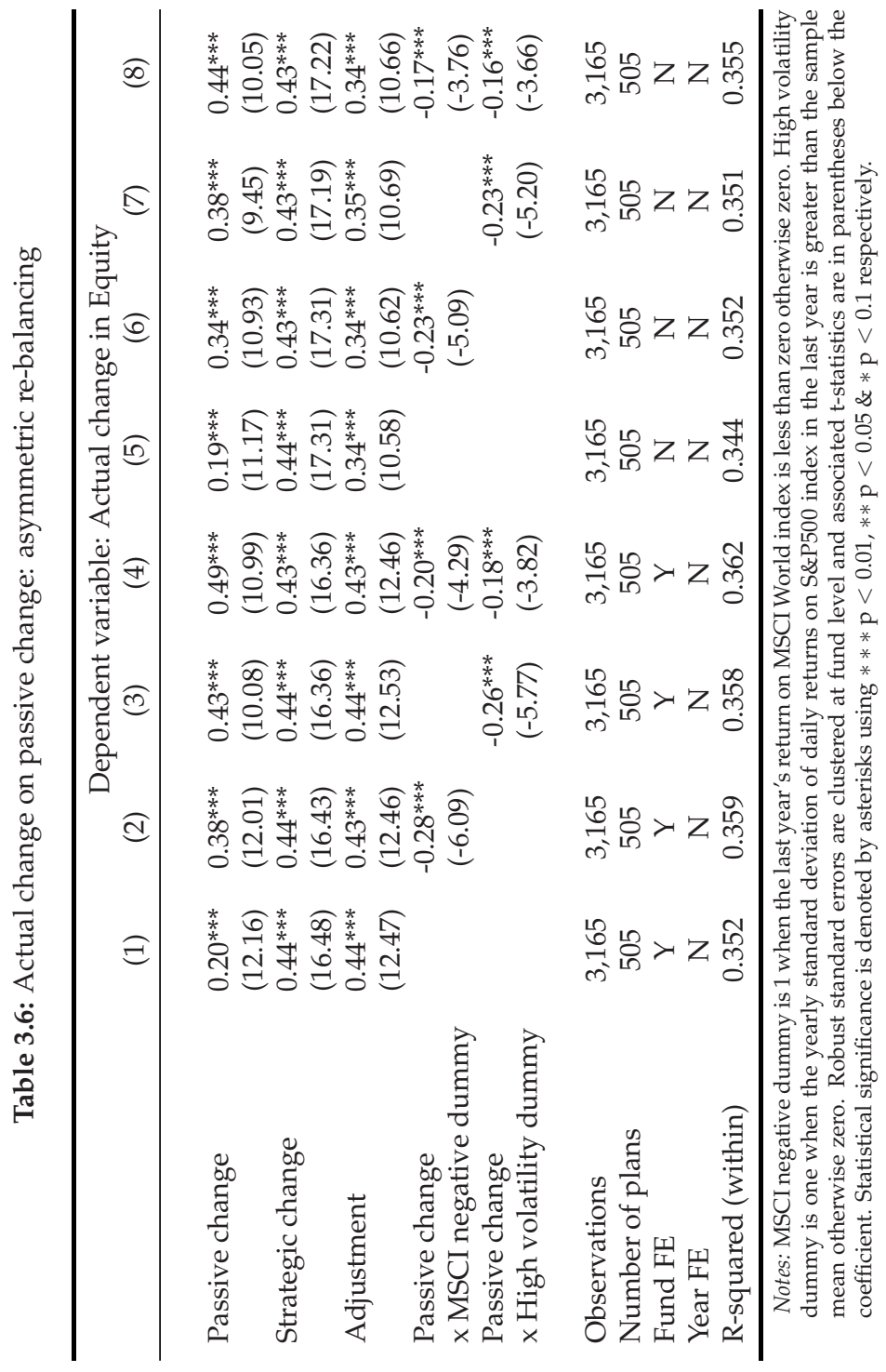


anced less compared to negative shocks. They conclude that pension funds limit any decline in portfolio weight of equity due to low returns, but when equity outperforms, it is not rebalanced as much. Thus, consistent with the results of Bikker, Broeders, and De Dreu (2010), we find that pension funds are asymmetric in responding to stock market shocks. They behave as momentum-type investors and take on more risk when the stock market is doing well but are contrarian when the stock market is doing poorly, consistent with aiming to benefit from mean-reversion in equity prices. Overall, the results of this section suggest that pension funds tend to be pro-cyclical on average when the stock market is doing well.

\subsubsection{Rebalancing costs}

Many pension funds use derivative strategies to achieve the desired shift in the risk exposure so that it stays close to the long-term strategic allocation. These so-called rebalancing overlays are derivative strategies that allow the pension fund to calibrate its risk exposure with strategic investment targets without actual buying or selling of securities, and they are therefore cost effective. Our CEM database has some information about the costs of these strategies to pension funds, and in this section, we analyze these costs. This is not the overall cost of rebalancing but concerns only partial costs pertaining specifically to synthetic adjustments using derivatives. This information is available for a few pension funds and over a few years only. In total, we have 162 fund-year observations. We regress these costs in basis points (bps) on differences between actual and strategic weights in equity, alternatives and bond asset classes and cross-sectional fund characteristics. The results of the regressions are presented in Table 3.5.

The most important result in Table 3.5 is that the costs of implementing the derivative strategies for steadying risk exposure have scale economies. The results clearly indicate that bigger pension funds have lower costs of implementing these strategies. This implies that it makes sense for bigger pension funds to use them to stabilize their risk exposure. In addition, US pension funds have lower costs of implementing these strategies. As expected, pension funds spend more on rebalancing overlays the further they are from their policy weights. The costs are indeed strongly determined by how far away the actual allocation is from its policy allocation. However, which asset class it is matters less as we obtain similar magnitudes of coefficients for equities and alternatives as well as for bonds. 


\subsection{Extensions}

\subsubsection{Cross-sectional variation in rebalancing}

Do all pension funds rebalance similarly, or are there any cross-sectional characteristics that influence their rebalancing behavior? Calvet, Campbell, and Sodini (2009) find that wealthy, more educated and financially sophisticated investors rebalance more actively. Bikker, Broeders, and De Dreu (2010) find that larger pension funds do less rebalancing. In the analysis of the previous section, we estimated one rebalancing coefficient for all pension funds in our sample. In this section, we extend the analysis to allow for any variation in rebalancing speeds across pension funds and we investigate whether there are any fund-specific features that are responsible for cross-sectional variation in rebalancing speeds. We use the following five variables:- size, the liability structure of the pension fund implied by the percentage of retired members, public fund, defined benefit (DB) fund, and US fund. We make the regression coefficients of passive change, strategic weight change and adjustment term in equation (3.4) a linear function of pension fund characteristics. Therefore, $\beta_{j}=\delta_{0, j}+\boldsymbol{\delta}_{j}^{\prime} \boldsymbol{X}_{i}$, where $j$ denotes the variables passive $\left(\beta_{1}\right)$, strategic $\left(\beta_{2}\right)$, adjustment $\left(\beta_{3}\right)$ and $\boldsymbol{X}_{i}$ is the vector of fund characteristics for $i$ th fund. All the cross-sectional variables are used as dummies, with large fund representing larger than median size and old fund representing larger than median percentage of retired members. Table 3.7 reports the coefficient vectors $\boldsymbol{\delta}_{j}$ for regression with year dummies in Panel I and without in Panel II.

Overall, we find qualified support for cross-sectional differences in rebalancing speeds. The results indicate that US pension funds are less likely to rebalance fully any change due to past returns. Additionally, defined benefit pension funds are also likely to rebalance less. These results are consistent with the observations of Papaioannou, Park, Pihlman, and Van der Hoorn (2013) who note that defined benefit US pension funds were net sellers of equity in 2008-09 when equity was performing poorly. Perhaps surprisingly, we find no evidence of size of fund having a significant effect on the rebalancing speed. There is however evidence that bigger pension funds take more risk az"az(Andonov, Bauer, and Cremers, 2013; Mohan and Zhang, 2014; Rauh, 2009) and according to Bikker, Broeders, and De Dreu (2010) large pension funds do have a higher rebalancing speed. Further, the percentage of retired members does not have any significant effect on the rebalancing speed, although the investment policy is known to be influenced by the age structure of the participants in the pension fund (Bikker, Broeders, Hollanders, and Ponds, 2012; Bodie, Merton, and Samuelson, 1992). Moreover, more liabilities associated with retired members make pension funds risk-averse. Next, we focus on the cross-sectional determinants of speeds of incorporating strategic asset allocation change. The results indicate that large funds are faster in incorporating the 
Table 3.7: Cross-sectional differences in rebalancing

\begin{tabular}{|c|c|c|c|}
\hline Panel I & Passive & Strategic & Adjustment \\
\hline Constant & $\begin{array}{c}-0.04 \\
(-0.57)\end{array}$ & $\begin{array}{c}0.32 * * * \\
(4.74)\end{array}$ & $\begin{array}{c}0.24^{* * *} \\
(3.83)\end{array}$ \\
\hline Large fund & $\begin{array}{c}0.01 \\
(0.28)\end{array}$ & $\begin{array}{l}0.07^{*} \\
(1.74)\end{array}$ & $\begin{array}{l}-0.04 \\
(-0.85)\end{array}$ \\
\hline Old fund & $\begin{array}{c}0.04 \\
(1.08)\end{array}$ & $\begin{array}{c}-0.01 \\
(-0.16)\end{array}$ & $\begin{array}{c}0.04 \\
(0.84)\end{array}$ \\
\hline Public dummy & $\begin{array}{c}0.04 \\
(1.08)\end{array}$ & $\begin{array}{c}-0.02 \\
(-0.46)\end{array}$ & $\begin{array}{l}0.08^{*} \\
(1.73)\end{array}$ \\
\hline Defined Benefit & $\begin{array}{l}0.09 * \\
(1.66)\end{array}$ & $\begin{array}{l}-0.01 \\
(-0.15)\end{array}$ & $\begin{array}{l}\mathbf{0 . 0 9 *} \\
(1.88)\end{array}$ \\
\hline US dummy & $\begin{array}{c}0.02 \\
(0.45)\end{array}$ & $\begin{array}{c}0.03 \\
(0.62)\end{array}$ & $\begin{array}{l}-0.07 \\
(-1.36)\end{array}$ \\
\hline $\begin{array}{l}\text { Fund FE } \\
\text { Year FE }\end{array}$ & $\begin{array}{l}\mathrm{N} \\
\mathrm{Y}\end{array}$ & & \\
\hline Panel II & Passive & Strategic & Adjustment \\
\hline Constant & $\begin{array}{c}0.05 \\
(0.80)\end{array}$ & $\begin{array}{c}0.39 * * * \\
(5.39)\end{array}$ & $\begin{array}{c}0.25^{* * *} \\
(3.46)\end{array}$ \\
\hline Large fund & $\begin{array}{c}-0.00 \\
(-0.01)\end{array}$ & $\begin{array}{l}0.09 * * \\
(2.19)\end{array}$ & $\begin{array}{c}-0.03 \\
(-0.64)\end{array}$ \\
\hline Old fund & $\begin{array}{c}0.03 \\
(0.66)\end{array}$ & $\begin{array}{c}0.01 \\
(0.19)\end{array}$ & $\begin{array}{c}0.04 \\
(0.78)\end{array}$ \\
\hline Public dummy & $\begin{array}{c}0.04 \\
(0.90)\end{array}$ & $\begin{array}{c}-0.01 \\
(-0.23)\end{array}$ & $\begin{array}{l}\mathbf{0 . 1 0 *} \\
(1.73)\end{array}$ \\
\hline Defined Benefit & $\begin{array}{c}0.07 \\
(1.46)\end{array}$ & $\begin{array}{l}-0.03 \\
(-0.63)\end{array}$ & $\begin{array}{l}\mathbf{0 . 0 9 *} \\
(1.74)\end{array}$ \\
\hline US dummy & $\begin{array}{l}0.07^{*} \\
(1.67)\end{array}$ & $\begin{array}{c}0.04 \\
(0.76)\end{array}$ & $\begin{array}{c}-0.05 \\
(-0.91)\end{array}$ \\
\hline $\begin{array}{l}\text { Fund FE } \\
\text { Year FE }\end{array}$ & $\begin{array}{l}\mathrm{N} \\
\mathrm{N}\end{array}$ & & \\
\hline
\end{tabular}

Notes: This table presents the results of panel regressions when the coefficient of three independent variables - passive change, strategic change and adjustment are made a linear function of fund characteristics. Therefore, $\beta_{j}=\delta_{0, j}+\boldsymbol{\delta}_{j}^{\prime} \boldsymbol{X}_{i}$, where $j$ denotes the variables passive $\left(\beta_{1}\right)$, strategic $\left(\beta_{2}\right)$ and adjustment $\left(\beta_{3}\right)$ and $\boldsymbol{X}_{i}$ is the vector of fund characteristics for $i$ th fund. This table reports the coefficient vectors $\boldsymbol{\delta}_{j}$ for regression with year fixed effects in Panel I and without in Panel II. Robust standard errors are clustered at fund level and associated t-statistics are in parentheses below the coefficient. Statistical significance is denoted by asterisks using $* * * \mathrm{p}<0.01, * * \mathrm{p}<0.05$ $\& * \mathrm{p}<0.1$ respectively. Additionally, coefficients significant at the $10 \%$ level appear in bold face. 


\subsection{Extensions}

strategic changes in their actual asset allocation. Lastly, looking at the adjustment $\beta \mathrm{s}$, we find that public and US funds are fastest in adjusting for the difference between actual and strategic weight in the previous year.

\subsubsection{Contribution of differently managed funds to rebalancing}

One of the causes of poor rebalancing behavior can be the principal-agent problem encountered by pension funds (Ang and Kjaer, 2012; Papaioannou, Park, Pihlman, and Van der Hoorn, 2013). There can be many principal (the asset owner) and agent (the asset manager) problems in pension funds. The asset managers, having superior information about investments, may use this for making decisions that benefit them instead of the asset owners. One example of this misalignment in pension funds is the following. Although pension funds have long horizon, the fund managers compensation is generally determined by their short-term performance. This implies that fund managers are unlikely to tolerate temporary short-term losses for long-term gains. One other principal-agent problem can be between internal and external managers. Internal management implies that the buying and selling decisions are made by the pension fund or its wholly owned subsidiaries, whereas in an externally managed fund, the assets are managed by external financial intermediaries. They are hired by the pension fund on the assumption that they have superior skills in managing the assets. However, Binsbergen, Jules, Brandt, and Koijen (2008) show that this can result in misalignment between the incentives of the pension fund and the asset manager, which can prove costly. ${ }^{14}$ In this section, we examine the contribution of internal and external management of equity to total equity rebalancing.

We also examine the contribution of passively and actively managed equity to total equity rebalancing. Passively managed equity corresponds to the replication of a broad market index, whereas actively managed equity takes bets on certain investment strategies to outperform the market and exploit the perceived change in time-varying investment opportunity set. These active management decisions can be related to variation over time in the allocation of funds across asset classes (market-timing) and allocation of funds within certain asset class (security selection). Engaging in these strategies would be one reason for moving away from the strategic asset allocation and not rebalancing. The total equity change $\Delta w_{i, t}$ of (3.4) can be decomposed as the sum of the change in internally and externally managed funds in equity. Similarly, it can be decomposed as the sum of passively and actively managed equity change. ${ }^{15}$ We then regress

\footnotetext{
${ }^{14}$ See also Blake, Rossi, Timmermann, Tonks, and Wermers (2013) for a discussion of shift from centralized to decentralized pension fund management.

${ }^{15}$ Since we decompose the active change in equity between the external \& internal managers and between active \& passive managers, we can find out how these type of asset management contribute to portfolio rebalancing.
} 
these decompositions on the right hand side of (3.4). ${ }^{16}$ The results are presented in Table 3.8, with Panel I presenting the regression results without and Panel II with year dummies.

The results suggest that external managers and active managers can be identified as the major source of the rebalancing coefficient observed in the baseline results of section 3.3.2. As between internally and externally managed equity, most of the passive change that is not rebalanced is attributed to externally managed equity. This suggests that agency problems between internal and external managers can lead to poor rebalancing behavior. Next, as between passively and actively managed equity, actively managed equity has a larger concentration of passive change that is not rebalanced. However, as soon as the year dummies are turned on, the coefficient becomes quantitatively smaller but also statistically insignificant. This suggests that actively managed funds tend to make active bets together in certain years and therefore show herding behavior. This should be of special concern to long-term investors like pension funds because institutional herding leads to negative long-term returns (Dasgupta, Prat, and Verardo, 2011). The results of this section show that to develop effective rebalancing rules on a pension fund level, special attention should be paid to external and active managers.

\subsubsection{Rebalancing in other asset classes}

We have previously considered rebalancing behavior of pension funds solely in equity. In this section, we further extend our analysis to alternatives and bonds. The rebalancing behavior can be different in these assets for two reasons. First, whereas there is strong evidence of the phenomenon of mean-reversion in equity, in bonds and especially in alternatives this evidence is slight. Pension funds therefore have less incentive to be active in rebalancing. Secondly, real estate and private equity are less liquid than public equity and it will therefore be more costly to rebalance them. Pension funds will avoid trading less liquid asset classes due to costs, and possibly may have a greater tolerance regarding closeness to stated strategic asset allocation. To analyze whether the rebalancing behavior in these asset classes is indeed influenced by these factors, we replicate our analysis of section 3.3.2 for these asset classes. Table 3.9 presents the panel regressions of change in actual portfolio weights on passive change for the three asset classes equities (in columns 1 \& 2 for comparison), alternatives (columns 3 \& 4) and bonds (columns $5 \& 6$ ). The + next to the variables denotes that it is calculated for the dependent variable of that column, for example, the strategic changet for column (3) is the change in the strategic weight in alternatives.

\footnotetext{
${ }^{16}$ This implies that the coefficients of regressions (2) \& (3) as well as (4) \& (5) in Table 3.8 should add to the coefficients in regression (1). However, there are small differences due to rounding.
} 
Table 3.8: Contributions of asset classes to equity rebalancing

\begin{tabular}{|c|c|c|c|c|c|}
\hline \multirow[t]{2}{*}{ Panel I } & \multicolumn{5}{|c|}{ Dependent variable: change in } \\
\hline & $\begin{array}{l}\text { Equity } \\
\text { (1) }\end{array}$ & $\begin{array}{c}\text { Internal Equity } \\
\text { (2) }\end{array}$ & $\begin{array}{l}\text { External Equity } \\
\text { (3) }\end{array}$ & $\begin{array}{c}\text { Passive Equity } \\
\text { (4) }\end{array}$ & $\begin{array}{c}\text { Active Equity } \\
\text { (5) }\end{array}$ \\
\hline Passive change & $\begin{array}{l}0.20^{* * * *} \\
(12.16)\end{array}$ & $\begin{array}{l}0.04^{* *} \\
(2.54)\end{array}$ & $\begin{array}{l}0.16^{* * *} \\
(8.06)\end{array}$ & $\begin{array}{l}0.05^{* *} \\
(2.13)\end{array}$ & $\begin{array}{c}0.16^{* * *} \\
(5.91)\end{array}$ \\
\hline Strategic change & $\begin{array}{l}0.44^{* * *} \\
(16.48)\end{array}$ & $\begin{array}{c}0.10^{* * *} \\
(3.71)\end{array}$ & $\begin{array}{l}0.34^{* * *} \\
(10.67)\end{array}$ & $\begin{array}{c}0.15^{* * *} \\
(5.32)\end{array}$ & $\begin{array}{c}0.29^{* * *} \\
(8.14)\end{array}$ \\
\hline Adjustment & $\begin{array}{l}0.44^{* * *} \\
(12.47)\end{array}$ & $\begin{array}{l}0.05^{* * *} \\
(2.68)\end{array}$ & $\begin{array}{l}0.38^{* * *} \\
(10.69)\end{array}$ & $\begin{array}{l}0.14^{* * *} \\
(5.87)\end{array}$ & $\begin{array}{l}0.30^{* * *} \\
(9.41)\end{array}$ \\
\hline Observations & 3,165 & 3,165 & 3,165 & 3,165 & 3,165 \\
\hline Number of plans & 505 & 505 & 505 & 505 & 505 \\
\hline Fund FE & Y & Y & Y & Y & Y \\
\hline Year FE & $\mathrm{N}$ & $\mathrm{N}$ & $\mathrm{N}$ & $\mathrm{N}$ & $\mathrm{N}$ \\
\hline R-squared (within) & 0.352 & 0.0254 & 0.215 & 0.0400 & 0.125 \\
\hline \multirow[t]{2}{*}{ Panel II } & \multicolumn{5}{|c|}{ Dependent variable: change in } \\
\hline & Equity & Internal Equity & External Equity & Passive Equity & Active Equity \\
\hline Passive change & $\begin{array}{l}0.10^{* *} \\
(2.40)\end{array}$ & $\begin{array}{c}0.01 \\
(0.34)\end{array}$ & $\begin{array}{l}0.09^{*} \\
(1.68)\end{array}$ & $\begin{array}{c}0.07 \\
(1.48)\end{array}$ & $\begin{array}{c}0.03 \\
(0.50)\end{array}$ \\
\hline Strategic change & $\begin{array}{l}0.37^{* * *} \\
(14.04)\end{array}$ & $\begin{array}{l}0.09^{* * *} \\
(3.32)\end{array}$ & $\begin{array}{l}0.28^{* * *} \\
(9.00)\end{array}$ & $\begin{array}{l}0.13^{* * *} \\
(4.47)\end{array}$ & $\begin{array}{l}0.24^{* * *} \\
(6.97)\end{array}$ \\
\hline Adjustment & $\begin{array}{l}0.40^{* * * *} \\
(11.83)\end{array}$ & $\begin{array}{c}0.05^{* * *} \\
(2.65)\end{array}$ & $\begin{array}{l}0.35^{* * *} \\
(10.16)\end{array}$ & $\begin{array}{c}0.13^{* * *} \\
(5.16)\end{array}$ & $\begin{array}{c}0.27^{* * *} \\
(8.62)\end{array}$ \\
\hline Observations & 3,165 & 3,165 & 3,165 & 3,165 & 3,165 \\
\hline Number of plans & 505 & 505 & 505 & 505 & 505 \\
\hline Fund FE & Y & Y & Y & $\mathrm{Y}$ & $\mathrm{Y}$ \\
\hline Year FE & Y & Y & Y & Y & Y \\
\hline R-squared (within) & 0.464 & 0.0329 & 0.294 & 0.0833 & 0.206 \\
\hline
\end{tabular}

Notes: This table presents the panel regressions of change in actual allocation of differently manged asset classes in Equity on overall passive change in Equity to determine their contributions to overall passive change. Panel I presents the regression results without and Panel II with year fixed effects. The coefficients of regressions presented in columns ( $2 \& 3$ ) and columns (4\&5) should add up to the coefficients of regression (1) but may not due to rounding. The regressions include all the funds that have information available in two consecutive years and we are able to calculate the passive share. Robust standard errors are clustered at fund level and associated t-statistics are in parentheses below the coefficient. Statistical significance is denoted by asterisks using $* * * \mathrm{p}<0.01, * * \mathrm{p}<0.05 \& * \mathrm{p}<0.1$ respectively. 
Table 3.9: Rebalancing regressions within asset classes

\section{Change Equity Change Alternatives Change Bond}

$\begin{array}{lllll}(1) & (2) & (3) & (4) & \text { (5) }\end{array}$

\begin{tabular}{|c|c|c|c|c|c|c|}
\hline Passive changet & $\begin{array}{l}0.10^{* *} \\
(2.40)\end{array}$ & $\begin{array}{l}0.20^{* * *} \\
(12.16)\end{array}$ & $\begin{array}{c}0.20^{* * *} \\
(4.60)\end{array}$ & $\begin{array}{c}0.29^{* * *} \\
(9.21)\end{array}$ & $\begin{array}{c}0.13^{* * *} \\
(3.10)\end{array}$ & $\begin{array}{l}0.19^{* * *} \\
(10.51)\end{array}$ \\
\hline Strategic changet & $\begin{array}{l}0.37^{* * *} \\
(14.04)\end{array}$ & $\begin{array}{l}0.44^{* * *} \\
(16.48)\end{array}$ & $\begin{array}{c}0.22^{* * *} \\
(7.22)\end{array}$ & $\begin{array}{c}0.24^{* * *} \\
(7.75)\end{array}$ & $\begin{array}{l}0.44^{* * *} \\
(12.92)\end{array}$ & $\begin{array}{l}0.46^{* * *} \\
(13.52)\end{array}$ \\
\hline Adjustment + & $\begin{array}{l}0.40^{* * *} \\
(11.83)\end{array}$ & $\begin{array}{l}0.44^{* * *} \\
(12.47)\end{array}$ & $\begin{array}{c}0.22^{* * *} \\
(8.07)\end{array}$ & $\begin{array}{c}0.22^{* * *} \\
(7.65)\end{array}$ & $\begin{array}{l}0.54^{* * *} \\
(17.51)\end{array}$ & $\begin{array}{l}0.55^{* * *} \\
(18.24)\end{array}$ \\
\hline Observations & 3,165 & 3,165 & 3,165 & 3,165 & 3,164 & 3,164 \\
\hline Number of plans & 505 & 505 & 505 & 505 & 505 & 505 \\
\hline Fund FE & $\mathrm{Y}$ & $\mathrm{Y}$ & $\mathrm{Y}$ & $\mathrm{Y}$ & $\mathrm{Y}$ & $\mathrm{Y}$ \\
\hline Year FE & $\mathrm{Y}$ & $\mathrm{N}$ & Y & $\mathrm{N}$ & Y & $\mathrm{N}$ \\
\hline R-squared (within) & 0.464 & 0.352 & 0.287 & 0.214 & 0.462 & 0.420 \\
\hline
\end{tabular}

Notes: This table presents the panel regressions of change in actual portfolio weights on passive change for three asset classes Equity (columns 1 \& 2), Alternatives (columns 3 \& 4) and Bond (columns 5 \& 6). The † next to the independent variables denotes that it is calculated for the dependent variable of that column, for example, the strategic changet for column (3) is the change in the strategic or policy weight in alternatives. The regressions include all the funds that have information available in two consecutive years and where we are able to calculate the passive share. Robust standard errors are clustered at fund level and associated t-statistics are in parentheses below the coefficient. Statistical significance is denoted by asterisks using $* * * \mathrm{p}<0.01, * * \mathrm{p}<0.05 \& * \mathrm{p}<0.1$ respectively. 
The results presented in Table 3.9 clearly show that pension fund are most passive in alternatives. ${ }^{17}$ They are slower than with both the other asset classes in rebalancing and in incorporating strategic changes as well as in closing the existing gap between strategic and actual allocations. It appears that the costs of rebalancing and liquidity issues are very important in relation to the alternative asset class. This has important implications for pension funds, since it can lead to substantial divergence from the desired long-term risk-return characteristics and underestimation of future liquidity needs, which can even spill over to other asset classes. This can set off a herd sale of assets to cover any liquidity shortfalls (Papaioannou, Park, Pihlman, and Van der Hoorn, 2013). As long-term investors, pension funds should avoid such pitfalls. For example, Ang and Kjaer (2012) point out that California Public Employees' Retirement System (CalPERS) had severe liquidity problems in 2008 when it sold equity to meet obligations in private equity and real estate investments. This meant CalPERS selling equity at a low price and missing out on the equity market rebound that followed the downturn. Not rebalancing can expose a fund to hidden and opaque risks for which pension fund managers are unprepared. Lastly, there is only a marginal difference between equity and bonds. It appears that, in terms of rebalancing, these two asset classes are managed similarly.

\subsection{Concluding remarks}

Institutional investors with long horizons for investing should rebalance their portfolio to preserve the desired risk-return characteristics specified by their strategic asset allocation. This requires the investors to be countercyclical, that is, sell the assets that have performed better in the past and buy the assets that have performed poorly. We study the changes in portfolio weights of pension funds over time and how they reflect past returns using a database of pension funds from the US, Canada and Europe which spans the period from 1990 to 2011. We find that pension funds actively rebalance their portfolio to counteract the impact of return on their portfolios significantly more than the rebalancing estimated for households by Calvet, Campbell, and Sodini (2009). However, a portion of the actual change in the equity weights can be attributed to passive change due to realized returns, unexpectedly in the case of professionally managed portfolios. Moreover, we find that the rebalancing behavior is not constant over time. Pension funds tend to rebalance considerably less following a year with a good stock market performance. This "moving with the market" and behaving procyclically can be detrimental both to their own performance and for the stability of the financial system.

\footnotetext{
${ }^{17}$ We assume that cash is the "residual" asset class and the weights in this asset class change such that the sum of changes in all asset class equals zero.
} 
An important issue that we do not take into account in this chapter is: How do pension funds determine the strategic asset allocation? Since our analysis is conditional on this, it is an important caveat regarding our results. It remains an open question as to how the strategic asset allocation relates to the fund characteristics and whether it relates to past returns. Moreover, we assume that pension funds are committed to what they state in their strategic asset allocation and that all pension funds interpret strategic asset allocation similarly. Another important limitation of our analysis is that in equilibrium, if all investors including pension funds hold the same portfolio, for example the market portfolio, then they cannot rebalance. However, when different pension funds have heterogeneous portfolios, as is generally the case, there can be substantial rebalancing between pension funds. Different portfolios will generate cross-sectional variation in passive changes, and funds with lower than average returns can buy stocks from pension funds with higher than average returns.

Additionally, we cannot control for any contractual issues between pension fund and asset managers. For example, it could be the case that the fund is unable to switch money from one external manager to another (across or within asset classes) quickly due to contractual obligations with the present manager, and this contributes to the rebalancing coefficient observed. Moreover, we assume that pension funds can freely make trades whenever and in whichever asset class they prefer. In practice, there can be certain restrictions on the frequency and size of the trades due to the market impact of pension funds, and limitations due to other rules, regulations and restrictions that govern pension funds. Lastly, our data does not contain information on the liabilities of pension funds. Therefore, we cannot control for any change in the value of liabilities and the funding ratio of funds in our analysis. 


\section{Chapter 4}

\section{Pension Fund Asset Allocation In Low Interest Rate Environment ${ }^{*}$}

\subsection{Introduction}

The financial crisis of 2008 has led to a substantial and lasting change in investment opportunities. Both long-term and short-term interest rates have now been at historic lows in many countries for more than five years, presenting new challenges for pension funds. One result has been a substantial increase in the present value of liabilities for Defined Benefit (DB) pension funds. At the same time, fixed-income has become a less attractive asset class due to lower expected returns, which has implications for Defined Contribution (DC) as well as DB funds. We examine the response of pension funds to this prolonged low interest rate environment by analyzing the changes in the portfolio of pensions funds since 2008. However, since other variables have also changed, we examine more generally the actual response of pension funds to variables that predict asset returns, and compare this to what the direction of the response should have been according to existing models in the strategic asset allocation literature that acknowledge predictive variables and the investment constraints of pension funds.

It is well established in the financial literature that macro-economic variables predict asset returns (Ang and Bekaert, 2007; Fama and French, 1989). It is also well established that changes in investment opportunities have implications for long-term investors. Long-term investors can therefore benefit by incorporating this information into their asset allocation (Campbell, Chan, and Viceira, 2003; Hoevenaars, Molenaar, Schotman, and Steenkamp, 2008). The goal of this chapter is to determine whether large institutional investors like pension funds incorporate macro-economic predictive variables for asset allocation. If they do, is this consistent with economic theory? Campbell,

*This chapter is co-authored with Dennis Bams (Maastricht University, Netspar) and Peter Schotman (Maastricht University, Netspar). 
Chan, and Viceira (2003) find that short-term interest rates forecast excess stock returns negatively. An investor should therefore view a decline in interest rates as an improvement in investment opportunities and invest more in stocks. Additionally, expected stock returns increase when the dividend-price ratio increases. Also stocks are negatively correlated with the dividend-price ratio, which implies that poor stock returns are associated with a high dividend-price ratio, in turn implying higher future stock returns. Thus, good current stock returns are associated with poor expected future stock returns. Yield spread predicts excess bond returns positively, thus an increase in yield spread implies that the investor should increase exposure to bonds to time the market. We test these predictions empirically.

We find that pension funds have on average reduced their allocation to equity and increased their allocation to bonds in the low-interest rate environment. This is inconsistent with the strategic asset allocation literature. However, this behavior is consistent with hedging the asset-liability duration mismatch risk. Next, we find that pension funds are unable to time the market in a way consistent with the return predictability literature. The dividend-price ratio shows the strongest relationship, but the sign is opposite to the expectation. However, when we examine the active changes by pension funds, they are consistent with economic theory. This suggests that when predictive variables move the portfolio away from the previously chosen optimal allocation, pension funds trade actively to rebalance it.

Our results contribute to the literature that examines empirically whether investors take into account economic conditions and vary their allocation over time in accordance with the literature on predictable expected returns. An extensive literature claims that investors can use predictive variables to improve their portfolio performance. Chalmers, Kaul, and Phillips (2013) find that individual investors react to changing macroeconomic conditions and reallocate their portfolios in response to forecasting variables. They study the aggregate asset allocation decisions of US mutual fund investors and consider mutual fund flows and the level of predictive variables; Jank (2012) considers changes in the level of predictive variables as an indicator of macro-economic news. However, the two studies reach different conclusions. Chalmers, Kaul, and Phillips (2013) find that investors increase risk as the economy is expect to improve, whereas Jank (2012) finds that mutual fund investors sell stocks when predictive variables signal high expected returns. However, our focus of study is on institutional investors. Jiang, Yao, and $\mathrm{Yu}$ (2007) find that mutual funds have positive market timing ability based on portfolio holdings. They find that active mutual funds use predictive economic variables, in particular dividend yield, to adjust the market exposure of the portfolio. They find that the average market timing measures are positive at short horizons. ${ }^{2}$ By con-

\footnotetext{
${ }^{2}$ Avramov, Barras, and Kosowski (2013) analyze the performance of hedge funds over changing economic conditions.
} 


\subsection{Introduction}

sidering the strategic asset allocation of the fund instead of the actual asset allocation, we avoid the bias that returns on the portfolio can move the portfolio.

Large institutional investors like pension funds which have liabilities usually perform asset-liability studies for asset allocation purposes. ${ }^{3}$. These asset-liability studies typically generate possible future economic scenarios. They are then used to understand what impact major decision variables, for example, portfolio choice, contribution management and indexation decisions, will have on the pension fund's solvency. Portfolio decisions can thereafter be made based on the results coming out of the studies. However, empirical evidence on how institutional investors actually incorporate macro-economic news in their portfolio is limited, and our results contribute to this literature.

The paper closest to us is that of Addoum, Van Binsbergen, and Brandt (2010) who find that pension fund mangers increase the riskiness of the portfolio when approaching the underfunding status from below to increase the chances of avoiding mandatory additional contributions. They study the market timing ability of pension funds, but consider only US defined benefit (DB) corporate plans, and only one predictive variable (dividend-price ratio). We extend the analysis on both these dimensions. They find that pension funds are unable to time the market in a way that is consistent with return predictability literature. They conclude that pension funds react strongly to regulatory requirements. The regulatory requirements for pension funds can override the sponsor's optimal investment strategy, and the pension funds may therefore be unable to time the market due to these regulatory constraints. Blome, Fachinger, Franzen, Scheuenstuhl, and Yermo (2007) analyze the impact of different regulations on the investments of pension funds. They find that the sensitivity of liabilities to interest rate changes can be the key driver of asset allocation decisions. They also conclude that strict funding requirements followed by pension funds may lead them to invest more conservatively, thereby increasing the total funding costs. This short-term regulation based on the funding ratio can induce real sub-optimal decisions, and pension funds will be unable to time the market. Plantin, Sapra, and Shin (2008) find that damage done by marking-to-market is substantial when the claims are long-lived as in the case of pension funds.

\footnotetext{
${ }^{3}$ For examples of Asset-Liability management (ALM) studies for pension funds see for example Bauer, Hoevenaars, and Steenkamp (2006) and van Binsbergen and Brandt (2015) The future scenarios of key economic variables are generated for example by a vector auto-regression (VAR) model.
} 
Table 4.1: Summary Statistics

\begin{tabular}{lcccccc}
\hline & Mean & Std. dev. & 5th percentile & Median & 95th Percentile & N \\
\hline A1. Regressions & & & & & & \\
Domestic T-bill & 3.41 & 2.14 & 0.07 & 3.40 & 7.11 & 4613 \\
Log DP Ratio & -3.99 & 0.30 & -4.47 & -4.04 & -3.43 & 4613 \\
Credit Spread & 1.05 & 0.63 & 0.54 & 0.95 & 3.37 & 4613 \\
Yield Spread & 1.66 & 1.26 & -0.28 & 1.71 & 3.52 & 4613 \\
& & & & & & \\
\hline
\end{tabular}

\begin{tabular}{lcccc}
\hline A2. Correlations & $(1)$ & $(2)$ & $(3)$ & $(4)$ \\
\hline Domestic T-bill (1) & 1 & & & \\
Log DP Ratio (2) & -0.04 & 1 & & \\
Credit Spread (3) & -0.46 & 0.46 & 1 & 1 \\
Yield Spread (4) & -0.71 & 0.30 & 0.18 & \\
\hline
\end{tabular}

\begin{tabular}{lcc}
\hline \hline & Mean & Std. dev. \\
\hline B. Model Calibration & & \\
Real T-bills & 0.92 & 1.61 \\
Excess Equities & 7.25 & 16.89 \\
Excess Bonds & 1.76 & 5.46 \\
Nominal Yield & 4.42 & 1.45 \\
DP ratio & -3.56 & 0.38 \\
Yield Spread & 1.12 & 0.45 \\
Credit Spread & 1.75 & 0.39 \\
\hline
\end{tabular}

Notes: This table gives the summary statistics of the macro-economic variables. Panel A shows the statistics of the variables used for the regressions with sample period 1990-2011. The Domestic T-bill is the short term Treasury Bills for United States, France or Canada depending on the pension fund. Panel B shows the statistics of the variables used to estimate the Campbell, Chan, and Viceira (2003) model with sample period 1952 Q2-2014 Q4. The variables are in logs and the mean excess log returns are adjusted by one-half of the variance. The sample statistics are annualized except for dividend-price ratio.

\subsection{Portfolio implications from the strategic asset allocation lit- erature}

What should have been the response of pension funds to the prolonged low interest rate environment according to models of strategic asset allocation? We show in this section that results from the literature imply that pension funds should have increased allocations to equity and reduced allocations to bonds. The theoretical framework for answering this question is provided by the extensive literature on strategic asset allocation. ${ }^{4}$ Past empirical research has identified various economic variables as predictors for expected returns. These variables are: short-term interest rates (Ang 
Table 4.2: VAR parameter estimation results (1952.Q2-2014.Q4)

\begin{tabular}{|c|c|c|c|c|c|c|c|c|}
\hline & $r t b_{t}$ & $x r_{t}$ & $x b_{t}$ & $y_{t}$ & $(d-p)_{t}$ & $s p r_{t}$ & $c s_{t}$ & $R^{2} / p$ \\
\hline$r t b_{t+1}$ & $\begin{array}{c}0.153 \\
(1.946)\end{array}$ & $\begin{array}{c}-0.002 \\
(-0.332)\end{array}$ & $\begin{array}{c}0.043 \\
(1.981)\end{array}$ & $\begin{array}{c}0.392 \\
(4.288)\end{array}$ & $\begin{array}{c}-0.003 \\
(-2.256)\end{array}$ & $\begin{array}{c}0.740 \\
(3.367)\end{array}$ & $\begin{array}{c}-0.861 \\
(-2.534)\end{array}$ & $\begin{array}{c}0.192 \\
(0.000)\end{array}$ \\
\hline$x r_{t+1}$ & $\begin{array}{c}0.262 \\
(0.295)\end{array}$ & $\begin{array}{c}0.084 \\
(1.124)\end{array}$ & $\begin{array}{c}0.222 \\
(0.954)\end{array}$ & $\begin{array}{c}-2.420 \\
(-2.593)\end{array}$ & $\begin{array}{c}0.056 \\
(3.095)\end{array}$ & $\begin{array}{c}-1.058 \\
(-0.387)\end{array}$ & $\begin{array}{c}3.189 \\
(0.791)\end{array}$ & $\begin{array}{c}0.077 \\
(0.002)\end{array}$ \\
\hline$x b_{t+1}$ & $\begin{array}{c}-0.122 \\
(-0.538)\end{array}$ & $\begin{array}{c}-0.058 \\
(-3.091)\end{array}$ & $\begin{array}{c}-0.039 \\
(-0.344)\end{array}$ & $\begin{array}{c}0.391 \\
(1.088)\end{array}$ & $\begin{array}{c}-0.008 \\
(-1.607)\end{array}$ & $\begin{array}{c}3.464 \\
(3.131)\end{array}$ & $\begin{array}{c}-0.710 \\
(-0.619)\end{array}$ & $\begin{array}{c}0.096 \\
(0.000)\end{array}$ \\
\hline$y_{t+1}$ & $\begin{array}{c}0.008 \\
(0.372)\end{array}$ & $\begin{array}{c}0.003 \\
(1.955)\end{array}$ & $\begin{array}{c}0.000 \\
(0.020)\end{array}$ & $\begin{array}{c}0.962 \\
(26.199)\end{array}$ & $\begin{array}{c}-0.000 \\
(-0.064)\end{array}$ & $\begin{array}{c}0.179 \\
(1.649)\end{array}$ & $\begin{array}{c}-0.180 \\
(-1.517)\end{array}$ & $\begin{array}{c}0.911 \\
(0.000)\end{array}$ \\
\hline$(d-p)_{t+1}$ & $\begin{array}{c}-0.614 \\
(-0.685)\end{array}$ & $\begin{array}{c}-0.076 \\
(-0.970)\end{array}$ & $\begin{array}{c}-0.135 \\
(-0.551)\end{array}$ & $\begin{array}{c}1.570 \\
(1.604)\end{array}$ & $\begin{array}{c}0.947 \\
(49.005)\end{array}$ & $\begin{array}{c}0.525 \\
(0.187)\end{array}$ & $\begin{array}{c}-4.997 \\
(-1.082)\end{array}$ & $\begin{array}{c}0.952 \\
(0.000)\end{array}$ \\
\hline$s p r_{t+1}$ & $\begin{array}{c}-0.003 \\
(-0.217)\end{array}$ & $\begin{array}{c}0.001 \\
(0.452)\end{array}$ & $\begin{array}{c}0.003 \\
(0.407)\end{array}$ & $\begin{array}{c}0.010 \\
(0.474)\end{array}$ & $\begin{array}{c}0.000 \\
(1.600)\end{array}$ & $\begin{array}{c}0.672 \\
(10.627)\end{array}$ & $\begin{array}{c}0.237 \\
(3.113)\end{array}$ & $\begin{array}{c}0.575 \\
(0.000)\end{array}$ \\
\hline$c s_{t+1}$ & $\begin{array}{c}-0.011 \\
(-1.657)\end{array}$ & $\begin{array}{c}-0.003 \\
(-3.374)\end{array}$ & $\begin{array}{c}-0.001 \\
(-0.230)\end{array}$ & $\begin{array}{c}0.023 \\
(2.199)\end{array}$ & $\begin{array}{c}-0.000 \\
(-2.327)\end{array}$ & $\begin{array}{c}0.017 \\
(0.720)\end{array}$ & $\begin{array}{c}0.888 \\
(15.332)\end{array}$ & $\begin{array}{c}0.842 \\
(0.000)\end{array}$ \\
\hline \multicolumn{9}{|c|}{ Cross-correlations of residuals } \\
\hline & $r t b$ & $x r$ & $x b$ & $y$ & $(d-p)$ & $s p r$ & CS & \\
\hline$r t b$ & 0.725 & 0.101 & 0.327 & -0.313 & -0.132 & 0.088 & 0.358 & \\
\hline$x r$ & - & 8.121 & 0.024 & -0.101 & -0.963 & 0.079 & -0.205 & \\
\hline$x b$ & - & - & 2.597 & -0.694 & -0.043 & -0.070 & 0.723 & \\
\hline$y$ & - & - & - & 0.216 & 0.126 & -0.660 & -0.446 & \\
\hline$(d-p)$ & - & - & - & - & 8.317 & -0.094 & 0.193 & \\
\hline$s p r$ & - & - & - & - & - & 0.147 & -0.117 & \\
\hline CS & - & - & - & - & - & - & 0.078 & \\
\hline
\end{tabular}

Notes: This table presents the results of VAR estimation with sample 1952 Q2- 2014 Q4. $r$ tb denotes the ex post real treasury bill rate, $x r$ denotes the excess stock return, $x b$ denotes the excess bond return, $y$ denotes the nominal treasury yield, $(d-p)$ denotes the dividend price ratio, spr denotes the yield spread and cs denotes the credit spread. The last column reports the R2 statistic for each equation in the system and the p-value of the F-test of the joint significance in parenthesis. Panel B reports the covariances of the innovations in the VAR, with the diagonal elements being the standard deviations per quarter. 
and Bekaert, 2007; Campbell, 1987); the dividend-price ratio (Campbell and Shiller, 1988; Fama and French, 1988a); the yield spread between long-term and short-term interest rates (Cochrane and Piazzesi, 2005; Fama and French, 1989; Shiller, Campbell, Schoenholtz, and Weiss, 1983), and the credit spread between BAA and AAA corporate bond yields (Hoevenaars, Molenaar, Schotman, and Steenkamp, 2008). These macroeconomic predictive variables including the short-term interest rate are used to derive optimal portfolios for long-term investors like pension funds. Campbell, Chan, and Viceira (2003) provide an approximate solution for the optimal portfolio choice in cash, stocks and bonds for an investor who faces a time-varying investment opportunity set in terms of a vector auto-regression (VAR) in returns and state variables. They show that the optimal portfolio rule $\left(\alpha_{t}\right)$ is a linear function of VAR state variables

$$
\boldsymbol{\alpha}_{t}=\boldsymbol{A}_{0}+\boldsymbol{A}_{1} \boldsymbol{z}_{t}
$$

where $\boldsymbol{z}_{t}$ is the $m \times 1$ state vector which is first order autoregressive. $\boldsymbol{A}_{0}$ and $\boldsymbol{A}_{1}$ are constant coefficient matrices estimated on the history of variables which are $(n-1) \times 1$ and $(n-1) \times m$ respectively. Here $n$ is the number of assets and $m$ is the total number of assets and other state variables. This model provides insights on how long-term investors should behave when asset returns are assumed to be predictable. The coefficient $\boldsymbol{A}_{1}$ implies the sensitivity of optimal portfolio choice to changes in state variables. Table 4.1 presents the summary statistics of the macro-economic variables. Panel A shows the statistics of the variables used for the regressions with sample period 19902011. The Domestic T-bill is the short term Treasury Bills for United States, France or Canada depending on the pension fund. Panel B shows the statistics of the variables used to estimate the Campbell, Chan, and Viceira (2003) model with sample period 1952 Q2-2014 Q4. The VAR parameter estimates are detailed in Table 4.2, which are in line with other studies on strategic asset allocation (Campbell, Chan, and Viceira, 2003; Diris, Palm, and Schotman, 2014; Hoevenaars, Molenaar, Schotman, and Steenkamp, 2008). Panel A of Table 4.3 shows the matrix $\boldsymbol{A}_{1}$ estimated from quarterly data for four levels of risk aversion $(\gamma=2,5,10,20)$. This matrix is normalized using the standard deviation of the state variables. It shows that portfolio allocation to stocks is negatively related to short-term interest rates, positively related to dividend-price ratio and credit spread and negatively related to yield spread. The signs are opposite for excess bond returns. Therefore the allocation to stocks should increase when the short-term interest rate declines. These signs are summarized in Panel B of Table 4.3. We test these signs in the empirical section. The magnitude of the coefficients increases as the risk-aversion parameter decreases. The data used to estimate the VAR and the matrix $\boldsymbol{A}_{1}$ is similar to other studies on strategic asset allocation and the details are given in the Appendix

\footnotetext{
${ }^{4} \mathrm{~A}$ seminal contribution in this area is the Campbell and Viceira (2002) textbook.
} 
Table 4.3: Sensitivity of the optimal portfolio allocation to changes in the state variables

\begin{tabular}{|c|c|c|c|c|c|c|c|}
\hline & Real rate & Ex stock & Ex bonds & Nom yield & Div-price ratio & Yield spread & Credit spread \\
\hline \multicolumn{8}{|l|}{ Panel A: } \\
\hline \multicolumn{8}{|l|}{$\gamma=2$} \\
\hline Ex stock & 11.78 & 0.38 & 3.02 & -160.31 & 13.65 & -263.21 & 614.28 \\
\hline Ex bonds & -55.37 & -2.48 & -5.34 & 367.09 & -27.15 & 6271.15 & -1409.46 \\
\hline \multicolumn{8}{|l|}{$\gamma=5$} \\
\hline Ex stock & 4.38 & 0.14 & 1.16 & -86.64 & 6.93 & -165.65 & 208.08 \\
\hline Ex bonds & -21.17 & -0.95 & -1.99 & 247.81 & -17.09 & 2839.00 & -427.91 \\
\hline \multicolumn{8}{|l|}{$\gamma=10$} \\
\hline Ex stock & 2.10 & 0.07 & 0.57 & -52.63 & 4.02 & -110.75 & 85.13 \\
\hline Ex bonds & -10.25 & -0.46 & -0.94 & 165.28 & -10.88 & 1549.83 & -132.74 \\
\hline \multicolumn{8}{|l|}{$\gamma=20$} \\
\hline Ex stock & 1.01 & 0.03 & 0.28 & -30.43 & 2.24 & -67.99 & 33.75 \\
\hline Ex bonds & -4.99 & -0.22 & -0.44 & 101.18 & -6.43 & 832.32 & -26.17 \\
\hline \multicolumn{8}{|l|}{ Panel B: } \\
\hline Ex stock & & & & - & + & - & + \\
\hline Ex bonds & & & & + & - & + & - \\
\hline
\end{tabular}

4.6.1.

Figure 4.3 in the appendix shows the optimal allocation to stocks and bonds according to Campbell, Chan, and Viceira (2003). As expected, the allocations are quite volatile, but they clearly imply that pension funds should have increased the allocation to equity and decreased the allocation to bonds since the start of the low interest environment. ${ }^{5}$ The optimal portfolio allocation for a long-term investor described in (4.1) is different from the optimal allocation of a short-term investor and can be formulated as a combination of a myopic and a hedging portfolio. Myopic is simply the mean-variance optimal portfolio. When investment opportunities are time varying, a risk-averse investor will hedge against the adverse changes in the investment opportunities set, thus giving rise to a hedging portfolio. When the investment opportunities are constant, the

\footnotetext{
${ }^{5}$ Indeed the changes over time do not appear to be very practical given the volatility, however they are indicative of the direction of portfolio movement, see Campbell, Chan, and Viceira (2003) for a discussion. A more elaborate model with constraints to prevent extreme movements could generate more practical results, however such a model is will require a numerical optimization procedure, as no analytical model exists.
} 


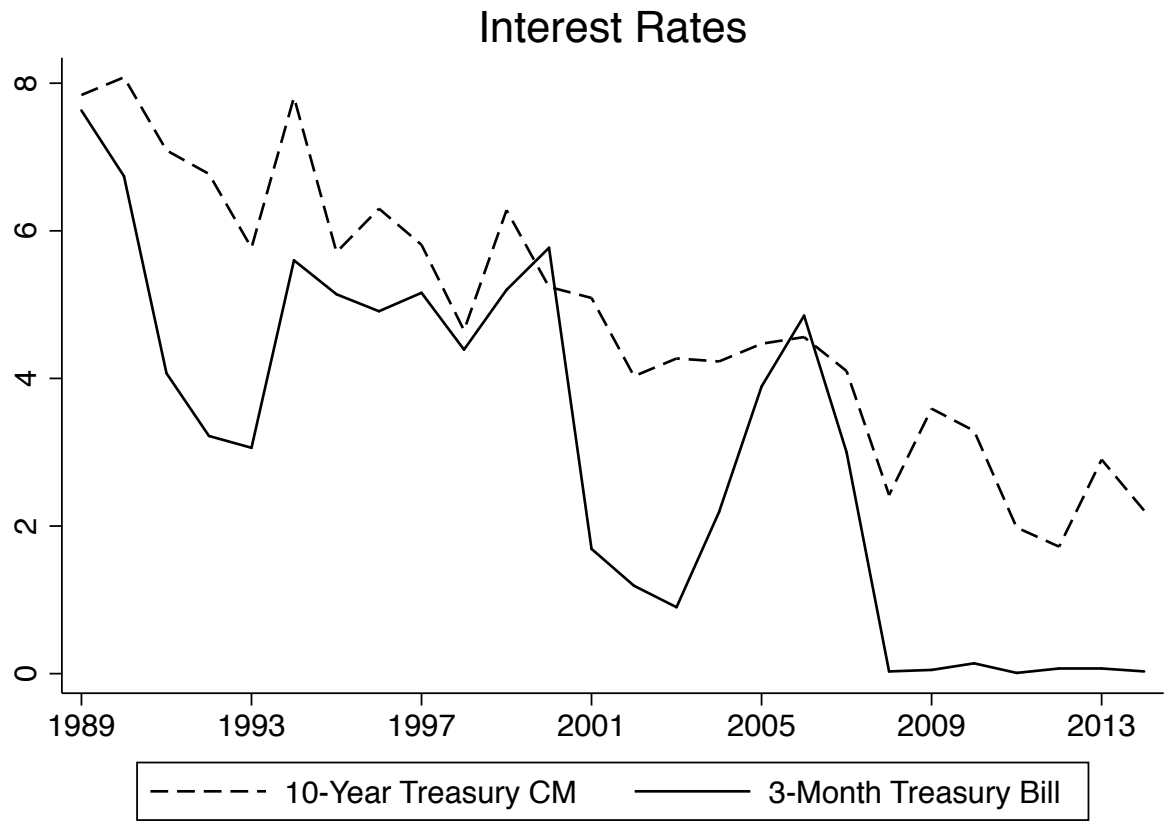

Figure 4.1: The level of interest rates. This figure provides the level of both short term three-Month Treasury Bill as well as long term ten-Year Treasury Constant Maturity Rate rates over the period 1989-2014. The Figure depicts that the short term interest rate has been almost zero from 2008 onwards as well as the long term interest rate has been at the lowest level since the start of the sample period.

hedging portfolio is zero.

Moreover, we also analyze the portfolio implications of the study by Ang and Bekaert (2002a) of asset allocation that takes into account return predictability as well as regimes in interest rates. Ang and Bekaert (2007) find that when short-term rates are low the subsequent equity returns tend to be high. They show that the short rate is a robust predictor in five countries and more significant than the dividend yield. This observation is exploited by the switching market-timing model for asset allocation regime developed in Ang and Bekaert (2002a). The model takes into account time variation in expected returns through a regime change and variations in interest rates. Two interest rate regimes are specified in the model: a normal regime with relatively low mean returns on short-term interest rates, low standard deviation and high autocorrelation (therefore more persistent); and a volatile regime with relatively high mean returns and standard deviation and lower autocorrelations. The second regime is therefore volatile, 
with higher interest rates, and less persistent. The researchers find that the equity beta with respect to interest rate is negative which implies that low interest rates are typically associated with high expected excess equity returns. This means that allocation to equity should be high when interest rates are low. Figure 4.4 in the appendix shows the allocation according to this model. The results again imply that pension funds should have increased the allocation to equity and decreased the allocation to bonds.

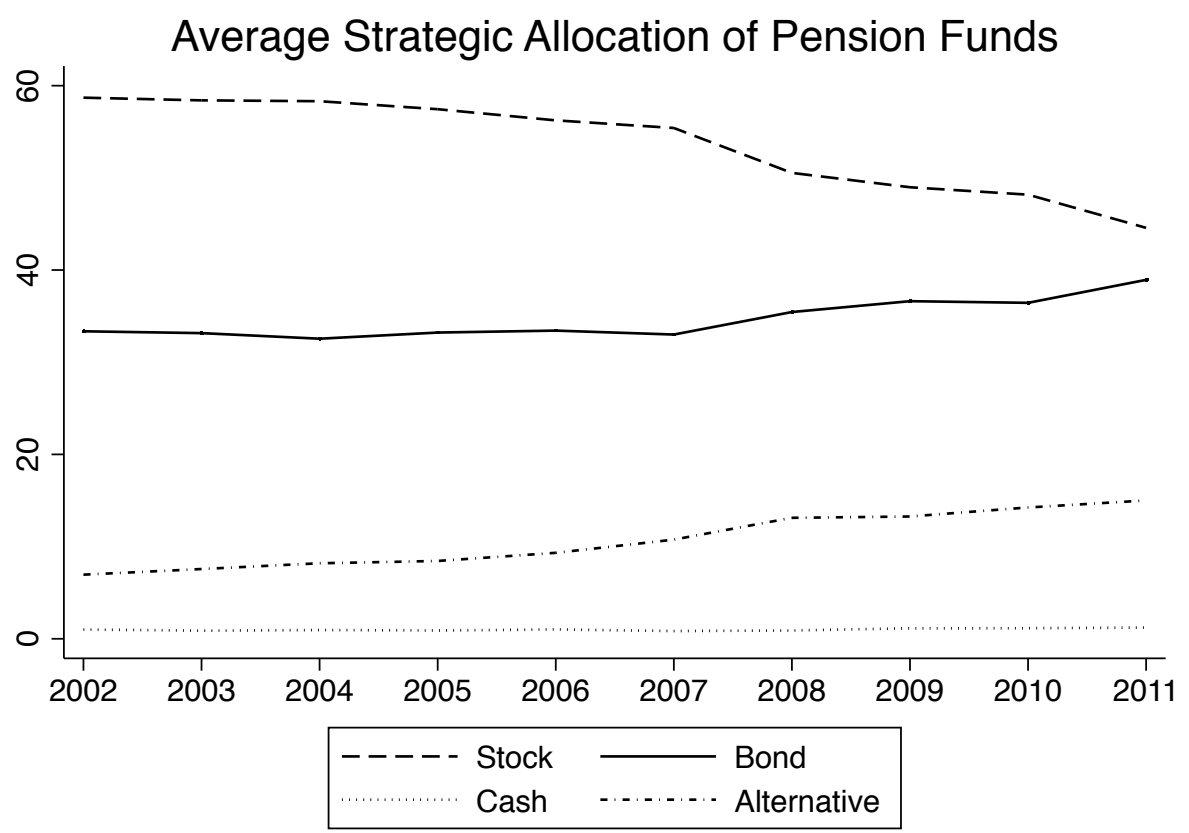

Figure 4.2: The average allocation of the pension funds is the mean of all funds in a given year as reported in the CEM database. The alternative asset class includes allocations to Real Estate, Private Equity, Hedge Funds and Commodities.

Figure 4.1 provides the level of both short-term three-month treasury bill as well as the long term ten-year treasury constant maturity rate over the 1989-2014. The figure shows that the short-term interest rate has been almost zero from 2008 onwards and the long-term interest rate has been at the lowest level since the start of the sample period. Figure 4.2 plots the average strategic allocation in the three asset classes and alternatives from the CEM database. ${ }^{6}$ The alternative asset class includes allocations to Real

${ }^{6}$ Our data is obtained from CEM Benchmarking Inc., a pension fund cost benchmarking company located in Toronto, Canada that collects data from pension funds annually via a survey, primarily for cost 
Table 4.4: Sensitivity of portfolio choice to state variables, with liabilities and longer horizons

\begin{tabular}{lcccc}
\hline Panel I & Nominal yield & Dividend yield & Yield Spread & Credit spread \\
\hline $\begin{array}{l}\gamma=5 \\
5 \text { year horizon }\end{array}$ & & & & \\
Stocks & -1526.1 & 3281.2 & -1250.7 & 1454.8 \\
Bonds & 3092.7 & -3801.6 & 3850.4 & 1806.5 \\
& & & & \\
20 year horizon & & & & \\
Stocks & -3566.8 & 8015.0 & -2806.4 & -178.1 \\
Bonds & 10135.6 & -9332.4 & 9891.9 & 5010.2 \\
& & & & \\
\hline$\gamma=20$ & & & & \\
5 year horizon & & & & \\
Stocks & -456.3 & 926.2 & -399.5 & 342.9 \\
Bonds & 912.6 & -1179.4 & 1108.8 & 434.5 \\
& & & & \\
20 year horizon & -1330.6 & 2581.9 & -1105.1 & -203.1 \\
Stocks & 3552.8 & -3566.2 & 3425.4 & 1656.3 \\
Bonds & & & & $?$ \\
\hline Panel II & - & + & + & $?$ \\
Stocks & + & - & + & $?$ \\
Bonds & & & & \\
\hline
\end{tabular}

Notes: The Panel I of this table presents the coefficient matrix $A_{1}$ from the equation $\alpha_{t}^{(\tau)}=A_{0}+$ $A_{1} z_{t} . \alpha_{t}^{(\tau)}$ is the optimal portfolio rule of Hoevenaars, Molenaar, Schotman, and Steenkamp (2008), for a pension fund with liabilities and horizon $\tau$. The constant coefficient matrices are calculated using the coefficients in their results. The results are presented for two levels of relative risk aversion parameter $(\gamma) 5$ and 20 and two horizons 5, 20 years. Panel II summarizes the expected signs. 
Estate, Private Equity, Hedge Funds and Commodities. ${ }^{7}$ This figure can be compared with the models of implied optimal allocations by Campbell, Chan, and Viceira (2003) and Ang and Bekaert (2002b), which are shown in the appendix. The figures plot the allocations only after 2002, to focus on the allocation before and during the low-interest rate environment. The Campbell, Chan, and Viceira (2003) model shows that the optimal allocation in bonds should be declining, whereas the optimal allocation to equity should be increasing. However, in the data we find the opposite. Average allocations to equity have been decreasing since the start of the low-interest rate regime and allocations to bonds have been increasing.

\subsubsection{Optimal portfolio choice with liabilities}

Pension funds have long-term liabilities. Assets that can hedge their long-term liabilities are therefore valuable for them. Moreover, many regulations for pension funds are based on their funding ratios. Therefore pension funds look particularly at the asset-liability mismatch risk of their portfolio and decide upon an acceptable duration mismatch between assets and liabilities, so that any changes in interest rates have a tolerable impact on their funding ratio. One might be concerned about the fact that the linear portfolio rule (4.1) of Campbell, Chan, and Viceira (2003) is for an investor without liabilities, and results may therefore not be completely relevant for pension funds, which do have liabilities. Hoevenaars, Molenaar, Schotman, and Steenkamp (2008) consider differences between the optimal portfolio of an asset-only and an assetliability investor. The Hoevenaars, Molenaar, Schotman, and Steenkamp (2008) model allows us to determine how the changes in the state variables affect optimal asset allocation for an investor with liabilities. Using their model and insights from Campbell, Chan, and Viceira (2003), we find that the optimal portfolio rule is a linear function of the state variables of the VAR(1) model, where the coefficients of the linear rule can be calculated from the VAR coefficients. 4.6.2 shows that the $\tau$ horizon optimal portfolio choice with liabilities is

$$
\boldsymbol{\alpha}_{t, L}^{(\tau)}=\tilde{\boldsymbol{A}}_{0}+\tilde{\boldsymbol{A}}_{1} \boldsymbol{z}_{t}
$$

Moreover, for the asset-only investor, the optimal portfolio choice is

$$
\boldsymbol{\alpha}_{t, A O}^{(\tau)}=\tilde{A}_{2}+\tilde{A}_{1} z_{t}
$$

where $\tilde{A}_{0}, \tilde{A}_{1}$ and $\tilde{A}_{2}$ are constant functions of estimated parameters of VAR(1) model and the risk-aversion parameter. The coefficient $\tilde{A}_{1}$ measures the sensitivity of optimal portfolio allocation to changes in the state variables. Additionally, the sensitivity $\tilde{A}_{1}$ does not change between the asset-liability and asset only investor.

benchmarking purposes.

${ }^{7}$ For more details on the database, we refer to Andonov (2014). 
The difference between the asset-liability and asset-only portfolio stems from the socalled hedging portfolio. The optimal portfolio rule can be decomposed into two components, a speculative portfolio and the hedging portfolio. The asset-only investor's hedging portfolio minimizes the risk of the asset mix, whereas the hedging portfolio of asset-liability investor takes into account the time-invariant covariance of assets and liabilities. The hedging portfolio in this setting does not change over time and is constant. The correlations and volatilities are assumed constant in the model and do not change with time. Overall, bonds are the best hedge against interest rate risk and therefore have a large weighting in the liability hedging portfolio, even in a constrained portfolio. $^{8}$

The inter-temporal hedging considerations of liabilities affect the optimal portfolio choice through $\tilde{A}_{0}$ and $\tilde{A}_{2}$ only as these are the constants that contain correlations with liabilities. The $\tilde{A}_{1}$ function is not dependent on the correlation between asset and liabilities. This sensitivity is related to liabilities through the coefficients of the VAR process. There is therefore no reason for the pension fund to change its allocation apart from the observed changes in the state variables. Table 4.4 presents the coefficient matrix $\tilde{A}_{1}$ for stocks and bonds and for the four main state variables. The results are shown for two values of risk aversion parameter $\gamma=5,20$ and two horizons 5,20. The results are consistent with the results from the earlier analysis and imply that the pension fund should have increased its allocation to stocks since the start of the low interest rate environment. The only change stems from the coefficient of credit spread, whose sign is different for short and long horizons.

The linear portfolio rules (4.1) of Campbell, Chan, and Viceira (2003) and Hoevenaars, Molenaar, Schotman, and Steenkamp (2008) are for an unconstrained investor, i.e. one who does not have any borrowing, short-selling or regulatory constraints. Imposing any of these constraints makes the portfolio choice much more complex: no tractable theoretical result can be derived, and only numerical solutions can be found. Pension funds do indeed have all of these constraints. It is therefore interesting to test whether pension funds can still utilize the benefits of timing the market in the presence of these constraints. One additional reason for change in the portfolio can be change in the risk aversion parameter. If the pension fund becomes more risk averse, then it will invest more in less-risky assets. Less-risky assets for long-term investors are longterm bonds. T-bills are risky at long horizons as they have a substantial roll-over risk. Hoevenaars, Molenaar, Schotman, and Steenkamp (2008) also show that bonds are the best hedge against real interest rate risk and therefore have a large weighting in the liability-hedge portfolio.

\footnotetext{
${ }^{8}$ See for example Table 5, 6 in Hoevenaars, Molenaar, Schotman, and Steenkamp (2008).
} 


\subsection{How do low interest rates affect asset allocation?}

The prolonged low interest rate environment poses a new challenge for the portfolio allocation of pension funds. Not only have the investment opportunities been affected, but also the market value of liabilities has increased due to low long-term interest rates, thus reducing the funding ratio of pension funds. Figure 4.1 shows that long-term as well as short-term interest rates have been exceptionally low since 2008. First, the empirical work in this section assesses how pension funds have responded to this special macro-economic situation. Secondly, we look at the cross-sectional characteristics of pension funds and examine whether different pension funds have responded differently. To explore pre and post 2008 equity allocation, we construct a new variable $\Delta \bar{w}_{i}$ which is the difference between the average allocation to equity in 2009, 2010, and 2011 and in 2005, 2006, and 2007 for pension fund $i$. We look at an average difference over three years to minimize any short-term changes and focus on long-term changes in the portfolio. The differences are calculated on the policy or strategic asset allocation, as this signals the explicit policy direction of the pension fund.

A statistically significantly positive $\Delta \bar{w}_{i}$ would indicate that pension funds have increased their allocation to equity in the low-interest rate environment. In the same way, we compute average change variables for fixed income and alternative asset classes. Table 4.5 provides summary statistics for these variables. Panel A assesses whether there is any significant change in allocation, and Panel B details the difference within various cross-sectional groups. The change in equity is negative at -6.97 percentage point and statistically significant. On the other hand, there is a significant increase in both bonds $(+2.36)$ and alternatives $(+4.43)$. This implies that pension funds, on average, have explicitly decided to reduce their exposure to equities and increase their exposure to bonds as well as alternatives since the onset of low interest rates. Next, we analyze the effect of all the cross-sectional variables together by using the following multivariate regression specification:

$$
\Delta \bar{w}_{i}^{j}=c_{0}+c_{1} \mathrm{US}_{i}+c_{2} \text { Public }_{i}+c_{3} \mathrm{DB}_{i}+c_{4} \log \text { Fund Size }_{i}+c_{5} \text { Retired }_{i}+\epsilon_{i}
$$

the super-script $j$ refers to equity, bonds and alternative asset classes. Table 4.6 presents the results of this regression. The standard errors are corrected for heterogeneity and lack of normality by using the Huber-White sandwich estimators.

There are two different motives at work here, a market-timing and a liability-hedging motive. The market-timing motive stems from the predictability literature. Since the short-term interest rate is low, expected returns on equity are high and therefore pen- 
Table 4.5: Summary statistics: Average change in strategic asset allocation before and during low-interest rate environment

\begin{tabular}{|c|c|c|c|c|}
\hline & Equity & Bonds & Alternatives & Obs \\
\hline \multicolumn{5}{|l|}{ Panel A: } \\
\hline $\begin{array}{l}\text { Difference } \\
\text { t-value }\end{array}$ & $\begin{array}{c}-6.97 \\
(-14.05)\end{array}$ & $\begin{array}{c}2.36 \\
(5.07)\end{array}$ & $\begin{array}{c}4.43 \\
(10.99)\end{array}$ & 313 \\
\hline \multicolumn{5}{|l|}{ Panel B: } \\
\hline US & -8.92 & 3.47 & 5.11 & 188 \\
\hline Non US & -4.04 & 0.69 & 3.40 & 125 \\
\hline Difference & -4.88 & 2.78 & 1.72 & \\
\hline t-value & $(-5.00)$ & $(2.96)$ & $(2.10)$ & \\
\hline Public & -4.93 & -1.82 & 6.38 & 110 \\
\hline Non-public & -8.00 & 4.66 & 3.25 & 200 \\
\hline Difference & 3.07 & -6.47 & 3.12 & \\
\hline t-value & (2.98) & $(-7.11)$ & (3.78) & \\
\hline DB & -7.51 & 3.00 & 4.36 & 260 \\
\hline Non-DB & -4.31 & -0.78 & 4.77 & 53 \\
\hline Difference & -3.21 & 3.77 & -0.42 & \\
\hline t-value & $(-2.45)$ & (3.08) & $(-0.39)$ & \\
\hline Large & -7.22 & 0.97 & 5.91 & 156 \\
\hline Small & -6.72 & 3.73 & 2.95 & 157 \\
\hline Difference & -0.50 & -2.76 & 2.96 & \\
\hline t-value & $(-0.50)$ & $(-3.01)$ & (3.75) & \\
\hline Old & -8.70 & 4.70 & 3.97 & 134 \\
\hline Young & -6.63 & 1.17 & 5.23 & 135 \\
\hline Difference & -2.07 & 3.53 & 1.26 & \\
\hline t-value & $(-2.01)$ & $(3.70)$ & $(1.40)$ & \\
\hline
\end{tabular}

Notes: This Table provides the results of t-tests of equality of mean of average change variable within various cross-sectional groups. The panel A test if the average change variable has a mean of zero., whereas panel B test if the means are different within different groups. Large group refers to the largest 50 percent pension funds and old refers to top 50 percent pension funds with the highest retired to active participants. 
Table 4.6: Average change in strategic asset allocation before and during low-interest rate environment

(1)

$(2)$

(3)

Difference equity Difference bond Difference alternatives

\begin{tabular}{|c|c|c|c|}
\hline US dummy & $\begin{array}{c}-4.55^{* * *} \\
(-4.29)\end{array}$ & $\begin{array}{l}2.05^{* *} \\
(2.18)\end{array}$ & $\begin{array}{l}1.66^{*} \\
(1.85)\end{array}$ \\
\hline \multirow[t]{2}{*}{ Public dummy } & $3.88^{* * *}$ & $-5.64^{* * *}$ & $1.91^{*}$ \\
\hline & $(3.63)$ & $(-6.46)$ & $(1.93)$ \\
\hline \multirow[t]{2}{*}{ Defined Benefit } & -0.07 & 0.40 & -1.32 \\
\hline & $(-0.04)$ & $(0.23)$ & $(-0.66)$ \\
\hline \multirow[t]{2}{*}{ Log Fund Size } & $-0.94^{* *}$ & -0.14 & $1.00^{* * *}$ \\
\hline & $(-2.43)$ & $(-0.47)$ & $(3.13)$ \\
\hline \multirow[t]{2}{*}{ Retired } & -2.50 & $3.81^{*}$ & -1.30 \\
\hline & $(-1.07)$ & $(1.73)$ & $(-0.66)$ \\
\hline \multirow[t]{2}{*}{ Constant } & 3.23 & 2.56 & -3.81 \\
\hline & $(0.91)$ & $(0.83)$ & $(-1.13)$ \\
\hline Observations & 266 & 266 & 266 \\
\hline R-squared & 0.13 & 0.15 & 0.10 \\
\hline
\end{tabular}


sion funds should increase their allocation to equity. On the other hand, since long-term interest rates are low pension funds should increase the allocation to bonds to reduce the duration gap between assets and liabilities in anticipation of a further decline in long-term interest rates. Duration of pension liabilities is a concept that measures the sensitivity of the liability to interest rates. The longer the duration of the liability of the pension fund, the greater is the impact of change in interest rates on the funding ratio. A further decline in interest rates at which liabilities are discounted will lower the funding ratio if liabilities have a longer duration than assets. However, this duration immunization at the moment of low long-term interest rates comes at a significant cost. The reason is that buying long-term bonds at historically low interest rates will lock in low yields.

If the pension fund has fully immunized its portfolio, then any change in interest rates will have a similar impact on asset and liabilities and the change in the funding ratio will be minimal. However, full immunization can be very costly due to hedging and transaction costs. The sensitivity of equity in response to changes in interest rate is not useful for liability hedging purposes, so its duration can be assumed to be zero. Thus to gain duration and match assets to liabilities, assets are likely to be shifted to the bond asset class.

The effect of interest rates is strongest for pension funds that have "hard" liabilities, which is the case for defined benefit (DB) pension funds. The overall effect of low interest rates on the funding ratio of the pension fund depends on the duration gap between asset and liabilities (Antolin, Schich, and Yermo, 2011). The effect can also vary depending on the financial reporting standards used by the pension fund. For example, discount rate, liability valuation method and asset valuation method (mark-to-market or mark-to-book) will also affect the strength of the impact on the fund's balance sheet. Pension funds may seek to hedge their interest rate risk by increasing the duration of their portfolio, for example by increasing the allocation to bonds in their portfolio. However, strong demand for hedging activities could further reduce the bond yield if all the institutional investors were to herd in a similar way. This would further worsen the financial situation of the pension funds.

The results of linear regression include five cross-sectional variables, two continuous variables - log of fund's assets and percentage of retired members - and three dummy variables to indicate a US fund, a public fund and a defined benefit (DB) fund. We find that US pension funds have strongly reduced their exposure to equity and increased exposure to the fixed-income asset class. One of the most important differences between US and non-US funds lies in the severe underfunding of US funds. This means that US funds are even more constrained than any other pension funds. Additionally, the available assets required for liability hedging are rather limited. Public funds in the US are severely underfunded even according to the relaxed accounting standards 
(Munnell, Aubry, and Quinby, 2011).

Public funds have, on the other hand, significantly increased their exposure to equity and reduced their exposure to bonds. The difference between Public and Corporate funds stems from the regulations they have to follow. In the US, for example, the public and corporate pension funds follow different financial accounting principles. The state and local public pension funds follow the Governmental Accounting Standards Board (GASB) balance sheet accounting. On the other hand, the corporate pension plans follow Financial Accounting Standards Board (FASB) for their financial accounting. One important difference is that corporate pension funds use a corporate bond yield curve as discounting rate whereas public pension funds use expected rate of return. Different rules for discounting liabilities have implications for the interest rate sensitivity of the funding ratio of the fund. More importantly, public funds have no motive for liability hedging since they use the expected rate of return as a liability discount rate which remains fixed. Therefore they can focus fully on market timing by increasing their exposure to equity when expected returns on equity are high. On the other hand, corporate pension funds do have a strong incentive to hedge their liabilities. Although mark-tomarket is considered better for transparency, we can see that this can put an additional constraint on pension funds, hindering their ability to time the market. Plantin, Sapra, and Shin (2008) find that damage done by marking-to-market is substantial when the claims have a long life, as in the case of pension funds.

According to life-cycle literature, pension funds should reduce the risk of their portfolio if they have a higher proportion of retired members. On the other hand, the effect of low long-term interest rates is exacerbated for pension funds with a longer duration of liabilities. This can be approximated by the percentage of retired members of the pension fund. If there are less retired members in the pension fund, then the duration of liabilities is larger than a pension fund that has more retired members, other things being equal. Therefore the effect of low long-term interest rates is relatively strong. We find a positive sign for the percentage of retired members, consistent with life cycle theory, but it is only marginally statistically significant. Furthermore, the significant and positive coefficients on the size variable show that larger pension funds increased their allocation to alternatives more. On the other hand, larger pension funds reduced their allocation to equity to about the same degree. ${ }^{9}$ 
Table 4.7: Robustness check - a comparison with another crisis period: We construct $\Delta \bar{w}_{i}$ which is the difference between the average allocation to equity in 2009, 2010, and 2011 and in 2000, 2001, and 2002 for pension fund i. 2000, 2001 and 2002 were chosen because the S\&P return had been negative for all three years

\begin{tabular}{|c|c|c|c|c|}
\hline & Equity & Bonds & Alternatives & Obs \\
\hline \multicolumn{5}{|l|}{ Panel A } \\
\hline $\begin{array}{l}\text { Difference } \\
\mathrm{t} \text {-value }\end{array}$ & $\begin{array}{c}-9.49 \\
(-12.10)\end{array}$ & $\begin{array}{l}1.86 \\
(2.53)\end{array}$ & $\begin{array}{c}7.66 \\
(12.82)\end{array}$ & 233 \\
\hline \multicolumn{5}{|l|}{ Panel B } \\
\hline US & -11.55 & 2.53 & 8.95 & 140 \\
\hline Non US & -6.37 & 0.86 & 5.71 & 93 \\
\hline Difference & -5.18 & 1.67 & 3.24 & \\
\hline t-value & $(-3.30)$ & (1.11) & $(2.70)$ & \\
\hline Public & -6.29 & -3.14 & 9.64 & 93 \\
\hline Non-public & -11.61 & 5.18 & 6.34 & 140 \\
\hline Difference & 5.32 & -8.33 & 3.30 & \\
\hline t-value & $(3.40)$ & $(-5.94)$ & $(2.75)$ & \\
\hline DB & -9.56 & 2.30 & 7.37 & 197 \\
\hline Non-DB & -9.07 & -0.53 & 9.20 & 36 \\
\hline Difference & -0.50 & 2.83 & -1.82 & \\
\hline t-value & $(-0.23)$ & (1.39) & $(-1.10)$ & \\
\hline Large & -10.53 & 0.69 & 9.90 & 116 \\
\hline Small & -8.45 & 3.02 & 5.43 & 117 \\
\hline Difference & -2.09 & -2.33 & 4.47 & \\
\hline t-value & $(-1.33)$ & $(-1.59)$ & (3.85) & \\
\hline Old & -11.91 & 5.27 & 6.55 & 101 \\
\hline Young & -7.36 & -1.30 & 8.86 & 102 \\
\hline Difference & -4.55 & 6.57 & -2.31 & \\
\hline t-value & $(-2.70)$ & $(4.36)$ & $(-1.78)$ & \\
\hline
\end{tabular}

Notes: This table provides the results of t-tests of equality of mean of average change variable within various cross-sectional groups. The panel A test if the average change variable has a mean of zero., whereas panel B test if the means are different within different groups. Large group refers to the largest 50 percent pension funds and old refers to top 50 percent pension funds with the highest retired to active participants. 
Table 4.8: Robustness regressions - a comparison with another crisis period: We construct $\Delta \bar{w}_{i}$ which is the difference between the average allocation to equity in 2009, 2010, and 2011 and in 2000, 2001, and 2002 for pension fund i. 2000, 2001 and 2002 were chosen because the S\&P return had been negative for all three years.

\begin{tabular}{lccc}
\hline & $(1)$ & $(2)$ & $(3)$ \\
\hline & Difference equity & Difference bonds & Difference alternatives \\
US dummy & $-5.58^{* * *}$ & $2.81^{*}$ & $2.29^{*}$ \\
Public dummy & $(-3.19)$ & $(1.70)$ & $(1.73)$ \\
& $6.69^{* * *}$ & $-7.90^{* * *}$ & 1.69 \\
Defined Benefit & $(3.99)$ & $(-5.59)$ & $(1.17)$ \\
& 0.77 & 1.74 & -2.10 \\
Log Fund Size & $(0.20)$ & $(0.52)$ & $(-0.72)$ \\
& $-1.33^{* *}$ & 0.06 & $1.28^{* * *}$ \\
Retired & $(-2.44)$ & $(0.11)$ & $(2.95)$ \\
& $-9.20^{* *}$ & $9.96^{* *}$ & -1.54 \\
Constant & $(-2.28)$ & $(2.30)$ & $(-0.54)$ \\
& 6.36 & -3.60 & -2.67 \\
& $(1.01)$ & $(-0.67)$ & $(-0.56)$ \\
Observations & 203 & 203 & 203 \\
R-squared & 0.15 & 0.19 & 0.11 \\
\hline
\end{tabular}

Notes: This table reports the OLS regression results of average change variable in each asset class on crosssectional fund characteristics. The Difference equity variable is the difference between the average strategic or policy allocation to equity in 2009, 2010, and 2011 and in 2000,2001, and 2002. The Difference bonds and Difference alternatives are similarly constructed. The observations include the pension funds for which atleast one observation in each period is available. Robust t-stats are in parentheses, statistical significance is denoted by $* * * \mathrm{p}<0.01, * * \mathrm{p}<0.05 \& * \mathrm{p}<0.1$. 


\subsubsection{Robustness check}

One might worry about the fact that pension funds changed their allocation substantially due to a crisis environment in the years following 2008. The methodology used for Tables 4.5 and 4.6 is designed in a fashion similar to several event studies in the finance literature, to compare the change in allocation before and during a low-interest rate environment. The main benefit of comparing portfolio allocation in $2009-2011$ to $2005-2007$ is that the fund characteristics and regulatory environment have not changed substantially and thus we can control for them. One additional benefit is that we do not need a pension fund to be in the database for a long time period, therefore we have more observations. To address the concern that the change in allocation can be due to the crisis environment, we compare the change in allocation in $2009-2011$ to another crisis period which does not exhibit significantly low interest rates.

We compare the allocation in $2009-2011$ with the crisis period $2000-2002$. We choose this crisis period as it is the most recent crisis before 2008, and the annual S\&P returns were negative for all three years. These two periods are also comparable in terms of business cycle contractions as specified by NBER. ${ }^{10}$ The latest business cycle contraction was from December 2007 to June 2009 and the one immediately proceeding this was during the period of our choice in March 2001 to November 2001. The results are presented in Tables 4.7 and 4.8 in the appendix.

Consistent with earlier results presented in Table 4.5, allocation to Equity and Alternatives has significantly increased and allocation to bonds significantly decreased. Changes for public and non-public funds have similar magnitudes and the same sign. Although the signs are consistent with Table 4.5, the results for defined benefit (DB) funds have become weaker statistically. However, we now only have 36 observations for non-DB funds, and this may have contributed to the lack of statistical significance. Similarly, the regression results presented in Table 4.8 are comparable to results presented in Table 4.6, where the signs, magnitude and statistical significance are comparable. Additionally, we find that the coefficient of the retired percentage is strongly negative in case of equity and vice-versa for bonds. This is to be expected, as a pension fund would decrease the allocation to risky assets when it has more retired people, in line with life-cycle theory. This analysis suggests that a crisis environment alone cannot explain the magnitude and sign of the coefficients that we observe in the tables. Since other macro-economic variables and expected returns on asset classes have also

\footnotetext{
${ }^{9}$ Rajan (2006) claims that periods of low interest rates induced by monetary policy provide investors with incentives to search-for-yield and invest more in risky assets. In unreported results, we added expected rate of return (EROR) of the pension fund to (4.4) and restricted the sample to the funds that did not change the EROR, to address the concerns about endogeneity. We found that pension funds which have a higher expected rate of return (EROR) assumption have invested significantly more in equities since the onset of the low interest rate environment.

${ }^{10}$ http://www.nber.org/cycles.html
} 
changed, we examine their effect more generally for the entire time-series in the next section.

\subsection{Pension fund asset allocation and predictive variables}

The return predictability literature indicates that the level of variables such as shortterm interest rate, dividend-price ratio, credit spread and yield spread predicts asset returns. In this section, we examine whether pension funds respond to the level of predictive variables in their asset allocation decisions. Inspired by the linear portfolio rule (4.1) of Campbell, Chan, and Viceira (2003), we specify the portfolio weight of the pension fund as a linear function of predictive variables. However, we introduce a lag on the independent variables because the pension funds' response would be delayed. We use the following regression model:

$$
w_{i, t}^{j}=\alpha+\beta_{1} Y_{t-1}+\beta_{2}(d-p)_{t-1}+\beta_{3} C S_{t-1}+\beta_{4} S p r_{t-1}+\theta_{i}+\epsilon_{i, t}
$$

The dependent variable is the strategic asset allocation for fund $i$ in asset class $j$, where $j$ can be equities, bonds, or alternative assets. The independent variables are the predictive variables: $Y_{t}$ is the short-term interest rate, $(d-p)_{t}$ is the log dividend-price ratio, $C S_{t}$ is the credit spread, and lastly $S p r_{t}$ is the yield spread between long-term and short-term yield. The summary statistics of the macro-economic variables are provided in Panel A of Table 4.1. This model is estimated with fixed-effects $\theta_{i}$. Therefore, the regression coefficients are driven by the variation over time within each pension fund. In addition, we use a model in which we include the five control variables used in section 4.3, which results in the following regression model:

$$
\begin{aligned}
w_{i, t}^{j}=\alpha+\beta_{1} Y_{t-1}+\beta_{2}(d-p)_{t-1} & +\beta_{3} C S_{t-1}+\beta_{4} S p r_{t-1}+\beta_{5} \log \text { Fund Size }_{i} \\
& +\beta_{6} \text { Retired }+\beta_{7} \mathrm{DB}+\beta_{8} \mathrm{US}+\beta_{9} \text { Public }+\epsilon_{i, t}
\end{aligned}
$$

the super-script $j$ refers to equities, bonds and alternative assets. Table 4.9 presents the regression results of strategic asset allocation in Equity, Bonds and Alternatives on one period lag of the variables of interest - domestic T-bills, log D-P ratio, credit spread and yield spread. The first three columns present the plan fixed effects specifications using equation (4.5) and the last three columns present the pooled specification in which we add five plan characteristics using (4.6). For all the regressions, the standard errors are clustered by fund as well as by year. The signs of the coefficients can be compared with the signs of the coefficients in Table 4.3 which are expected if the pension funds are able to time the market. In terms of statistical significance, the results are strongest for dividend-price ratio. Since a high dividend-price ratio forecasts high excess stock re- 
turns, we expect a positive relationship between strategic allocation to equity and level of dividend-price ratio. Surprisingly, we find that the opposite is true in our empirical tests. The coefficient is statistically significantly negative.

We also find a statistically significant relationship between the other three predictive variables and strategic asset allocation. However, the signs are again inconsistent for T-bills and Yield spread. In the pooled specifications, after controlling for various fund characteristics we find that the relationships between the predictive variable and strategic allocation still holds. Thus, the results are robust to controlling for cross-sectional fund characteristics. ${ }^{11}$

The results show that the level of equity allocation is positively correlated with lagged short-term interest rates, negatively correlated with lagged dividend-price ratio, and positively related to lagged yield spread. For equity allocation, all of the coefficients are statistically significant. Pension funds make decisions that appear to be in contrast with the model predictions, as they increase the exposure to equity precisely when the predictive variables signal low expected returns. The results show that the level of equity allocation is positively correlated with credit spread, which has the correct sign; however, the signification weakens when we add the control variables. The economic significance is also strong, for example a one percentage point increase in short term interest rate implies a 0.95 percentage point increase in strategic equity allocation. Similar magnitudes are found for yield spread and slightly magnitudes higher for credit spread. The highest magnitude of the coefficient is found for the dividend-price ratio; however, the standard deviation is also small for this variable. For example, a 0.30 (one standard deviation) increase in dividend price ratio implies a $3.15(0.3 \times-10.5)$ percentage point decrease in strategic asset allocation to equity.

Similarly, the results for the dividend-price ratio are statistically strongest for strategic bond and alternatives allocation. However, again the signs are inconsistent with theory. The signs remain the same and still statistically significant when we consider the pooled regression with additional control variables. The signs of the control variables are in accordance with expectations. The pension funds invest more conservatively when the percentage of retired members in the pension fund increases, in line with life-cycle theory. US funds and DB funds take more risk than the average fund in the sample. Lastly, larger pension funds are investing more in alternative asset classes as expected; however, there seems to be asset substitution from equities to alternatives by these pension funds.

The results discussed above suggest that pension funds are not able to invest taking into account macro-economic information that predicts future asset returns. One of the

\footnotetext{
${ }^{11}$ In unreported results, we repeat our analysis of Table 4.9 with actual asset allocation. The results are statistically weaker compared to Table 4.9, possibly because of portfolio movements due to realized returns. However, sign are consistent and the statistical significance of the dividend-price ratio is still found to be high.
} 
possible reasons could be that pension funds are constrained from fully benefiting from the changing economic conditions. Although they are aware of the possible benefits of shifting their portfolio weights, they are unable to invest like an unconstrained investor. For example, (Shin, 2010, Chapter 5) provides a theoretical model with mark-market accounting for pension funds in which demand for bonds by a liability hedging fund increases as the price of the bonds increases. This behavior is clearly not desirable from a market timing perspective.

\subsubsection{Active changes and asset allocation}

Pension funds are allowed to deviate from their strategic asset allocation in the short term in order to benefit from the changing investment scenario. ${ }^{12}$ This involves under or over weighting a particular asset class relative to the strategic benchmark, based on the market or economic considerations. Moreover, any change in the macro-economic scenario is reflected in changes in the predictive variables. Jank (2012) also carries out an analysis with changes in the variables. For this reason, we examine the relationship between the active changes (i.e. the explicit active investment decisions of the pension fund) and the lagged changes in predictive variables. The active change, denoted by Act $_{i, t+1}$, is the change in the weight of the risky asset due to active investment decisions by the fund managers. Following Calvet, Campbell, and Sodini (2009), we calculate Act $_{i, j, t}$, the active change for fund $i$ at time $t$, in asset class $j$, where $j$ is either equity, bonds or alternatives. It is calculated in the following way

$$
\operatorname{Act}_{i, j, t+1}=w_{i, j, t+1}-w_{i, j, t} \times\left(\frac{1+r_{i, j, t}}{1+r_{i, p, t}}\right)
$$

where $w$ and $r$ denote weights and returns respectively. Thus, the return of asset class $j$ for fund $i$ at time $t$ is denoted by $r_{i, j, t}$ and $r_{i, p, t}$ similarly denotes the return for the whole portfolio of the fund. We use the following regression model:

$$
\operatorname{Act}_{i, j, t}=\alpha+\beta_{1} \Delta Y_{t-1}+\beta_{2} \Delta(d-p)_{t-1}+\beta_{3} \Delta C S_{t-1}+\beta_{4} \Delta S p r_{t-1}+\theta_{i}+\epsilon_{i, t}
$$

As before, log dividend-price ratio is denoted by $(d-p)$, credit spread by $C S, Y$ is the nominal T-Bill rate. The coefficients of interest are $\beta_{1}, \beta_{2}, \beta_{3}$, and $\beta_{4}$. Finally, $\theta_{i}$ denotes the fund fixed effects. The results of regression (4.8) are presented in Table 4.10.

We find that the relationship between active changes in asset allocation and predictive variables is consistent with theoretical predictions. The coefficients for changes in T-bill rates and changes in yield spread are negative and statistically significant. There-

\footnotetext{
${ }^{12}$ For a brief description of the strategic portfolio and the tolerance around it for active decisions by the largest pension fund in the US, California Public Employees' Retirement System (CalPERS) see https: //www.calpers.ca.gov/docs/forms-publications/cerbt-strategy-1.pdf
} 


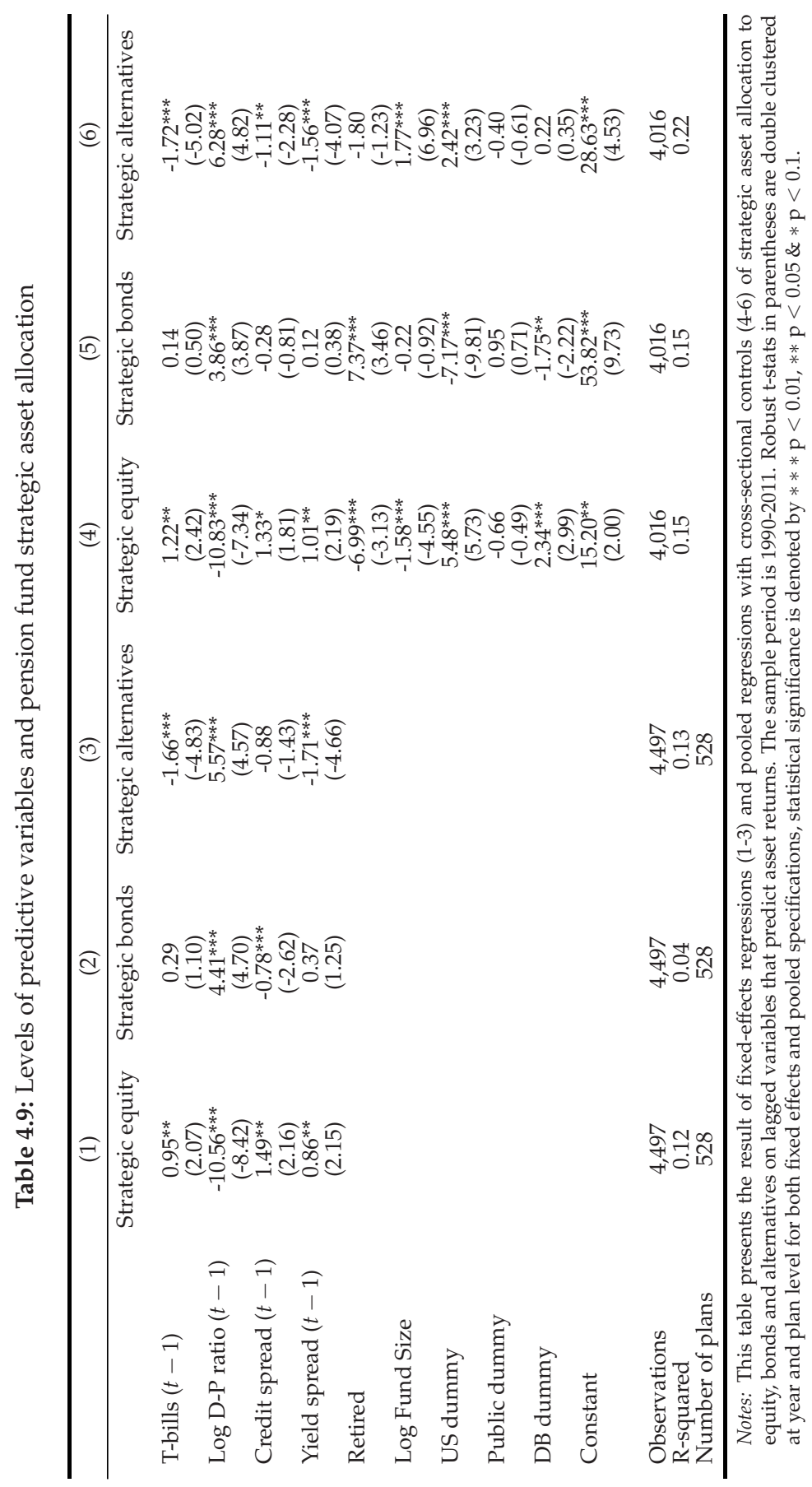


Table 4.10: Active changes in asset allocation and changes in predictive variables

\begin{tabular}{lccc}
\hline & $(1)$ & $(2)$ & $(3)$ \\
\hline & Active equity & Active bonds & Active alternatives \\
& & & \\
$\Delta$ T-bills $(t-1)$ & $-1.59^{* * *}$ & $1.50^{* * *}$ & 0.13 \\
& $(-2.84)$ & $(3.40)$ & $(1.16)$ \\
$\Delta$ Log D-P ratio $(t-1)$ & $11.72^{* * *}$ & $-10.44^{* * *}$ & $-1.68^{* *}$ \\
& $(3.87)$ & $(-3.88)$ & $(-2.03)$ \\
$\Delta$ Credit spread $(t-1)$ & -1.16 & $1.55^{* *}$ & -0.27 \\
& $(-1.46)$ & $(2.13)$ & $(-1.38)$ \\
$\Delta$ Yield spread $(t-1)$ & $-1.63^{* * *}$ & $1.38^{* * *}$ & $0.26^{* *}$ \\
& $(-2.81)$ & $(2.88)$ & $(2.05)$ \\
Observations & & & 2,564 \\
R-squared & 2,564 & 2,563 & 0.07 \\
Number of planid & 0.25 & 0.22 & 340 \\
\hline
\end{tabular}

Notes: This table presents the result of fixed-effects regressions of active change in asset allocation in equity, bonds, and alternatives on lagged changes in variables that predict asset returns. Active change measures the active investment decisions of the pension fund managers. The sample period is 19902011. Robust $\mathrm{t}$-stats in parentheses are double clustered at year and plan level, statistical significance is denoted by $* * * \mathrm{p}<0.01, * * \mathrm{p}<0.05 \& * \mathrm{p}<0.1$.

fore when the value of T-bills increases, then pension funds actively reduce the allocation to equities, consistent with theoretical prediction. Similarly, when the yield spread widens, the pension funds reduce their exposure to equity. The coefficient for dividendprice ratio is positive. When the change in the D-P ratio is positive, the pension funds increase their exposure to equity.

There are two possible explanations. First, when the changes in predictive variables change the actual portfolio of the pension funds, they actively trade in order to negate this mechanical movement, consistent with the market-timing motive. The changes in predictive variables can move the pension fund portfolio because the returns on various asset classes are correlated with predictive variables, as is clear from cross-correlations of residuals in Table 4.2. When the realized returns move the portfolio away from the optimal allocation, pension funds actively trade in order to rebalance back to the previous optimal. Secondly, pension funds can take into account the predictive variables in actively under or over-weighting the portfolio relative to the strategic portfolio. This 
implies that pension funds exploit the predictive variables in the short-term via active bets.

\subsection{Concluding remarks}

This chapter addresses two related questions regarding the portfolio allocation of pension funds. First, how have pension funds responded to the fundamental changes in the economy since the start of the low interest rate environment? Secondly and more generally, are pension funds able to time the market in a way that is consistent with finance literature on return predictability? It is important to determine whether the pension funds are able to exploit the changes in investment opportunities as long-term investors. Pension funds are also constrained investors, raising the question of whether this affects their ability to time the market and invest in a way that is consistent with economic theory.

We find that pension funds have responded strongly to this fundamental change in the economy, and there are interesting cross-sectional differences in their response. Overall, pension funds have reduced their allocation to the equity asset class and increase their allocation to fixed income and alternative asset classes. From a market timing perspective, this is inconsistent with the finance literature on return predictability, which would suggest an increase in equity allocation and reduction in fixed income exposure. More generally, we next analyze the response of pension funds to other variables that have been found to predict asset returns. We find that pension funds are largely unable to time the market and miss out on benefiting from changes in the investment opportunity set. One of the possible reasons is that various constraints are binding on the pension funds and prevent them from investing as an efficient investor.

Next, analyzing the active changes of pension funds net of changes due to realized returns we find that pension funds actively rebalance the allocation to neutralize the changes in actual portfolio reflecting changes in predictive variables. Although pension funds are long-term investors, future work could analyze a shorter horizon response of the pension funds to changes in predictive variables. However, we are unable to do so due to the data only being available annually. These results raise interesting questions about the constraints pension funds face when investing. It would be a question for future research to test which specific short-term constraints on pension funds, for example regulations or short term liability hedging motives, contribute the most to under-performance of the pension funds and restrict them from exploiting the benefits from changes in the investment opportunities set. 


\subsection{Appendix}

\subsubsection{Data sources}

To calibrate the VAR model of Campbell, Chan, and Viceira (2003), we use post-war quarterly data for the US stock market as in their paper. However, our data extends from the second quarter of 1952 to the fourth quarter of 2014, and therefore includes the special macro-economic conditions of low interest rates since 2007-08. We obtain most of our data from the Board of Governors of the Federal Reserve System (FRED) and Wharton Research Data Services (WRDS). The three assets are short-term ex post real interest rates, excess stock returns and excess bond returns. The short-term ex post real interest rates are constructed as log lagged yield on three-Month Treasury Bill (obtained from FRED website) minus the log Inflation (obtained from WRDS). The excess stock returns are constructed as the difference between the log Value-Weighted Return-including dividends on NYSE/AMEX/NASDAQ (obtained from WRDS) and the log three-Month Treasury Bill (obtained from FRED). Lastly, the excess bond return is constructed as the difference between log five Year Bond Returns (obtained from WRDS) and log three-Month Treasury Bill (again obtained from FRED). As the data on Yield on 5-year bond from WRDS is only available after quarter one of 1961, we prepend that with data from Campbell, Chan, and Viceira (2003) for 1952 Quarter two to 1960 Quarter four.

The return predictive variables that we use are short-term nominal interest rate, the dividend-price ratio, the yield spread and lastly we add credit spread as an additional state variable as in Hoevenaars, Molenaar, Schotman, and Steenkamp (2008). The short-term nominal interest rate is log yield on three-Month Treasury Bill (obtained from FRED). To construct the dividend-price ratio, we follow Campbell, Chan, and Viceira (2003). First, a dividend payouts series is constructed using the Value-Weighted Return including dividends and price index series Value-Weighted Return excluding dividends (both obtained from WRDS). The dividend series is then the sum of dividends payments over the past year implied from the monthly data. The dividend-price ratio is then simply the log of dividend minus the price index. The log yield spread is constructed as the difference between the log yield on a five-year bond and the log yield on the three-month Treasury bill (both obtained from the FRED). Lastly, the credit spread is constructed as the difference between log Moody's Seasoned Baa Corporate Bond Yield (DAAA) and log yield on ten Year Treasury Constant Maturity Rate (both obtained from FRED).

For the regression analysis we make use of annual macro data from 1990 to 2011. The data is also international. For this reason and for reasons of comparison with other studies, the data used for regression analysis is slightly different than the data for the VAR model calibration. We use quarterly data to model the VAR because we have more 
data points to estimate our model, so there is less model uncertainty about the parameter and this is also consistent and comparable with other studies like Campbell, Chan, and Viceira (2003); Hoevenaars, Molenaar, Schotman, and Steenkamp $(2008,2014)$.

The domestic nominal yield is the Interest Rates, Government Securities, Treasury Bills series for Canada, United States and France (as an approximation for the Euro area). All these series are obtained from FRED database; the original source is International Monetary Fund (IMF) International Financial Statistics. The dividend-price ratio is constructed from the "Irrational Exuberance" data obtained from Robert Shiller's website. The log dividend-price ratio is the log of average dividend in the preceding twelve months divided by the S\&P composite price. The yield spread is constructed as the difference between the Moody's Seasoned Aaa Corporate Bond Yield and Moody's Seasoned Baa Corporate Bond Yield (both obtained from FRED). The long-term interest rate is constructed using the Long-Term Government Bond Yields: 10-year: Main (Including Benchmark) series for Canada, United States and France. All these series are obtained from FRED; the original source is Organisation for Economic Co-operation and Development (OECD) Main Economic Indicators. The yield spread is then the difference between the domestic long-term and domestic short-term interest rates.

\subsubsection{Optimal asset allocation with liabilities}

Let the VAR model be given by

$$
z_{t+1}=\Phi_{0}+\Phi_{1} z_{t}+v_{t+1}
$$

where

$$
z_{t}=\left(\begin{array}{c}
r_{t b, t} \\
s_{t} \\
x_{t}
\end{array}\right)
$$

The excess returns on asset $i$ are denoted by $x_{i, t}=r_{i, t}-r_{t b, t}$ which are calculated in excess of return on t-bills $r_{t b, t}$ and the state variables are given by $s_{t}$. Assuming that we have CRRA preferences on the future funding ratio of the pension fund with riskaversion parameter $(\gamma)$ and with $\tau$ period return with fixed horizon specific portfolio weights, given that pension funds rebalance to the initial weight at the end of the period and at some future point in time $(t+\tau)$, if the investor chooses to invest $\alpha_{t}$ in the risky assets, then the portfolio return is given by the following log-linear approximation using the Taylors series expansion, that is

$$
V_{t}^{(\tau)}=\max _{\alpha_{t}^{(\tau)}} \mathbb{E}\left[\frac{F_{t+\tau}^{1-\gamma}}{1-\gamma}\right]
$$


Hoevenaars, Molenaar, Schotman, and Steenkamp (2008) show that in this case the optimal portfolio choice for an asset-liability investor is given by

$$
\alpha_{t, L}^{(\tau)}=\frac{1}{\gamma}\left(\left(1-\frac{1}{\gamma}\right) \Sigma_{A A}^{(\tau)}+\frac{1}{\gamma} \Sigma_{A A}\right)^{-1}\left(\mu_{t, A}^{(\tau)}+\frac{1}{2} \sigma_{A}^{2}-(1-\gamma) \sigma_{A L}^{(\tau)}\right)
$$

whereas the the same for asset only investor is given by

$$
\alpha_{t, A O}^{(\tau)}=\frac{1}{\gamma}\left(\left(1-\frac{1}{\gamma}\right) \Sigma_{A A}^{(\tau)}+\frac{1}{\gamma} \Sigma_{A A}\right)^{-1}\left(\mu_{t, A}^{(\tau)}+\frac{1}{2} \sigma_{A}^{2}+(1-\gamma) \sigma_{A r}^{(\tau)}\right)
$$

From (4.9), we can calculate

$$
\mu_{t}^{(\tau)}=\mathbb{E}_{t}\left(z_{t+1} \ldots z_{t+\tau}\right)=\left[\sum_{j=1}^{\tau} \sum_{i=0}^{j-1} \Phi_{1}^{i}\right] \Phi_{0}+\left[\sum_{j=1}^{\tau} \Phi_{1}^{j}\right] z_{t}
$$

Note that the conditional mean depends on the state variables. Finally, the conditional variance is given by

$$
\Sigma^{(\tau)}=\operatorname{Var}_{t}\left(z_{t+1} \ldots+z_{t+\tau}\right)=\operatorname{Var}_{t}\left[\sum_{j=1}^{\tau}\left[\sum_{i=0}^{\tau-j} \Phi_{1}^{i} v_{t+j}\right]\right]=\sum_{j=1}^{\tau}\left[\left(\sum_{i=0}^{j-1} \Phi_{1}^{i}\right) \Sigma\left(\sum_{i=0}^{j-1} \Phi_{1}^{i}\right)^{\prime}\right]
$$

From these matrices, we can select the relevant rows and columns relevant for $x_{t}$ for portfolio choice and calculate $\Sigma_{A A}^{(\tau)}, \Sigma_{A A}$ and $\mu_{t, A}^{(\tau)}$ using a selection matrix $H$ that selects the $x_{t}$ relevant row and columns from the whole matrix. Note that this means

$$
\boldsymbol{\alpha}_{t, L}^{(\tau)}=\tilde{A}_{0}+\tilde{A}_{1} z_{t}
$$

Moreover, for the asset-only investor the optimal portfolio choice is

$$
\boldsymbol{\alpha}_{t, A O}^{(\tau)}=\tilde{A}_{2}+\tilde{A}_{1} z_{t}
$$

where $\tilde{A}_{0}, \tilde{A}_{1}$ and $\tilde{A}_{2}$ are constant functions of estimated parameters of the VAR(1) model and the risk aversion parameter. The coefficient $\tilde{A}_{1}$ measures the sensitivity of optimal portfolio allocation to changes in the state variables. Additionally, the sensitivity $\tilde{\boldsymbol{A}}_{1}$ does not change between investment as an asset-liability or asset only investor.

\subsubsection{Figures}




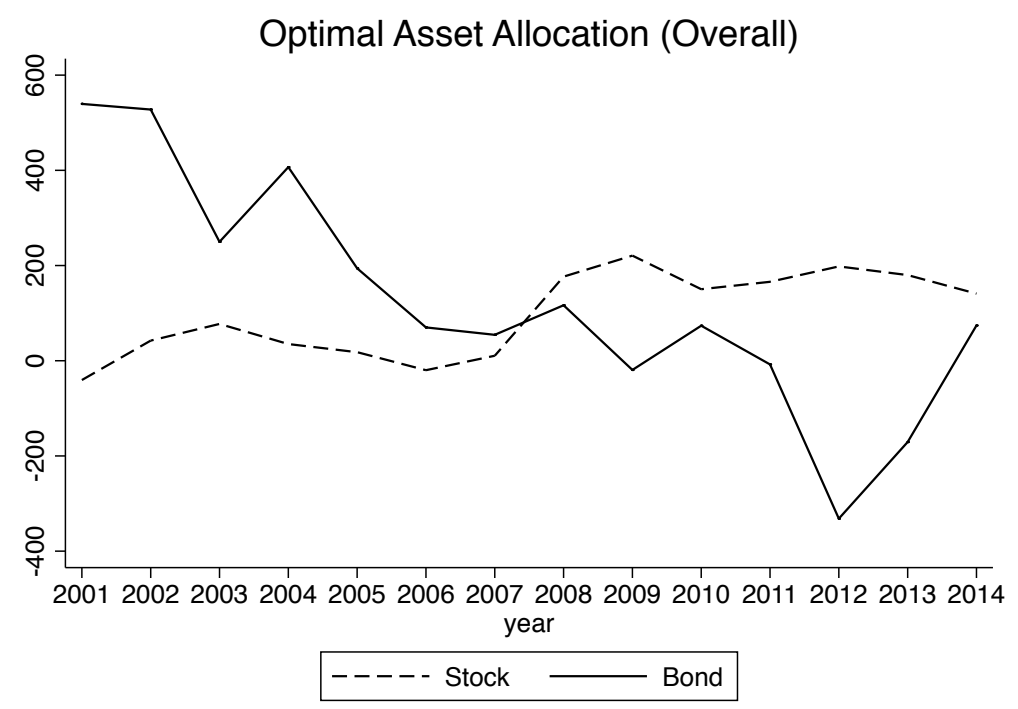

Figure 4.3: The model implied optimal strategic asset allocation and actual allocation of pension funds before and since the low-interest rate environment. The model implied strategic asset allocation is calculated from Campbell, Chan, and Viceira (2003) model. The weight in stock and bond is average of the four quarters in a given year. The time discount factor equals 0.92 annually, the relative risk aversion is equal to 5 and the elasticity of inter-temporal substitution is 1 . 


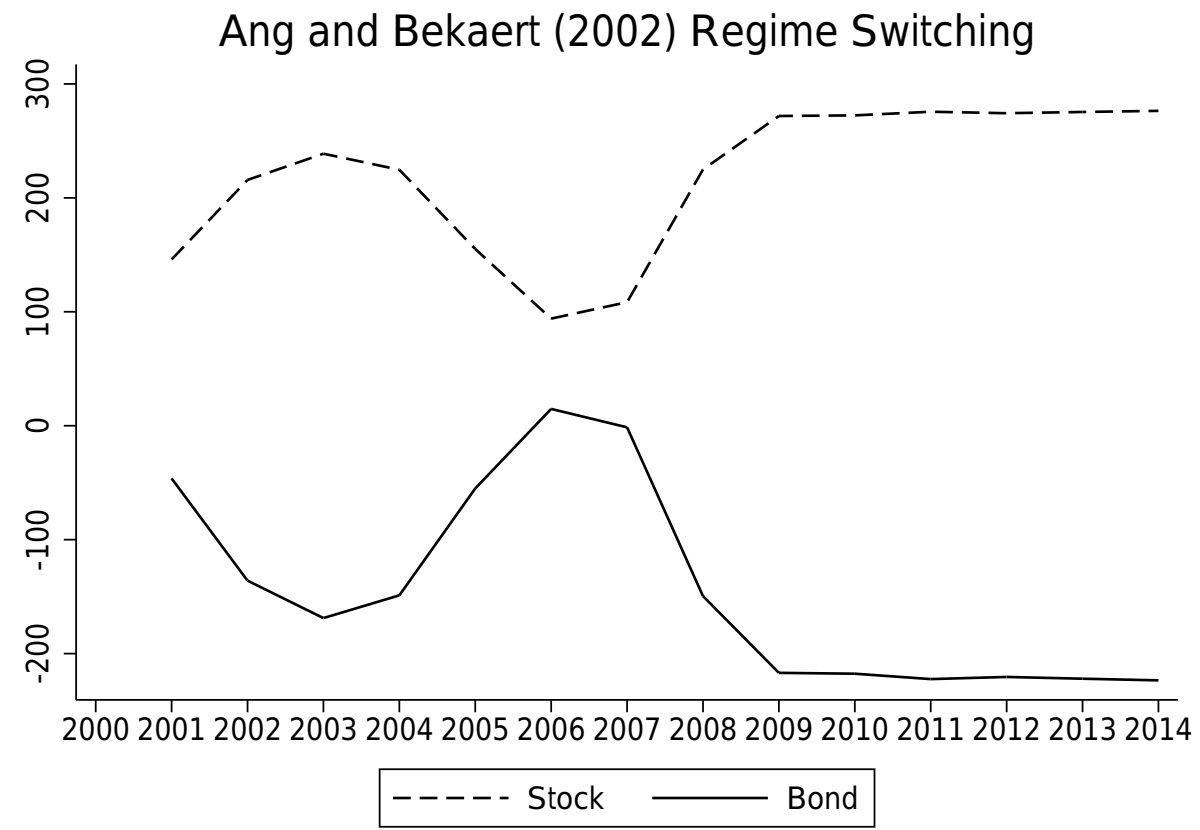

Figure 4.4: Asset allocation in a regime switching model (Ang and Bekaert, 2002a). This figure replicates model I of the Inquire version of their paper which incorporates predictability of returns, extended to the end of 2014. The values in the second panel are averages over year. 



\section{Chapter 5}

\section{Conclusion}

This dissertation is a compilation of three related studies on pension funds, and in particular on pension contracts, fund management and risk management. The chapters concentrate on topical issues currently facing pension funds, namely: how to organize new pension contracts, how to invest for the long term and how to respond to the historically low interest rates prevalent in the aftermath of the 2008 financial crisis. The findings of the chapters contribute to our understanding of these practical issues, and can aid pension funds, the pension regulators and individuals themselves in being better prepared to face these challenges.

\subsection{Summary of findings}

The second chapter evaluates the benefits of intergenerational risk-sharing in a pension system without any guarantees. More and more employers around the world are concerned about what corporate pension guarantees mean for the balance sheet of the company. Many companies have gone bankrupt due to overwhelming pension liabilities. Accordingly, many companies are moving from Defined Benefit (DB) to Defined Contribution (DC) for just this reason. When an employer does not want to carry the risk of the pension, employees can share the risk among themselves. One of the main findings of the chapter is that risk-sharing is welfare improving even without any sort of employer guarantee.

In particular, I analyze a collective defined contribution (CDC) pension fund which aims at intergenerational risk sharing among different age cohorts using a return smoothing mechanism. Using a utility based framework, I find that approximately one third of unexpected return shocks should be passed on directly to all the cohorts in the year the shock occurs, by means of the smoothing mechanism. I demonstrate that risk-sharing implemented in this way is welfare improving compared to a plan with no risk sharing, and is more sustainable compared to a defined benefit pension fund. Additionally, 
I show that the asset allocation of such a pension fund automatically corresponds to the life-cycle portfolio choice theory.

In the next chapter, I move on to analyze the investments of pension funds, and evaluate their long-term mindset. This question is constantly raised at academic and practitioner conferences, as there is strong potential for increasing the returns of individuals' saving for retirement. I consider a long-horizon investor as an investor that is not influenced by recent returns on the portfolio in setting investment objectives. This investor rebalances any substantial changes to the portfolio due to market movements. This means that the investor is not "moving with the market", which could be a buylow and sell-high strategy and hence harmful for investment performance.

So, the main question boils down to: how does the portfolio of a long-term investor like a pension fund change relative to the stated strategic portfolio? I investigate the dynamics of pension fund portfolios using an international database of pension funds that spans over twenty years, and I focus on portfolio rebalancing. I find that a significant proportion of the change in the weight of equity is related to passive change in the portfolio due to realized equity returns. Moreover, pension funds engage in asymmetric rebalancing, as they rebalance poorly when the stock market is doing well but strongly when the stock market is doing badly. Actual changes in the equity portfolio only partially reflect strategic changes. I also study cross-sectional differences in rebalancing. The results indicate that US and defined benefit pension funds rebalance less. Moreover, external managers and active managers can be identified as the major source of poor rebalancing. Lastly, as between asset classes, pension funds are more passive in alternative investments.

Continuing the analysis of the investments of pension funds in the next chapter, I look at the effects of a low-interest rate environment on pension fund investments. Interest rates are important for pension funds because they serve as an indicator of future economic activity and thus of the performance of multi-asset class pension fund portfolios. Moreover, long-term interest rates determine the market value of pension liabilities. Thus, a decrease in long-term interest rates depresses the funding ratio of pension funds, ceteris paribus. Interest rates have been exceptionally low since 2008 and this has led to a significant change in investment opportunities. For this reason, I try to answer the question of whether this has led to any substantial changes in pension fund portfolios and whether there are any insights from the academic literature on how to overcome the challenges posed by low interest rates.

I analyze changes in the portfolio policies of pension funds since the start of the current low interest rate environment. I find that they have on average reduced the allocation to equity and increased the allocation to fixed income, which is inconsistent with the literature on strategic asset allocation. Next, more generally, I investigate empirically the relationship between variables that predict asset returns and portfolio 
allocation in levels as well as changes. I find that the dividend-price ratio shows the strongest relationship among other variables. However, I find a negative relationship as opposed to a positive one as predicted by the literature. Overall, the results suggest that pension funds are unable to incorporate predictive information in their strategic asset allocation, but they do take active decisions by under or over-weighting their portfolio relative to the stated strategic portfolio in order to benefit from time-varying investment opportunities. Analyzing these results in the context of the results of Chapter 3, actively managed portfolios that make market timing decisions also appear to be chiefly responsible for the procyclical investment behavior. Given that more and more pension risks are being transferred to employees from employers, via e.g. CDC contracts discussed in Chapter 2, these results points towards causes of major future setbacks in retirement.

\subsection{Future research}

These are exciting times for research in pension finance. Any outstanding research has real potential for impacting lives in a substantive and positive way. Moreover, as the coverage of pensions increases in developing countries, the influence of pension research will also increase. Results of the research can help formulate better governance regulations, which need to evolve as quickly as the pension systems themselves are evolving.

There are multiple directions in which the research presented in this dissertation can be extended. In analyzing the collective defined contribution (CDC) system, I have assumed that the introduction of a CDC pension contract would mean that the firm does not have any liability in relation to underfunding of its pension fund. One interesting avenue would however be to introduce a "soft" guarantee. If the pension fund of a company is performing very poorly, the employees may have an incentive to leave the company. This is because they will not expect to receive a big part of their salary in the future in the form of their pension payments. This suggests that although the firm does not have any explicit obligation in times of pension fund underfunding, it may nonetheless in practice have to help the fund out regardless. This type of question can be tackled in a theoretical model. Another aspect is that the analysis in this dissertation is set in a partial equilibrium framework. This is a simplifying assumption, but clearly pension funds form a big part of the economy and equilibrium considerations are important. It would therefore be worth exploring how the results will hold in equilibrium.

It is clear that there are multiple interesting possibilities for further examination regarding pension fund investments, which can build on the results of chapter three and four. First, regulations for pension funds generally do not receive as much attention as 
those for the banks. However, pension fund regulations have a long way to go towards facilitating, or at minimum not hindering, pension funds in investing optimally for the long term. Further analysis is required about whether and/or how funding and other regulatory requirements are encouraging pro-cyclical investment behavior. Secondly, it has been well understood that pension funds have become a large part of the economy. However, their potential for long-term macroeconomic effects on the wider economy has not been fully understood. This is a promising area for both theoretical and empirical research. Lastly, I have considered pension funds separately from the private wealth of an individual. It would be worth analyzing pension fund wealth in combination with personal savings, social security benefits and any additional private savings in a retirement account, which together will form the total wealth of an individual in retirement. 


\section{Chapter 6}

\section{Valorisation}

This dissertation contributes to the understanding of the design of collective pension funds and their investment choices. Therefore, the results of this dissertation are of direct economic relevance to pension funds, pension regulators, policy makers and individuals as the ultimate stakeholders. ${ }^{1}$

Pension funds are currently facing unintended consequences of low interest rates. Market interest rates are important for them, as they go into the assumptions that they make for their liabilities and asset allocations. Low interest rates increase the market value of liabilities of the pension funds, which decreases their funding ratio, the ratio between the market value of their asset and liabilities. Pension funds can respond to this special macroeconomic situation by changing their asset allocation to change the return on the assets. Chapter 4 of the thesis contributes to the understanding of what pension funds have done since the start of the low interest rate environment and what they should they have done according to the strategic asset allocation models.

Governments typically play a significant role in a country's pension system. They are fully responsible for the first pillar pensions, but also have a large role in providing a legal \& tax framework and supervision. Therefore, they are concerned by the well-being of the pension funds. ${ }^{2}$ Organizations like OECD that frequently advice governments have also been interested in the effects of low interest rates on pension funds. For example Antolin, Schich, and Yermo (2011) discuss how protracted low interest rates could affect both the assets and the liabilities of the pension funds. They hypothesize that pension funds affected by lower interest rates will seek higher yields via riskier investments. Moreover, interest rate hedging activities by pension funds

\footnotetext{
${ }^{1}$ The pension system of a country can be thought of comprising three pillars: a government provided basic old age pension, occupational pension schemes, and private savings. This thesis focuses on the second pillar pensions i.e. the occupational pension schemes.

${ }^{2}$ In the Netherlands, junior social affairs minister Jetta Klijnsma has expressed concerns about the effect on low interest rates on pension funds due to European Central Banks decision to cut interest rates further and benefits cuts are expected due to decline in funding ratios.
} 
can put further downward pressure on bond yields. Chapter 4 adds to this discussion by showing that pension funds have chosen to reduce their investment risk since the start of low interest rate environment. More generally, we provide the insights on the direction of response using models in the strategic asset allocation literature that incorporate macroeconomic variables in addition to the short-term interest rate. The results provide empirical evidence on how institutional investors like pension funds actually incorporate macroeconomic news in their portfolio as compared to traditional models.

The pension fund industry is characterized by its focus on long-term decision-making approach for investments. This long-term focus is largely driven by their liability structure. Thanks to long investment horizons, they should be able to easily withstand short-term uncertain market conditions. However, there is a concern from the regulators as well as pension fund managers themselves that pension funds tend to invest for short-term performance and in line with the asset prices. For example a paper by International Monetary Fund (IMF) researchers, Papaioannou, Park, Pihlman, and Van der Hoorn (2013), discusses the procyclical investment behavior of institutional investors including pension funds. They state that the market volatility driven by procyclicality can have detrimental effect on the real economy. Chapter 3 contributes to the discussion in this area, where the analysis is focused on portfolio rebalancing to analyze pension funds' response to realized returns and hence evaluates their procyclicality. An institutionalized rebalancing strategy by pension funds can be one of the ways to minimize procylicality and promote investment for the long term. In this way, pension funds can bring stability to markets and earn risk premiums not available to short-term investors.

The estimates of rebalancing that we find for pension funds in the analysis of chapter 3 are higher than the estimates of individual investors found in the literature. However, the rebalancing varies over time and pension funds follow asymmetric rebalancing. They rebalance more when stock market is performing poorly but less when it is performing well. Moreover, actively managed equity and externally managed assets can be identified as a major source of rebalancing coefficient observed in the baseline results. These results can assist pension funds in creating and following an institutionalized rebalancing framework. This can help pension funds profit from the meanreverting behavior of asset prices and benefit from buy low and sell high dynamics.

The Collective Defined Contribution (CDC) discussed in Chapter 2 adds to the current public debate on pension system reform in the Netherlands but also, for example, in the UK and Canada. These type of pension funds have already been introduced or are likely to be introduced in the near future for many public as well as private pension funds in these countries. With the decline of traditional Defined Benefit (DB) pension funds, they are now emerging as a viable alternative. They come in many shapes and forms however, the main idea is that the benefits of the participants are allowed to be adjusted with the returns on pension fund assets. This gives rise to the question as to 
how exactly these adjustments can be applied. Chapter 2 discusses one way to incorporate the adjustment: by smoothing out returns applied to the pension rights over many periods.

The sustainability of these schemes is very important from the point of view of both regulators and participants. Chapter 2 points out that there is tradeoff between high risk sharing and low risk sharing. High level of risk sharing is welfare improving from a utility perspective but increases the risk that the pension fund will become severely underfunded. This is because the underfunding of the fund is not passed on to the participants quickly enough. This raises questions about the sustainability of the pension funds as the future generations may refuse to take part in an underfunded system, where a big portion of their contribution will be used to pay benefits to current retirees. Therefore, the regulators have to find a balance for pension funds in a way that allows for adjustment in accruals of pension rights and promotes sustainability of the pension system as a whole but also protects the interests of future generations. 



\section{References}

ABEL, A. B. (1990): "Asset prices under habit formation and catching up with the Joneses," The American Economic Review, pp. 38-42.

Addoum, J. M., J. H. VAN Binsbergen, AND M. W. Brandt (2010): “Asset Allocation and Managerial Assumptions in Corporate Pension Plans," Available at SSRN 1710902.

Altunbas, Y., L. GAmbaCorTA, AND D. MARQues-IbANEZ (2012): “Do bank characteristics influence the effect of monetary policy on bank risk?," Economics Letters, 117(1), 220-222.

Andonov, A. (2014): Pension fund asset allocation and performance. PhD dissertation, Maastricht University.

Andonov, A., R. BAuer, AND K. Cremers (2012): “Can large pension funds beat the market? Asset allocation, market timing, security selection and the limits of liquidity," .

Andonov, A., R. BAuer, AND M. Cremers (2013): "Pension fund asset allocation and liability discount rates: Camouflage and reckless risk taking by US public plans?," SSRN.

ANG, A., AND G. BEKAERT (2002a): "How regimes affect asset allocation," .

(2002b): “Regime switches in interest rates," Journal of Business \& Economic Statistics, 20(2), 163-182.

(2007): "Stock return predictability: Is it there?," Review of Financial studies, 20(3), 651-707.

ANG, A., M. W. BRAndt, AND D. F. Denison (2014): "Review of the active management of the norwegian government pension fund global," External Report to the Norwegian Ministry of Finance.

ANG, A., AND K. N. KJAER (2012): "Investing for the Long Run," .

ANTOLIN, P., S. SCHICH, AND J. YERMO (2011): "The economic impact of protracted low interest rates on pension funds and insurance companies," OECD Journal: Financial Market Trends, 2011(1), 237-256.

AVRAMOV, D., L. BARRAS, AND R. KOSOWSKI (2013): "Hedge fund return predictability under the magnifying glass," Journal of Financial and Quantitative Analysis, 48(04), 1057-1083.

BALVERS, R., Y. WU, AND E. Gilliland (2000): "Mean reversion across national stock markets and parametric contrarian investment strategies," Journal of Finance, pp. 745-772.

BAuer, R., K. CRemers, AND R. Frehen (2010): "Pension fund performance and costs: Small is beautiful," Available at SSRN 965388.

Bauer, R., R. HoevenaArs, AND T. Steenkamp (2006): “Asset liability management," Oxford Handbook of Pensions and Retirement Income, pp. 417-440. 
BeEtSma, R. M., AND L. Bovenberg (2009): "Pensions and Intergenerational Risk-sharing in General Equilibrium," Economica, 76(302), 364-386.

BeEtsma, R. M., AND A. Bucciol (2015): "Risk reallocation in defined-contribution funded pension systems," Macroeconomic Dynamics, 19(01), 22-57.

BEETSMA, R. M., W. E. RomP, AND S. J. Vos (2012): “Voluntary participation and intergenerational risk sharing in a funded pension system," European Economic Review, 56(6), 1310-1324.

(2013): “Intergenerational Risk Sharing, Pensions, and Endogenous Labour Supply in General Equilibrium*," The Scandinavian Journal of Economics, 115(1), 141-154.

BENARTZI, S., AND R. H. ThALER (2001): “Naive diversification strategies in defined contribution saving plans," American economic review, pp. 79-98.

BikKer, J. A., D. Broeders, AND J. De Dreu (2010): "Stock market performance and pension fund investment policy: rebalancing, free float, or market timing," International Journal of Central Banking, $6(2), 53-79$.

Bikker, J. A., D. W. Broeders, D. A. Hollanders, AND E. H. Ponds (2012): “Pension Funds Asset Allocation and Participant Age: A Test of the Life-Cycle Model," Journal of Risk and Insurance, 79(3), 595-618.

Binsbergen, V., H. Jules, M. W. Brandt, AND R. S. Koijen (2008): “Optimal decentralized investment management," The Journal of Finance, 63(4), 1849-1895.

Blake, D., B. N. Lehmann, AND A. Timmermann (1999): “Asset allocation dynamics and pension fund performance," The Journal of Business, 72(4), 429-461.

Blake, D., A. G. Rossi, A. Timmermann, I. Tonks, AND R. Wermers (2013): “Decentralized investment management: Evidence from the pension fund industry," The Journal of Finance, 68(3), 1133-1178.

Blome, S., K. Fachinger, D. Franzen, G. Scheuenstuhl, And J. Yermo (2007): “Pension fund regulation and risk management: results from an ALM optimisation exercise," OECD Working Papers on Insurance and Private Pensions, (08).

Bodie, Z., R. C. MERTON, AND W. F. SAMUELSON (1992): “Labor supply flexibility and portfolio choice in a life cycle model," Journal of Economic Dynamics and Control, 16(3), 427-449.

Bonenkamp, J., A. Meijdam, E. Ponds, AND E. Westerhout (2014): “Reinventing Intergenerational Risk Sharing," Netspar Panel Paper, 40.

BovenberG, L., R. Koijen, T. Nijman, And C. Teulings (2007): "Saving and investing over the life cycle and the role of collective pension funds," De Economist, 155(4), 347-415.

BROWN, J., AND J. Poterba (2006): “Household ownership of variable annuities," Discussion paper, National Bureau of Economic Research.

BROWN, J. R., N. LIANG, AND S. WeisBenNER (2007): “Individual account investment options and portfolio choice: Behavioral lessons from 401 (k) plans," Journal of Public Economics, 91(10), 1992-2013.

BROWN, J. R., AND S. J. WeisbenNeR (2014): “Why do individuals choose defined contribution plans? Evidence from participants in a large public plan," Journal of Public Economics, 116, 35-46. 
BROWN, K. C., L. GARLAPPI, AND C. TIU (2010): “Asset allocation and portfolio performance: Evidence from university endowment funds," Journal of Financial Markets, 13(2), 268-294.

Calvet, L. E., J. Y. CAmpbell, AND P. Sodini (2009): “Fight or flight? Portfolio rebalancing by individual investors," The Quarterly Journal of Economics, 124(1), 301-348.

CAMPBELL, J. Y. (1987): “Stock returns and the term structure," Journal of financial economics, 18(2), 373-399.

CAMPbell, J. Y., Y. L. ChAN, AND L. M. ViCeira (2003): “A multivariate model of strategic asset allocation," Journal of financial economics, 67(1), 41-80.

CAMPBell, J. Y., AND R. J. Shiller (1988): “The dividend-price ratio and expectations of future dividends and discount factors," Review of financial studies, 1(3), 195-228.

CAMPBell, J. Y., AND L. M. ViceiRA (2002): Strategic asset allocation: portfolio choice for long-term investors. Oxford University Press.

CAmpbell, J. Y., AND M. YOGO (2006): “Efficient tests of stock return predictability," Journal of financial economics, 81(1), 27-60.

Chalmers, J., A. Kaul, AND B. Phillips (2013): "The wisdom of crowds: Mutual fund investors aggregate asset allocation decisions," Journal of Banking \& Finance.

Chen, D. H., R. M. BeEtSma, E. H. Ponds, AND W. E. RomP (2014): “Intergenerational risk-sharing through funded pensions and public debt," Journal of Pension Economics and Finance, pp. 1-33.

CHOI, J., D. LAIBSON, AND B. MADRIAN (2011): “\$100 bills on the sidewalk: Suboptimal investment in 401 (k) plans," Review of Economics and Statistics, 93(3), 748-763.

Cochrane, J. H. (2008): “The dog that did not bark: A defense of return predictability," Review of Financial Studies, 21(4), 1533-1575.

Cochrane, J. H., AND M. Piazzesi (2005): “Bond Risk Premia,” American Economic Review, 95(1), 138160.

CUI, J., F. JONG, AND E. PONDS (2011): “Intergenerational risk sharing within funded pension schemes," Journal of Pension Economics and Finance, 10(01), 1-29.

Curcuru, S. E., C. P. Thomas, F. E. WARnOcK, AND J. Wongswan (2011): “US International Equity Investment and Past and Prospective Returns.," American Economic Review, 101(7), 3440-55.

Dasgupta, A., A. Prat, AND M. Verardo (2011): “The price impact of institutional herding," Review of Financial Studies, p. hhq137.

DiRIS, B., F. PALM, AND P. SCHOTMAn (2014): “Long-term strategic asset allocation: an out-of-sample evaluation," Management Science.

DRUCKeR, P. (1976): “The Unseen Revolution: How Pension Socialism Come to America,” .

FAMA, E. F., AND K. R. FRENCH (1988a): “Dividend yields and expected stock returns," Journal of financial economics, 22(1), 3-25.

(1988b): "Permanent and temporary components of stock prices," The Journal of Political Economy, pp. 246-273. 
(1989): "Business conditions and expected returns on stocks and bonds," Journal of financial economics, 25(1), 23-49.

Forman, J. B., AND M. J. SABIN (2014): “Tontine Pensions: A Solution to the State and Local Pension Underfunding Crisis," University of Pennsylvania Law Review, 163.

Goecke, O. (2013): "Pension saving schemes with return smoothing mechanism," Insurance: Mathematics and Economics, 53(3), 678-689.

GolLieR, C. (2008): "Intergenerational risk-sharing and risk-taking of a pension fund," Journal of Public Economics, 92(5-6), 1463-1485.

Grosen, A., AND P. Lochte Jorgensen (2000): "Fair valuation of life insurance liabilities: The impact of interest rate guarantees, surrender options, and bonus policies," Insurance: Mathematics and Economics, 26(1), 37-57.

Guillén, M., P. L. JørGensen, AND J. P. Nielsen (2006): “Return smoothing mechanisms in life and pension insurance: Path-dependent contingent claims," Insurance: Mathematics and Economics, 38(2), 229-252.

Hoevenaars, R. P., R. D. MolenaAr, P. C. Schotman, And T. Steenkamp (2008): “Strategic asset allocation with liabilities: Beyond stocks and bonds," Journal of Economic Dynamics and Control, 32(9), 2939-2970.

HoevenaArs, R. P., R. D. MolenaAr, P. C. Schotman, And T. Steenkamp (2014): “Strategic Asset Allocation For Long-Term Investors: Parameter Uncertainty And Prior Information," Journal of Applied Econometrics, 29(3), 353-376.

IBBOTSON, R. G., AND P. D. KAPLAN (2000): “Does asset allocation policy explain 40, 90, or 100 percent of performance?," Financial Analysts Journal, pp. 26-33.

JANK, S. (2012): "Mutual fund flows, expected returns, and the real economy," Journal of Banking \& Finance, 36(11), 3060-3070.

JegadeEsh, N., AND S. TitmAn (1993): "Returns to buying winners and selling losers: Implications for stock market efficiency," The Journal of finance, 48(1), 65-91.

JIANG, G. J., T. YAO, AND T. YU (2007): “Do mutual funds time the market? Evidence from portfolio holdings," Journal of Financial Economics, 86(3), 724-758.

Koijen, R. S., T. E. Nijman, AND B. J. Werker (2011): “Optimal Annuity Risk Management,” Review of finance, 15(4), 799-833.

KREPS, D. M. (1990): A course in microeconomic theory. Harvester Wheatsheaf New York.

Lowenstein, R. (2008): While America aged: how pension debts ruined General Motors, stopped the NYC subways, bankrupted San Diego, and loom as the next financial crisis. Penguin.

LuSARDI, A., AND O. MitchelLI (2007): "Financial literacy and retirement preparedness: Evidence and implications for financial education," Business Economics, 42(1), 35-44.

LUTTMER, E. F. (2005): “Neighbors as negatives: Relative earnings and well-being," The Quarterly Journal of Economics, 120(3), 963-1002. 


\section{REFERENCES}

LYNCH, A. W., AND P. BALDUZZI (2000): "Predictability and transaction costs: The impact on rebalancing rules and behavior," The Journal of Finance, 55(5), 2285-2309.

MAdDAlOnI, A., AND J.-L. PeYdRÓ (2011): “Bank risk-taking, securitization, supervision, and low interest rates: Evidence from the Euro-area and the US lending standards," Review of Financial Studies, 24(6), 2121-2165.

Merton, R. C. (1969): "Lifetime portfolio selection under uncertainty: The continuous-time case," The review of Economics and Statistics, pp. 247-257.

(1971): "Optimum consumption and portfolio rules in a continuous-time model," Journal of economic theory, 3(4), 373-413.

MilevsKY, M. A. (2014): "Portfolio choice and longevity risk in the late seventeenth century: a reexamination of the first English tontine," Financial History Review, 21(03), 225-258.

MOHAN, N., AND T. ZHANG (2014): "An analysis of risk-taking behavior for public defined benefit pension plans," Journal of Banking \& Finance, 40, 403 - 419.

Munnell, A. H., J.-P. AubrY, AND L. Quinby (2011): "Public pension funding in practice," Journal of Pension Economics and Finance, 10(02), 247-268.

NordHAus, W. D. (2007): "A Review of the" Stern Review on the Economics of Climate Change"," Journal of Economic Literature, pp. 686-702.

NOVY-MARX, R., AND J. RAUH (2011): "Public pension promises: how big are they and what are they worth?," The Journal of Finance, 66(4), 1211-1249.

NOVY-MARX, R., AND J. D. RAUH (2009): “The liabilities and risks of state-sponsored pension plans," The Journal of Economic Perspectives, pp. 191-210.

(2014): "Linking benefits to investment performance in US public pension systems," Journal of Public Economics, 116, 47-61.

Papaioannou, M. M. G., M. J. Park, J. Pihlman, And H. VAn der Hoorn (2013): Procyclical Behavior of Institutional Investors During the Recent Financial Crisis: Causes, Impacts, and Challenges, no. 13-193. International Monetary Fund.

PenNacchi, G., AND M. RASTAD (2011): "Portfolio allocation for public pension funds," Journal of Pension Economics and Finance, 10(2), 221-245.

Plantin, G., H. SAPRA, AND H. S. ShIn (2008): “Marking-to-Market: Panacea or Pandora's Box?,” Journal of accounting research, 46(2), 435-460.

Poterba, J. M., AND L. H. Summers (1988): "Mean reversion in stock prices: Evidence and implications," Journal of financial economics, 22(1), 27-59.

RadDatZ, C., AND S. L. SChmuKLeR (2012): “On the international transmission of shocks: Microevidence from mutual fund portfolios," Journal of International Economics, 88(2), 357-374.

RAJAN, R. G. (2006): “Has finance made the world riskier?," European Financial Management, 12(4), 499533. 
RAUH, J. D. (2009): "Risk shifting versus risk management: investment policy in corporate pension plans," Review of Financial Studies, 22(7), 2687-2733.

Rauh, J. D., I. Stefanescu, AND S. P. Zeldes (2013): "Cost shifting and the freezing of corporate pension plans," .

SHILLER, R. J. (1999): "Social security and institutions for intergenerational, intragenerational, and international risk-sharing," in Carnegie-Rochester Conference Series on Public Policy, vol. 50, pp. 165-204. Elsevier.

Shiller, R. J., J. Y. CAMPbelL, K. L. SchoenholtZ, AND L. Weiss (1983): “Forward rates and future policy: Interpreting the term structure of interest rates," Brookings Papers on Economic Activity, pp. 173223.

SHIN, H. S. (2010): Risk and liquidity. Oxford University Press.

Siegmann, A. (2011): "Minimum funding ratios for defined-benefit pension funds," Journal of Pension Economics and Finance, 10(03), 417-434.

Thurley, D. (2014): “Defined ambition pension schemes," House of Commons Library Standard Note.

Timmermann, A., AND D. BlaKe (2005): “International Asset Allocation with Time-Varying Investment Opportunities," The Journal of Business, 78(1), 71-98.

VAn Bilsen, S., AND A. Bovenberg (2014): "Valuation and Hedging of Variable Annuities in Pension Schemes," .

VAn Binsbergen, J., AND M. W. Brandt (2015): “Optimal Asset Allocation in Asset Liability Management," Handbook of Fixed Income, edited by Pietro Veronesi.

VAN BOMMEL, J. (2007): "Intergenerational risk sharing and bank raids," Available at SSRN 965178. 


\section{Curriculum Vitae}

Mukul Tyagi (Ghaziabad, India, 1988) received BSc (Hons) Mathematics from University of Delhi, India in 2009 and MSc Stochastics and Financial Mathematics from University of Amsterdam, The Netherlands in 2011. He became a PhD candidate at the Finance Department of Maastricht University in 2011. Subsequently, he became a junior research fellow of Netspar (Network for Studies on Pensions, Aging and Retirement). During the PhD studies, he was a teaching assistant for master courses "Financial Risk Management" and "Equity Analysis \& Portfolio Management" as well as bachelor course "Macroeconomics and Finance". In addition, he also supervised bachelor and master theses. During the last year of $\mathrm{PhD}$ studies, he spent four months at the Rotman School of Management, University of Toronto.

This dissertation was made possible by generous financial help from Rabobank, Utrecht. In addition, Mukul was a co-recipient of a research grant by Global Risk Institute in Financial Services (GRI), Toronto. He also gratefully acknowledges research allowance received from Rotman International Center for Pension Management, Toronto.

The research in this dissertation has been presented at multiple academic conferences as well as practitioner oriented workshops in the pension industry. These include Netspar Balance Sheet Management (Maastricht, 2012), International Mathematical Finance Conference (Miami, 2013), Netspar International Conference (Frankfurt, 2013), Louis-Andre Gerard-Varet conference (Aix-en-Provence, 2014), Netspar Pension Day (Utrecht, 2014), Rabobank (Utrecht, 2014), Delhi School of Economics (Delhi, 2014), ISI Annual Conference (Delhi, 2014), Royal Economic Society Annual Conference (Manchester, 2015), Institutional and Individual Investors: Saving for Old Age Conference (Bath, 2015), European Economic Association (Mannheim, 2015). The invaluable feedback received in these conferences greatly improved the thesis.

Since October 2015, Mukul works for ABN AMRO, Amsterdam in the Markets and ALM Treasury Risk Modeling department. 


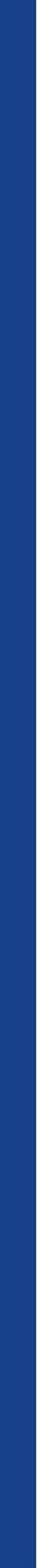

